\title{
MULTIDISCIPLINARY ACCIDENT INVESTIGATION SINGLE VEHICLE ACCIDENT STUDY VOLUME II: Technical Report
}

Kuruce, Morrow, Fogarty, Janicok and Klapper

University of Miami

Post Office Box 8294

Coral Gables, Porida

Contract No. DOT HS-060-3-671

Contract Amt. \$229,882

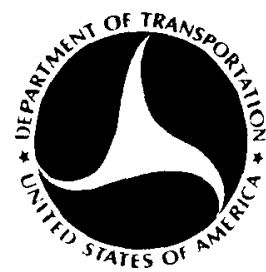

NOVEMBER 1977

FINAL REPORT

This document is available to the U.S. public through the National Technical Information Service, Springfield, Virginia 22161

Prepared For

U.S. DEPARTMENT OF TRANSPORTATION

National Highway Traffic Safety Administration

Washington, D.C. 20590 
Prepared for the Department of Transportation, National Highway Traffic Safety Administration, under Contract No. DOT-HS-060-3-671. The opinions, findings and conclusions expressed in this publication are those of the authors and not necessarily those of the National Highway Traffic Safety Administration. 
Technical Keport Documentation Page

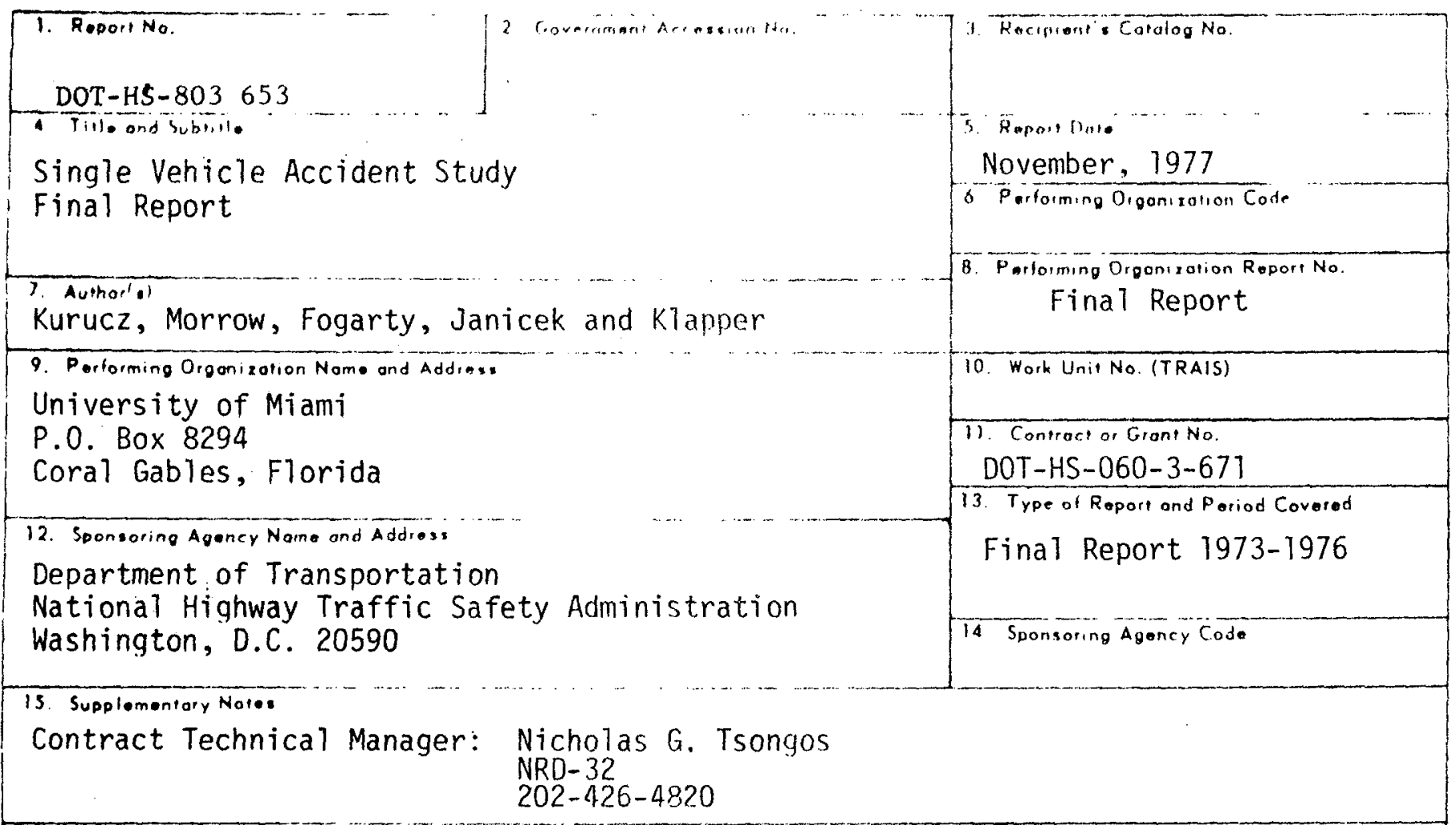

16. Abstroct

The general objectives of this study were to determine the nature and causes of single vehicle accidents, describe their resulting consequences, and develop recommendations to effect a reduction in the frequency and severity of these accidents. Analyses were based on in-depth investigations of 609 single vehicle accidents in Dade County, Florida, and police reported data on all County accidents during the study period. Comparisons of single vehicle and non-single vehicle accident characteristics were made as well as comparisons involving fatal and alcohol involved single vehicle accidents. Causal factors for accident causation and injury production were identified and certain quantitative models developed. The models include consideration of the effectiveness of breakaway light standards and energy absorbing devices, the redirection capabilities of curbs, roadway departure characteristics, and speed relationships. The analyses were used to develop and support countermeasure recommendations.

This: is Volume II (Technical Report) of a three-volume report. Volume I is the Executive Summary and the Appendices are presented in Volume III.

17. Koy Words

Automobile accidents, single vehicle, causal factors, roadsides, breakaway light standards, curb redirection, countermeasures, alcohol, fatal
18. Distribution Statement

Document is available to the public

through the National Technical Information Service, Springfield, Virginia 22161

\begin{tabular}{|c|c|c|c|}
\hline 19. Securiey Classelt. (of this report) & 20. Security Clossit. (ol this pogo) & 21. No. ol Pages & 22. Price \\
\hline Unclassified & Unclassified & 143 & \\
\hline
\end{tabular}


METAIC CONVERSION FACTORS

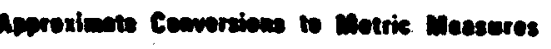

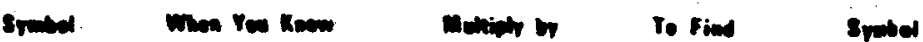

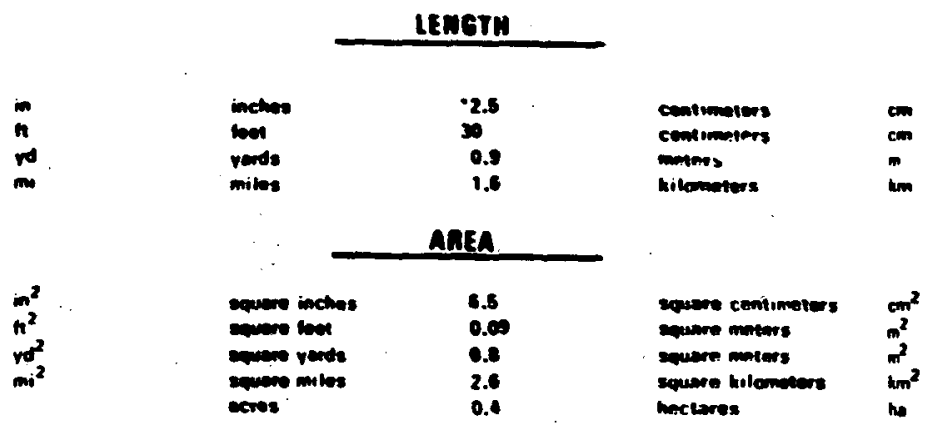

H.

ind

\section{mass (miniti)}
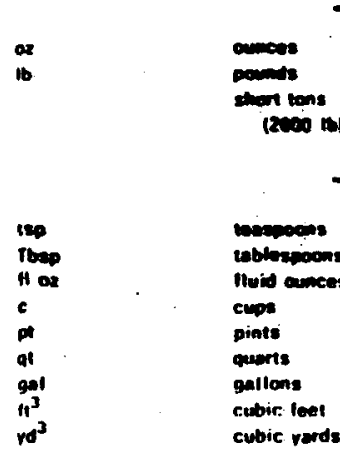

20.

votume

\begin{tabular}{|c|c|}
\hline $\begin{array}{l}5 \\
15\end{array}$ & $\begin{array}{l}\text { millitivers } \\
\text { milliliters }\end{array}$ \\
\hline 30 & mulliliters \\
\hline $\begin{array}{l}0.26 \\
0.47\end{array}$ & litums \\
\hline 0.09 & $\begin{array}{l}\text { liters } \\
\text { titers }\end{array}$ \\
\hline 3.0 & lieess \\
\hline 0.03 & cubit monitur \\
\hline $0 . \pi$ & cubic mitiers \\
\hline
\end{tabular}

TEmpenatune (oxect)

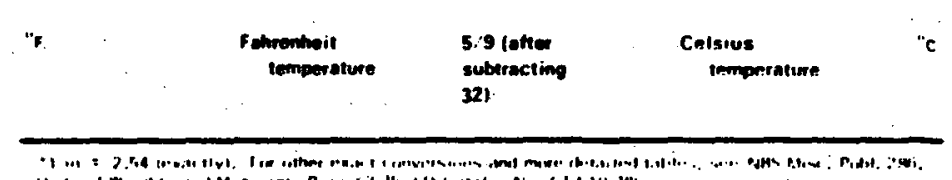

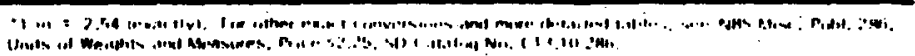
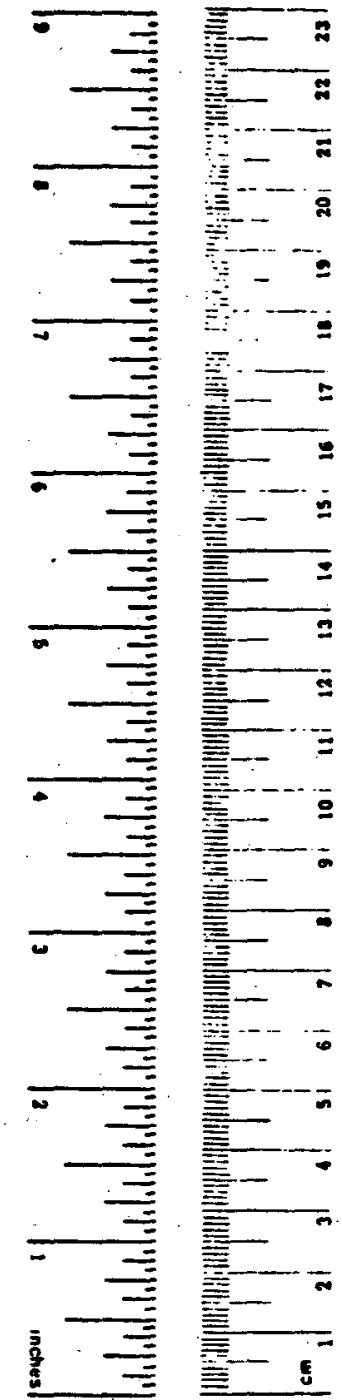

srabol

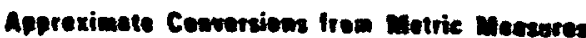

men You know' Mellinity by

To fies

Srated

- millimentors

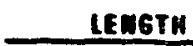

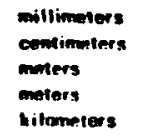

$m_{i m}^{m}$ meters

0.04
0.4
3.3
1.1
0.6

miles

\begin{tabular}{cc} 
& AREA.. \\
\hline & 0.16 \\
& 1.2 \\
& 0.4
\end{tabular}

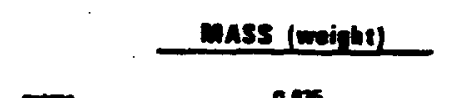

tilosims

ig
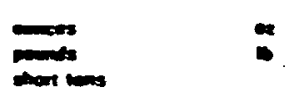

$$
\text { votume }
$$

milliliters

livers

liters

coubic moters

0.03
2.1

$m+$
$\vdots$
$m^{3}$

cubres meters

0.03
2.1
1.06
0.26

1.06
0.26
35
1.3

ims

andic

contic non

"1

\section{TEMPERATUnE (exaet)}

$\frac{\text { Colsicus }}{\text { cemperenture }}$


LIST OF TABLES $\ldots \ldots \ldots \ldots \ldots$

LIST OF FIGURES $\ldots \ldots \ldots \ldots \ldots \ldots$ vii

ACKNOWLEGEMENTS _...

1.0 INTRODUCTION

1.1 Background and Justification-.................... 1-1

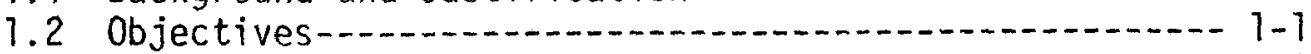

1.3 Scope-1...

2.0 METHODOLOGY

2.1 Project Organization-....... 2-1

2.2 Data Collection-................................... 2-2

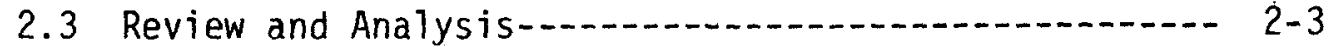

2.4 Base Data Collection-.............................. 2-3

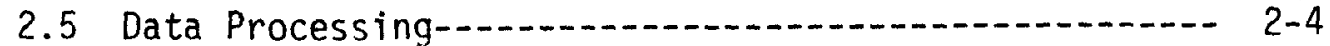

2.6 Data Analysis-...................... 2- 5

2.7 Causal Factors Analysis-............................ 2-6

2.8 Countermeasure Selection and Evaluation............. 2-6

3.0 SINGLE VEHICLE ACCIDENT PROBLEM AND STUDY AREA DESCRIPTION

3.1 The National Single Vehicle Accident Picture-......- 3-1

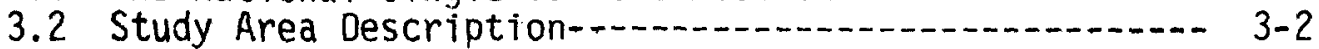

4.0 SINGLE VEHICLE ACCIDENT CHARACTERISTICS

4.1 Types of Accidents

4.2 Driver Characteristics-....................... 4-15

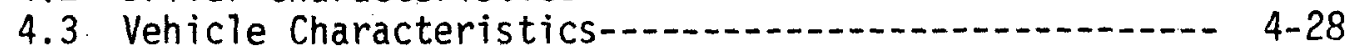

4.4 Environmental Characteristics-....................... 43

\subsection{CAUSAL FACTORS}

5.1 Single Vehicle Accident Mode1-................... 5-1

5.2 Event Sequence Failures-........................... 5-13

5.3 Causal Factors Classification-..................... 5-17

5.4 Causal Factors Contributing to Accident Causation---- 5-22

5.5 Causal Factors Influencing Damage and Injury Severity 5-25

5.6 Causal Factors Summary-_. 5-30 


\subsection{SELECTED ACCIDENT AND INJURY PRODUCING MECCHANISMS}

6.1 Analysis of Impact Attenuating Devices_........ 6-1

6.2 Analysis of Curbs-_... $6-8$

6.3 Analys is of Rollover Accidents

7.0 MOTOR VEHICLE SAFETY STANDARDS (MVSS) AND HIGHWAY SAFETY PROGRAM STANDARDS (HSPS)

7.1 Motor Vehicle Safety Standards' Involvement and Evaluation- 7-1

7.2 Restraint Systems Evaluation (MVSS 208/210)

7.3 Highway Safety Program Standards-_.

8.0 CONCLUSIONS AND COUNTERMEASURES

8.1 Countermeasures for Accident Causation--.... 8-1

8.2. Countermeasures for Damage and Injury Production-.......- 8-9 


\section{LIST OF TABLES}

Table

Page

$3-7$

$3-2$

Percent Distribution of Accidents (Nationa1)

$3-2$

Summary of Differences: in National and Study Area

(Dade County) Non-Accident Characteristics

$3-4$

3-3 Summary of Differences, in National and Study Area

(Dade County) Accident Characteristics .............

$3-5$

Summary of Primary Differences Between Dade County

Single Vehicle and Non-Single Vehicle Accident

Characteristics

4-3

Summary of Primary Differences Between Dade County

Single Vehicle and In-Depth Single Vehicle Accident

4-3

Characteristics

4-4

$4-5$

4-6

$4-7$

Crash Occurrence By Configuration and Location-......-

Crash Configuration By Impact Sequence -...-...-

Type of Objects Impacted

Location of objects Impacted-

Summary of Primary Dififerences Between Dade County

Single Vehicle and Non-Single Vehicle Accident

Driver Characteristics

Involvement Ratios and Conviction Record By Driver

Age, Sex, and Race ..

$4-9$

4- 10

Summary of In-Depth Driver Characteristics .........

Summary of Primary Differences Between Dade County

Single Vehicle and Non-Single Vehicle Accident

4-11

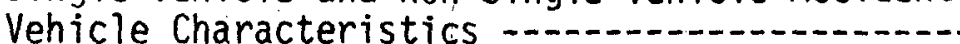

$4-12$

$4-13$

Involvement Ratios By Vehicle Type and Defects ......-

Summary of In-Depth Vehicle Characteristics ........-

Summary of Primary Differences Between Dade County

Single Vehicle and Non-Single Vehicle Accident

Environmental Characteristics .....................................

Summary of Primary Differences Between Dade County Single Vehicle And In-Depth Single Vehicle Environmental Characteristics

$4-9$

$4-9$

$4-10$

$4-11$

4-21

4-25

4-27

4-30

4-32

4-33

4-34

Summary of In-Depth Environmental Characteristics ....

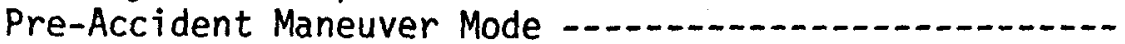

$4-38$

Task Presented To The Driver

$5-3$

$5-2$

$5-3$

$5-4$

Driver Response To Task -

$5-6$

Resultant Driver/Vehicle Action

$5-9$

$5-5$

$5-6$

Failures in the Event Sequence Which Contributed to

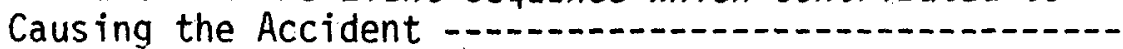

$5-14$

$5-7$

Failures in the Event Sequence By Crash Occurrence ---

$5-16$

$5-8$

Event Sequence Failures By Number of Accidents, Crash

Occurrences and Causal Factors 
5-9 Distribution of Causal Factors By Type for Each

Event Sequence Failure --..-.-.- 5-23

5-10 Causal Factors By Type and Relevance -..............- 5-24

5-11 Human Causal Factors Contributing to Accident

5-12 Vehicular Causal Factors Contributing to Accident

5-13 Environmental Causal Factor Categories Contributing

5-14 Environmental Causal Factors Most Frequently

5-15 Environmental Causal Factor Categories Contributing

6-1 Vo Accident Causation - Vauting By Bridgerail Type and Impact Configuration -

6-2 Vehicle Damage and Loss of Control By Type of

6-3 Charb Impacted istics of In-Depth Sample Related to

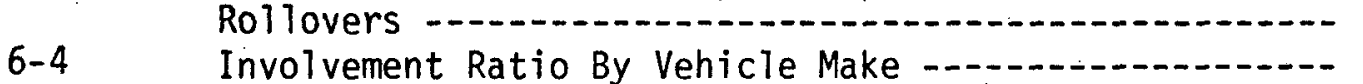

7-1 Results of Chi-Square Tests for the Overall

Effectiveness of MVSS

7-2 Summary of Overall Characteristics Which May Vary 


\section{LIST OF FIGURES}

Figure

Page

$2-1$

3-1

$=4-1$

Single Vehicle Accident Study Data Flow

$2-5$

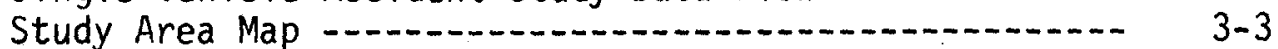

Summary of Primary Differences Between Types of

Fatal and Other (Non-Fatal) Dade County Single

Vehicle Accidents

4-2 Summary of Primary Differences Between Types of

Alcohol Involved and Other (Non-Alcohol Involved)

$4-3$

Dade County Single Vehicle Accidents ...............-

Damage Extent as Measured by the Vehicle Deformation

$4-4$

Index (VDI)

$4-11$

Driver Injury Severity as Measured by the Abbreviated

Injury Scale (AIS)

$4-12$

4-5

$4-6$

$4-7$

4-8

$4-9$

4- 10

Driver Injury Severity (AIS) Vs. Rollover Involvement

$4-12$

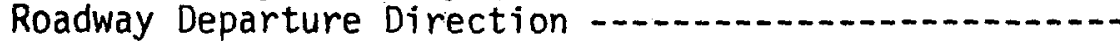

Pre-Crash Speed Versus Posted Speed Limit

Departure Speed Vs. Posted Speed Limit

$4-13$

$4-14$

4-16

Departure Angle Vs. Posted Speed Limit

$4-17$

Off-Road Speed Vs. Posted Speed and Departure

$4-11$

Distance for Straight Roadways

$4-18$

Dff-Road Angle Vs. Posted Speed and Departure

4-12 Summary of Primary Differences Between Fatal and

Other (Non-Fatal) Dade County Single Vehicle

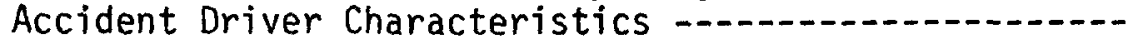

4-13 Summary of Primary Differences Between Alcohol

Involved and Other (Non-Alcohol) Dade County

Single Vehicle Accident Driver Characteristics

4-14 Percent of Accidents in Which Pre-Crash Speed Exceeds

Posted Speed Limit _.....

4-15 Summary of Primary Differences Between Fatal Vs. Non-

Fatal Accident and Alcohol Involved Vs. Non-Alcohol

Accident Vehicle Characteristics _...................

4-16 Summary of Primary Differences Between Fatal and Other (Non-Fatal) Dade County Single Vehicle Environ-

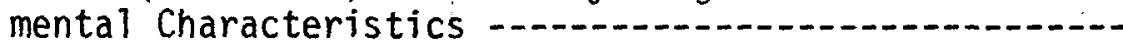

4-17 Summary of Primary Differences Between Alcohol

Involved and Other (Non-Alcohol) Dade County

Single Vehicle Accident Environmental Characteristics

$5-1$

Single Vehicle Accident Model

$4-36$

$5-2$

$5-3$

Pre-Accident Event Sequence _.........................

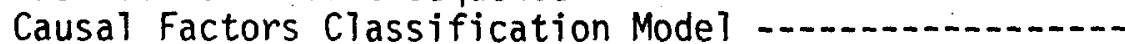

Causal Factors By Type -...

$5-4$

$5-5$

Causal Factors Per Accident 
6-1 Driver Injury Vs. Impact Speed for Light Pole Collisions by Type of Pole and Restraint Use -..... 6-2 Driver Injury Vs. Impact Speed for Rigid objects and E/A Devices by Vehicle Weight (in Ibs.) -..... 6-4

6-3 Restrained and Unrestrained Driver AIS Vs. Speed for Guardrail Impacts and Rigid Object Impacts -..-- 6-6

6-4 Front Seat Passenger AIS Vs. Speed for Guardrail Impacts and Rigid Object Impacts -............. 6-8

6-5 Curb Redirection Boundaries $6-9$

7-1 Serious Injury Vs. Restraint Use and Ejection Status -......... 7-6 


\section{ACKNOWLEDGEMENTS}

This report could not have been completed without the interest, competence and devotion to research as shown by many individuals. The Principals wish to acknowledge the troopers of the Florida Highway Patrol, the officers of the Dade County Public Safety Department and the City of Miami Police Department as well as the research team members (Joseph Metka, Viima Harris, Anthony Janicek, James Klapper, Dr. Joseph Davis, Glenn Sudduth, Carole Haviland, Libby Utes, Angel Li, Robert Orgaz, John Durbak, Larry Keeler, Bruce Ivey, and John Hasse11). Special appreciation is also extended to the Dade County Citizens Safety Council for their cooperation and assistance. A sincere thank you to Carol DiLaurenzio and Vilma Harris for their efforts in preparing the final report. 


\subsection{INTRODUCTION}

In JuTy, 1973, the Department of Transportation, through the National Highway Traffic Safety Administration, funded the University of Miami in Coral Gables, Florida, to conduct a study of single vehicle accidents. This report describes the methodology utilized to perform the study, the nature of the accident events investigated, the characteristics of the drivers, vehicles and highway conditions encountered and the causal factors contributing to accident causation and injury/damage production. Specific and general countermeasures recommended to reduce the frequency of occurrence and the severity of single vehicle accidents are also included in this report.

\subsection{BACKGROUND AND JUSTIFICATION}

Single vehicle accidents account for approximately 20 percent of the national roadway crash occurrences and nearly 40 percent of the resulting highway fatalities. Due to the frequency and the high-risk potential involved, single vehicle accidents constitute a serious problem which has not been specifically subjected to a full-scale investigation.

Earlier multidisciplinary accident investigation studies sponsored by NHTSA have provided some insight into this type of accident but have not provided a consistent and adequate data base for evaluation. Single vehicle accidents may be considered as unique since the typical. driver/driver or driver/pedestrian relationships are essentially absent. The driver/highway interactions and the effects of the roadside characteristics appear to be more important in this type of accident.

\subsection{OBJECTIVES}

The general objective of this research study was to determine the nature and causes of single vehicle accidents and their resulting consequences along with recommendations to effect a reduction in the frequency and severity of these accident events. The achievement of this overall objective was to be realized through meeting the following specified objectives: 
1. Determine the causal factors for single vehicle accidents,

2. Study the human, vehicular and environmental elements involved relevant to the accidents investigated,

3. Study at-crash environmental and vehicular factors with special emphasis on evaluating the effects of roadside obstructions, restraining devices and occupant protection in interior impacts,

4. Estimate the probable impact of the Federal Motor Vehicle Safety Standards (MVSS) and the Highway Safety Program Standards (HSPS) relevant to the single vehicle accidents, and

5. Recommend appropriate countermeasures that are conclusive, can be implemented, and which reduce the rate and severity of single vehicle accidents.

\subsection{SCOPE}

This study involved an on-scene, in-depth investigation of over 600 single vehicle accidents in a manner similar to that utilized in multidisciplinary accident investigation. The human, vehicular and environmental factors involved in the pre-crash and at-crash phase of each accident were investigated and evaluated. The qualifying crash occurrences included impacts with fixed or transient objects, vehicle rollovers and other crash configurations which resulted in substantial vehicle damage or injury to one or more of the occupants.

Impacts with parked or disabled vehicles were included in the data sample. The influence of other moving vehicles which were involved from a causal viewpoint, but were not contacted, was also evaluated. Although qualifying crash occurrences on the roadway were included in this study, the major emphas is was directed toward the evaluation of off-roadway impacts and rollovers.

A1l classes of vehicles (passenger cars, trucks, motorcycles, etc.) were investigated in the conduct of this study. A major emphasis was placed on accidents on freeways and major streets and highways with a corresponding deletion of central business district accidents. The overall accident population did, however, include crash occurrences on virtually every roadway type and classification. The sample area for the selection of single vehicle accident events was limited to the confines of Dade County, Florida. 


\subsection{METHODOLOGY}

A brief description of the methodlogy utilized in the conduct of this study is presented in this section. The activities involved include: the project organization, data collection and processing, causal factor identification, data analys is and countermeasure development.

\subsection{PROJECT ORGANIZATION}

The first stage of the project organization consisted of the identification of those data elements and the design of those activities which were necessary for the achievement of the study objectives. This included the selection of the appropriate data analys is techniques and data processing procedures, as well as the design of the field investigation methodology. Field data forms were designed, field tested and modified appropriately to promote the collection of reliable and complete data in a format directly applicable for computer analyses. The procedures for the selection and notification of qualifying accident events were established in consultation with the participating police agencies. The cooperation of other community agencies was also solicited and obtained at this time, for the collection of accident histories, driver records, medical information and other important data items.

The selection of project personnel was carried out in conjunction with the design of the study and the development of community cooperation. Personnel with prior experience in field investigation and data collection and analysis were available from earlier research projects involving multidisciplinary accident investigation. This included individuals competent in the areas of accident reconstruction, human factors, vehicular autopsy, highway engineering, photography and medicine. Additional staff was acquired to assist in the data processing and analys is phases of the study. The specific training required for all personnel, including that necessary for police officers, was conducted during this initial organizational phase. 


\subsection{DATA COLLECTION}

The data requirements of this study necessitated a full-scale investigation at the scene of the accident immediately after the crash occurrence. Procedures were therefore developed for selection and notification of accident events, on-scene data collection, and subsequent data collection.

The primary responsibility for the notification of qualifying single vehicle accident events resided with the police officers in the field. Due to the liaison with cooperating police agencies, officers who regularly investigated automobile accidents were aware of the research project and the criteria for the selection of qualifying accident events. Upon their arrival at an accident scene, the officers initially ascertained whether the accident met the study criteria and whether traffic conditions permitted a complete on-scene investigation. The officer would then notify the police dispatcher who, in turn, would contact the study team by telephone or by use of page boy recall. Acceptance of the accident and estimated time of arrival were then relayed to the field officer.

The field investigation team normally consisted of three people. During the period of time which elapsed from notification to the arrival of the investigation team, the police officer usually explained the research program to the driver and, if possible, requested that the driver fill out a 50 question form dealing with basic human factors data. Upon arrival, the environmental specialist began documentation of physical evidence. Specific emphas is was directed toward documentation of that evidence (skid marks, debris location, etc.) which deteriorates rapidly with time. At the same time, the vehicle specialist began the collection of perishable vehicle data. The team member responsible for the human factors completed all appropriate interviews and, if applicable, accompanied the police officer to the hospital for a follow-up evaluation of occupant injuries. The data collected included the specific information listed in the Human, Vehicle, and Environmental Forms in Appendix A. Prior to leaving the accident scene, an evaluation of the accident event was conducted by the field investigation team. Included in this evaluation were a basic reconstruction of the accident (speed, vehicle trajectory, occupant kinematics, etc.) and a preliminary assessment of the causal factors contributing to accident causation and injury/damage production.

The specific data requirements and the nature of certain accident events precluded the completion of the data collection process at 
the scene. Due to adverse traffic conditions, some permanent environmental data (e.g. travel lane cross slope) were collected at a more favorable time. Lengthy inspections of suspected defects in vehicle components or systems were performed at wrecker yards to prevent unnecessary traffic congestion and hazards. Other data (e.g. accident history, driver record, detailed medical information) were also collected at a later time.

\subsection{REVIEW AND ANALYSIS}

Upon completion of the field data collection and the subsequent data collection, an independent review and analys is of each case was conducted. This process was carried out to ensure the completeness and accuracy of the field forms and to promote consistency in interpretation of all data elements. In addition, the reconstruction of the vehicle dynamics, the occupant kinematics, the injury producing mechanisms, and the causal factors were completely reviewed. This review process culminated in filling out the Dynamics Supplement, Human Factors Supplement, and Causal Factor Supplement forms presented in Appendix $A$. The detailed review and analysis tasks are described in Appendix $C$.

In addition to the preceding activities, the review process included an overall evaluation of each of the 628 cases investigated in the field. Seven of these cases were determined to be inadequate due to missing or questionable data elements and were dropped from the study data base. Of the remaining 621 single vehicle accidents, twelve cases were judged to be inappropriate for inclusion in the general data analysis. These accident events were of a nature (e.g. accidents on work sites involving a construction vehicle) that did not, in our opinion, meet the mainline intent or scope of this study. These twelve cases have been retained in the basic data file but have been excluded from analysis. The results and conclusions of this study are based upon the remaining 609 single vehicle accidents.

\subsection{BASE DATA COLLECTION}

Data describing drivers, vehicles, highways, and accidents in both the Dade County study area and on the national level were obtained in order to conduct various comparative, representativeness, and risk analyses. 
Desired information was obtained by acquiring and processing raw data as well as from published sources. Specifically, vehicle registration and driver license data for Dade County was obtained on magnetic tapes from the Florida Department of Highway Safety and Motor Vehicles. Motor vehicle inspection data was obtained by sampling 1445 inspection slips from the Motor Vehicle Inspection Division of the Dade County Department of Public Works. Data on highways in the study area were provided by the Dade County Department of Traffic and Transportation in both published form and on magnetic tape. Information on all accidents occurring in the study area was provided on magnetic tapes by the Dade County Public Safety Department. National data was obtained from publications by the National Safety. Council and the Motor Vehicle Manufacturers Association.

\subsection{DATA PROCESSING}

The general flow of data from acquisition through the preparation of tables and graphs is presented in the flow chart of Figure 2-1. The upper portion of the flow chart describes the processing of the 628 single vehicle field investigations from field data collection to the generation of the tape master file containing the sample data. As indicated, the human, vehicle, and environmental forms were keypunched and edited as coding was completed. The review process took place concurrently and generated both corrections to the basic human, vehicle, and environmental data and supplementary data on occupant kinematics, causation, and vehicle dynamics. After coding, keypunching, and editing, the supplementary data was added to the single vehicle accident sample master file. The acquisition of base population data is described in the lower portion of Figure $2-1$, along with the processing of all data files. The final output is the tables and graphs presented in this report.

Several methods of checking errors were employed in the processing of the single vehicle accident sample data. The case review process was the primary method of checking for logical and coding errors. During review each human, vehicle, and environmental data element was examined for consistency and accuracy. Keypunch errors were checked by utilizing the verification process during keypunching, visually checking card listings, and by processing punched cards through editing programs which checked selected data element values against their allowable range. Correction forms were processed for all errors so detected. A final check for errors was made during the building of special analysis files and the preparation of tables and graphs. Any unusual observed values were traced back to the source case, checked for accuracy, and corrected if required. The final single vehicle accident sample master file is on 9-track 1600 BPI 
magnetic tape in card image format as described in Appendixes $A$ and B.

Base population tape files, such as the driver license file, were basically assumed to be correct as received from the source. A limited amount of error checking was done, however; while generating special analysis files. Consideration was given only to data elements used in computing quantities of interest and consisted primarily of range checks for reasonable data values. Any "errors" so detected were deleted from the computations.

\subsection{DATA ANALYSIS}

Many types of analysis and techniques were employed in the study. The various analys is presented in this report can, however, be broadly classified as descriptive, comparative, and special purpose. Al though the analysis procedures are described in detail in subsequent sections of this report, an overview follows.

The primary purpose of the descriptive analyses was to develop a coherent picture of single vehicle accidents and identify the extent of the single vehicle accident problem. These analyses consisted of the calculation of relative frequencies, means, and standard deviations as appropriate for variables which describe:

Types of single vehicle accidents Drivers involved Vehicles involved Environmental conditions involved How single vehicle accidents happen Why single vehicle accidents happen Injury production Damage production

Appropriate national, study area (Dade County), and single vehicle accident sample data were used.

Comparative analyses were performed in order to determine the representativeness of various samples and subpopulations, to gain insight into causation and to identify high risk groups. In particular, comparisons of national, Dade County, and the accident sample were performed as well as comparisons of total and accident involved drivers/vehicles, fatal and non-fatal single vehicle accidents, and alcohol and non-alcohol involved accidents. The comparisons were made utilizing Chi-Square analysis and tests for differences in sample means where appropriate. 
Several special analyses were performed using the detailed data from the single vehicle accident sample. These analyses include evaluations of the performance of various protective devices (e.g. breakaway poles, guard rails), quantitative descriptions regarding the effects of various vehicle characteristics (e.g. vehicle type), and the description of vehicle dynamics during the accident sequence. The special analyses utilized several statistical techniques, including regression analys is and discriminant analysis.

Motor Vehicle Safety Standards were also evaluated to determine their effectiveness in reducing injury and where appropriate, vehicle damage. The analysis consisted primarily of Chi-Square tests on the distribution of injury severity for drivers of vehicles having model years before and after the standards went into effect, although some other statistical tests were utilized. Analysis of the involvement of both motor vehicle and highway safety standards was also performed.

\subsection{CAUSAL FACTOR ANALYSIS}

The determination of the causal mechanisms for accident causation and damage/injury production was approached from both qualitative and quantitative aspects. As previously indicated, specific human, vehicular, and environmental causal factors were identified during the field investigation and the review and analysis process. This qualitative approach depended, in part, upon the collective expertise and judgement of the team members involved in this evaluation. A detailed explanation of this analysis and the identified causal factors are presented in Section 5.0.

The methodology utilized in the evaluation and classification of causal factors allowed for the identification of causal relationships that could be subjected to quantitative analysis. These analyses focus primarily on injury producing causal mechanisms and are presented in Section 6.0 .

\subsection{COUNTERMEASURE SELECTION AND EVALUATION}

The countermeasures considered and proposed herein include a range from recommendations for further study in general problem areas to specific, implementable countermeasures. Human, vehicular and environmental countermeasures involving legislation, standards, and engineering practice were considered for the reduction of accident frequency and/or severity. 
Potential countermeasures were initially generated by suggestions from the field investigation personnel, team members involved in the review and analysis process, and a review of the highway safety literature. Recommended countermeasures were selected on the bas is of the relative frequency of involvement of the causal factor(s) to which the countermeasure applied and/or the degree to which accident severity might be reduced as indicated by analyses of the data obtained in this study. Consideration was also given to anticipated ease of implementation of specific countermeasures. 


\subsection{SINGLE VEHICLE ACCIDENT PROBLEM AND \\ STUDY AREA DESCRIPTION}

The purpose of this section is to describe the national single vehicle accident problem and the characteristics of the study area in which detailed data were collected.

\subsection{THE NATIONAL SINGLE VEHICLE ACCIDENT PICTURE}

Al though there is little detailed national information on the nature and causes of single vehicle accidents, the extent of the problem can be approximated by examination of Table 3-1. As indicated, single vehicle accidents constituted approximately $18.0 \%$ of all 1974 motor vehicle accidents while accounting for $32.8 \%$ of the fatal accidents. If the accident categories "Other Road Vehicle, Train and Parked Car" (a "roadside object") are included in the definition of a single vehicle accident, the percentages become $29.8 \%$ and $39.5 \%$ respectively. Using the $18.0 \%$ and $32.8 \%$ figures, the 1974 national fatality rate was 1:213 for single vehicle accidents and 1:475 for other motor vehicle accidents.

If pedestrian accidents are excluded from consideration, the single vehicle accident problem appears even more serious. With this exclusion, single vehicle accidents account for approximately $18.4 \%$ of the remaining total accidents and $41.4 \%$ of the remaining fatal accidents. The increase in percentage of fatalities is substantia1. Adding the "Other Road Vehicle, Train and Parked Car" categories yield $30.4 \%$ of all accidents and $49.8 \%$ of fatalities. Using the $18.4 \%$ and $41.4 \%$ figures, the 1974 fatality rates, excluding pedestrian accidents, now become $1: 213$ for single vehicle accidents and 1:669 for other motor vehicle accidents.

The above percentages emphasize the seriousness of the single vehicle accident problem. The fatality rate for single vehicle accidents is at least 3 times that for multiple vehicle accidents even without considering the fact that multiple vehicie accidents have the potential for at least two fatalities per accident. The present report is intended to provide insights as to the nature and causes of single vehicle accidents as well as recommendations to reduce the incidence and severity of such accidents. 
TABLE 3-1. PERCENT DISTRIBUTION OF ACCIDENTS (NATIONAL ${ }^{\top}$ )

\begin{tabular}{|c|c|c|}
\hline Type of Accident & Fatal Accidents & All Accidents \\
\hline $\begin{array}{c}\text { Collision With } \\
\text { Fixed Object } \\
\text { Other Object, Animal }\end{array}$ & 19.4 & 11.7 \\
& .8 & 2.5 \\
$\begin{array}{c}\text { Noncollision } \\
\text { Overturning } \\
\text { Other Noncollision }\end{array}$ & 11.0 & 2.8 \\
TOTAL SINGLE VEHICLE & 1.6 & 1.0 \\
\hline Collision With \\
Other Road Vehicle, Train \\
Parked Car & 32.8 & 18.0 \\
\hline ALL OTHER ACCIDENTS & 4.5 & 1.2 \\
\hline TOTAL & 2.2 & 10.6 \\
\hline
\end{tabular}

1 Accident Facts, 1975 Edition

\subsection{STUDY AREA DESCRIPTION}

The single vehicle accident study area was Dade County, Florida. A description of the demographic characteristics of Dade County and a discussion of its representativeness as a sample area follows.

\subsubsection{DADE COUNTY DEMOGRAPHIC CHARACTERISTICS}

Dade County is a generally flat 2346 square mile area located on the Atlantic seacoast of southeast Florida. There are approximately $1.4 \mathrm{mil}$ lion residents in the developed areas which are concentrated in the eastern portion of the county as indicated in Figure 3-1. Currently there are approximately 1,050,000 resident drivers operating 1,013,000 registered vehicles on 5,148 miles of roadways. The roadways are primarily urban, however, some are clearly rural in their construction, character, and maintenance. Additional demographic information is presented in Appendix D.

There were approximately 61,000 reported accidents in Dade County during 1974 , resulting in 235 fatalities. A more detailed breakdown of study area accidents and accident related factors is presented in the next section. 


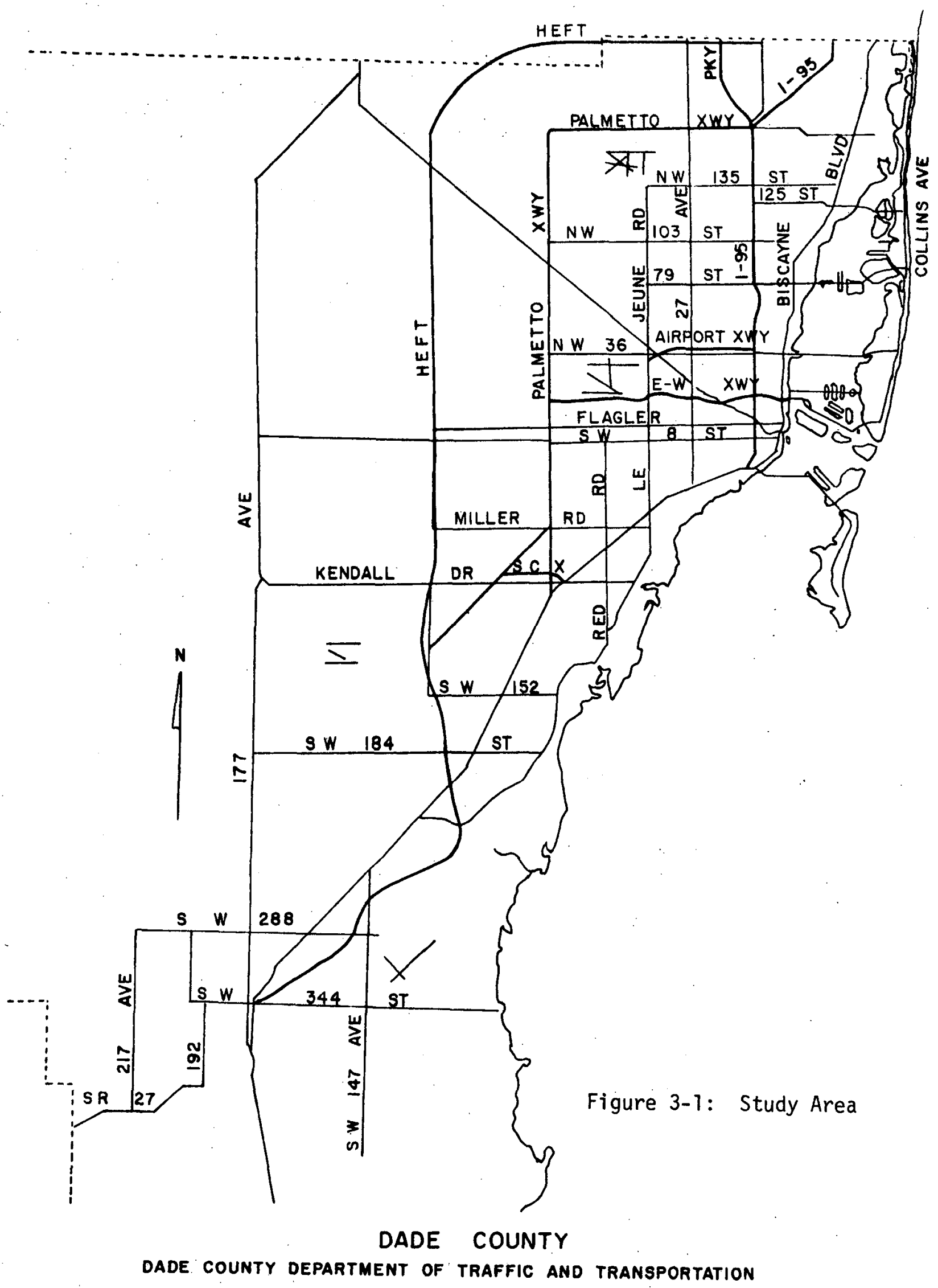




\subsubsection{REPRESENTATIVENESS OF THE STUDY AREA}

The purpose of this section is to discuss how closely Dade County driver, vehicle, roadway, and accident characteristics match corresponding national characteristics. The discussion considers non-accident characteristics and accident characteristics separately.

\section{Non-accident Characteristics}

Comparisons of non-accident involved characteristics are summarized in Table 3-2 and presented in detail in Tables E-1 through E-5 of Appendix E. As indicated in Table 3-2, the Dade County licensed driver age and sex distributions are within five percent of the national distributions. The only notable difference is that Dade County has somewhat fewer $(2.7 \%)$ drivers under 20 years old and more $(2.8 \%)$ drivers over 60 years old. With respect to registered vehicle make and age distributions, the only notable difference is that the percentage of Chevrolets registered in Dade County is $5.1 \%$ more than the national percentage. Although the distributions of highway mileage by system do not differ by more than five percent in any category, the accuracy of the Dade County data is in question due to variations in reporting.

On the basis of the relatively few non-accident characteristics for which comparable data were available, Dade County can be considered reasonably representative of the U.S. It is obvious, however, that Dade County is not representative with respect to other geographic characteristics such as mountainous terrain and cold weather phenonmena.

TABLE 3-2. SUMMARY OF DIFFERENCES IN NATIONAL AND STUDY AREA (DADE COUNTY) NON-ACCIDENT CHARACTERISTICS

\begin{tabular}{|l|c|}
\hline Characteristics & Difference in Excess of Five Percent \\
\hline Driver Age & None \\
Driver Sex & None \\
Vehicle Make & $5.1 \%$ more Chevrolets in county \\
Vehicle Model Year & None \\
Highway Mileage & None \\
\hline
\end{tabular}

7 See Appendix E 


\section{Accident Characteristics}

Comparisons of accident involved characteristics are summarized in Table 3-3 and presented in detail in Tables E-6 through E-14 of Appendix E. The tables consider selected accident, driver, vehicle, and environmental characteristics.

As indicated in Table 3-3, Dade County has a somewhat greater $(6.8 \%)$ percentage of multiple vehicle accidents. Although there is no hourly difference greater than five percent, Dade County does have a larger (6.4\%) percentage of daytime (7 A.M. to 5 P.M.) accidents. Consistent with the greater percentage of multiple vehicle accidents in Dade County, there are more Dade County accidents in which "Failed to Yield" $(9.9 \%)$ and "Followed too Closely" $(7.5 \%)$ are identified as types of improper driving and fewer (9.3\%) "Speed too Fast" accidents. The notable difference in the accident severity distributions is the substantially greater $(26.2 \%)$ percentage of nonfatal injury accidents which occur in Dade County.

TABLE 3-3. SUMMARY OF DIFFERENCES IN NATIONAL AND STUDY AREA (DADE COUNTY) ACCIDENT CHARACTERISTICS

\begin{tabular}{|c|c|}
\hline Characteristic & Difference in Excess of Five Percent \\
\hline Accident Type & $\begin{array}{l}6.8 \% \text { more multiple vehicle accidents in } \\
\text { county }\end{array}$ \\
\hline Hour of Day & None \\
\hline Improper Driving & $\begin{array}{l}9.9 \% \text { more failure to yield, } 7.5 \% \text { more } \\
\text { followed too closely, and } 9.3 \% \text { fewer } \\
\text { speed too fast accidents in county }\end{array}$ \\
\hline Accident Severity & $\begin{array}{l}26.2 \% \text { more nonfatal injury accidents in } \\
\text { county }\end{array}$ \\
\hline Driver Age & $\begin{array}{l}11.8 \% \text { fewer under } 25 \text { drivers in county } \\
\text { accidents }\end{array}$ \\
\hline Driver Sex & None \\
\hline Vehicle Type & $6.1 \%$ more passenger cars in county accidents \\
\hline Class of Trafficway & Almost all categories \\
\hline Surface Condition & $\begin{array}{l}13.5 \% \text { more dry, } 7.5 \% \text { fewer wet, and } 8.0 \% \\
\text { fewer (none) snowy or icy accidents in county }\end{array}$ \\
\hline
\end{tabular}


It should be noted at this point, that the most probable reason for the higher percentage of multiple vehicle/nonfatal injury accidents in Dade County is the Florida accident reporting criterion. Accidents in which there is property damage only, need not be reported, unless the damage is in excess of $\$ 100$. This leads to an under reporting of minor property damage accidents and a consequent over representation of nonfatal injury accidents.

With respect to the age and sex distributions of accident involved drivers, the only notable difference is that fewer $(11.8 \%)$ Dade County drivers under 25 years of age are involved in accidents. This is consistent with the fact that Dade County has fewer licensed drivers in this age category. Dade County a7so has a greater $(6.1 \%)$ percentage of accident involved passenger cars. The distribution of accident involved vehicle types, however, closely matches the distribution of Dade County registered vehicle types.

The distributions of class of trafficway and road surface condition differ significantly. Comparison of class of trafficway distributions should be made with great care, however, due to varied interpretations of what constitutes an urban vs. rural roadway. For the Dade County distribution, only accidents which occur on local streets are considered to be urban accidents even though many state and county road accidents occur in areas which would characteristically be considered urban areas. As would be expected given the south Florida climate, Dade County experiences a greater (13.5\%) percentage of dry road surface accidents. 


\subsection{SINGLE VEHICLE ACCIDENT CHARACTERISTICS}

The purpose of this section is to describe and compare various single vehicle accident characteristics. Selected statistics derived from the total Dade County accident population, the in-depth sample of 609 single vehicle accidents, and various base populations such as Dade County vehicle registrations are presented. Single vehicle accident types, drivers, involved vehicles, and environmental conditions are discussed in separate subsections since they constitute major categories of interest. Within each category the representativeness of the in-depth sample, the identification of high risk groups, and comparisons between types of accidents are considered. For the purposes of this section, a single vehicle accident is an accident involving one vehicle which collides with an object (excluding parked vehicles) or an animal, rolls over, or becomes disabled due to some other noncollision event such as a fire.

\subsection{TYPES OF ACCIDENTS}

Comparisons of accident characteristics describing the type of accident, time of occurrence, location, and resulting injury and damage are summarized in Tables 4-1 and 4-2, Figures 4-1 and 4-2, and are presented in detail in Tables F-1 through F-22 of Appendix F.

The tables report statistics for three data sets: the in-depth sample of 609 single vehicle accidents, all reported single vehicle accidents in Dade County during the period for which in-depth data were collected (approximately thirteen months), and a sample of four out of ten of the remaining non-single vehicle accidents in Dade County. The Dade County data were taken from the Public Safety Department accident tape files.

Note that total counts for the three data sets vary between the detailed tables presented in Appendix F. The differences are caused by the elimination of the "unknown" or "not stated" categories for each variable table. Inclusion of these categories would make comparisons between data sets difficult. However, it is necessary to assume that the elimination of the categories does not introduce bias in the remaining percentages. Although this assumption may not be entirely correct, it is believed to be 
preferable to an attempt to make comparisons of percentage distributions with the "unknown" or "not stated" categories included.

\subsubsection{COMPARISONS OF SINGLE VEHICLE ACCIDENT AND NON-SINGLE VEHICLE ACCIDENT CHARACTERISTICS}

The primary differences between Dade County single vehicle accidents and other Dade County accidents in terms of selected characteristics are presented in Table 4-1. This table is derived from detailed Tables F-1 through F-9 of Appendix F.

As indicated, the predominant single vehicle accident type is a collision with an object, while the predominant other accident type is collision between two or more vehicles (including parked vehicles). Rollovers (8.3\%) and other non-collision accidents (8.8\%) account for most of the remaining single vehicle accident types. Somewhat unexpectedly, the number of occupants per vehicle is about the same in both cases.

Comparisons of location and time characteristics show that single vehicle accidents are more likely to occur off the roadway, in open country/highway areas, on weekends, and during the nighttime than other types of accidents. Note that "open countryl highway" is a Dade County classification indicating a type of area which can be considered rural in character. Although not shown in Table 4-1, a greater percentage of single vehicle accidents also occur in residential areas (39.7\%) than do other accident types $(31.3 \%)$. Single vehicle accidents are most likely to occur on Saturdays and Sundays, while other accident types are least likely to occur on these days. The greatest difference occurs on Sunday which accounts for $16.6 \%$ of the single vehicle accidents as compared to $9.4 \%$ of the other accident types. The tendency for single vehicle accidents to occur at night and/or on weekends suggests alcohol involvement, although these are also the times when traffic volumes are relatively low. That is, given that a driver fails to properly perform the driving task at night and/or on a weekend, he is less likely to collide with another vehicle since fewer of them are available as potential targets. The role of alcohol is discussed in the next section.

Dade County single vehicle accidents are clearly more severe than non-single vehicle accidents, In terms of fatalities, the fatality rate per 1000 , single vehicle accidents is more than twice the rate for other types of accidents. The increased severity is even more pronounced when considering fatalities per 1000 
involved people. Here the single vehicle accident rate is nearly five times the rate for other types of accidents. Although not shown in Table 4-1, more single vehicle accidents resulted in at. least one fatality $(.7 \%)$ as compared with other types of accidents $(.3 \%)$.

TABLE 4-1. SUMMARY OF PRIMARY DIFFERENCES BETMEEN DADE COUNTY SINGLE VEHICLE AND NQN-SINGLE VEHICLE ACCIDENT CHARACTERISTICS

\begin{tabular}{|l|c|c|}
\hline Characteristic & $\begin{array}{c}\text { Other } \\
\text { Accidents }\end{array}$ & $\begin{array}{c}\text { Single Vehicle } \\
\text { Accidents }\end{array}$ \\
\hline General: & & \\
Collision With Object & $0.0 \%$ & $81.3 \%$ \\
Collision With Other & \\
Motor Vehicle2 & $98.0 \%$ & $0.0 \%$ \\
Vehicles/Accident & 2.12 & 1.00 \\
Occupants/Vehicle & 1.47 & 1.50 \\
\hline Location/Time: & & \\
Off Roadway & $9.9 \%$ & $80.4 \%$ \\
Business Area & $56.7 \%$ & $29.5 \%$ \\
Open Country/Highway & $10.2 \%$ & $27.7 \%$ \\
Weekend & $23.2 \%$ & $33.8 \%$ \\
8 p.m. to 6 a.m. & $16.5 \%$ & $42.0 \%$ \\
\hline Injury/Damage & & \\
Fatalities/1000 Accidents & 3.21 & 7.40 \\
Fatalities/1000 People & 1.03 & 4.91 \\
Injuries/l000 Accidents & 560 & 493 \\
Injuries/lono People & 179 & 327 \\
Property Damage (Non-Veh.) & & $9.9 \%$ \\
in Excess of \$500 & $.4 \%$ & \\
\hline
\end{tabular}

1 See Appendix F, Tables F-1 through F-9.

2 Includes parked motor vehicles.

Similar results hold for injuries and damage. Even though the injury rate per 1000 accidents is somewhat lower for single vehicle accidents, the injury rate per 1000 involved people is nearly twice the rate for other accident types. This results from the combined effects of there being fewer people per single 
vehicle accident and the fact that more single vehicle accidents result in at least one injury $(38 \%)$ as compared to other types of accidents (33.2\%). The amount of property damage per accident also indicates that single vehicle accidents are more severe in that more such accidents have non-vehicle damage in excess of $\$ 500$ as estimated by police officers on their traffic accident reports.

\subsubsection{COMPARISON OF TYPES OF FATAL AND ALCOHOL INVOLVED SINGLE VEHICLE ACCIDENTS}

Comparisons of Dade County fatal vs. non-fatal and alcohol involved vs. non-alcohol involved single vehicle accidents by various accident type characteristics are presented in Figures 4-1 and 4-2. These figures are derived from Tables F-10 through F-22 of Appendix F. A fatal accident is defined to be one in which at least ione person, not necessarily the driver, is killed. An alcohol involved accident is defined to be one in which the driver has a positive blood alcohol test and/or is listed as "driving under the influence" or "had been drinking" in the Contributing Cause portion of the police report. Approximately $.7 \%$ of the County single vehicle accidents are fatal accidents and $14.3 \%$ are alcohol involved accidents.

Fatal vs. non-fatal accidents are compared in Figure 4-7. As shown, fatal accidents are about twice as likely to be of the non-collision type (i.e., rollover, fire, submergence, etc.) than non-fatal accidents. This supports the view that noncollision accidents, in particular rollovers, are generally more severe than other types of single vehicle accidents. Although the percentage of off roadway accidents is slightly greater for fatal accidents, the major difference in terms of accident location occurs in the open country/highway category. As shown, fatal accidents are nearly twice as likely to occur in open country/highway areas than non-fatal accidents. This may be due to the combined effects of higher speed limits in such areas and the fact that high speed accidents generally result in more severe injuries. The tendency for fatal single vehicle accidents to occur late at night and/or on weekends is even stronger than that observed previously for single vehicle accidents in general. Nearly one third of the fatal accidents occur on Sunday and better than forty percent occur between 10 p.m. and $2 \mathrm{a} . \mathrm{m}$. The possibility of alcohol involvement in fatal single vehicle accidents appears quite high. In fact, an additional $15.4 \%$ of the fatal accidents occur between $5-7$ p.m., a traditional "happy hour" time period. 
FIGURE 4-1. SUMMARY OF PRIMARY DIFFERENCES BETWEEN TYPES

OF FATAL AND. OTHER (NON-FATAL) DADE COUNTY

SINGLE VEHICLE ACCIDENTS $?$

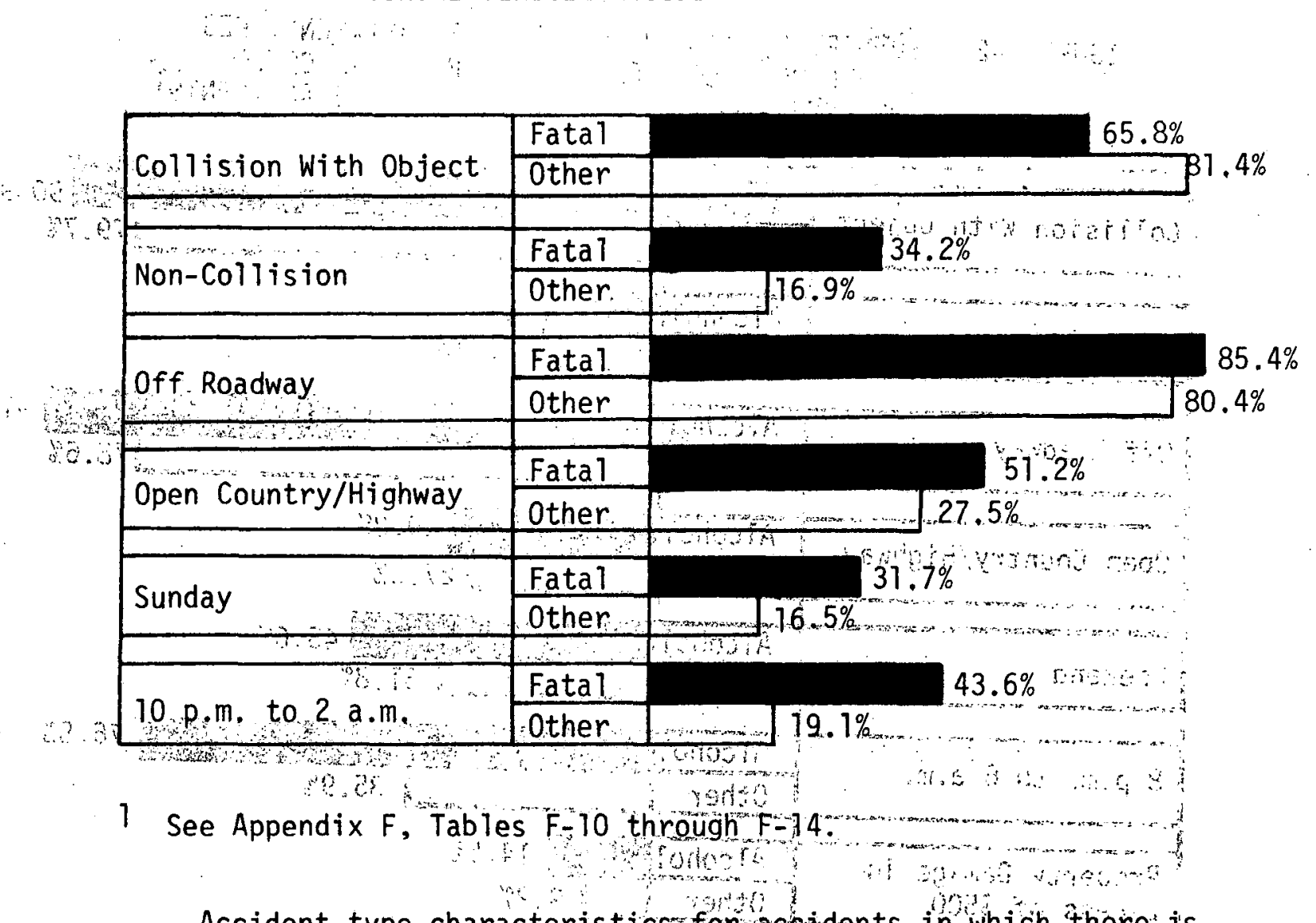

Accident type characteristics for aceidents in which there is some evidence that the driver was unden the influence of aleohol are compared in Figure 4-2... A though generally similar, detailed distributions show that somewhat more al cohol involved accidents are object collisions, off roadway, and in open country.highway. areas than non-alcohol accidents As expected, ; iarge, percentages of alcohol involved accidents occur on the weekend and/or during the nighttime. The alcohol involved accidents are cleariy more severe in terms of both injuries and ron-vehicle property damage.

Silt should be noted at this point that caution must be used in interpreting the results, of Figure $4-2$. This is due touthe possible bias introduced by poli ce officers reporting alcohol involvement when confronted with a severe, off road $6 \mathrm{bject}$ cojtis ion There may be astendency to more active sy seek and identifiy lacohol orinvolvement in such circums tances.

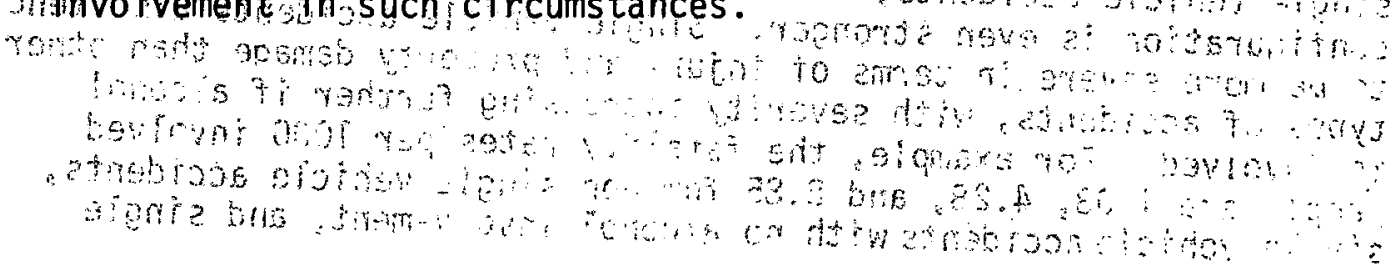


FIGURE 4-2. SUMMARY OF PRIMARY DIFFERENCES BETWEEN TYPES OF ALCOHOL INVOLVED AND OTHER (NON-ALCOHOL INVOLVED) DADE COUNTY SINGLE VEHICLE ACCIDENTS ${ }^{7}$

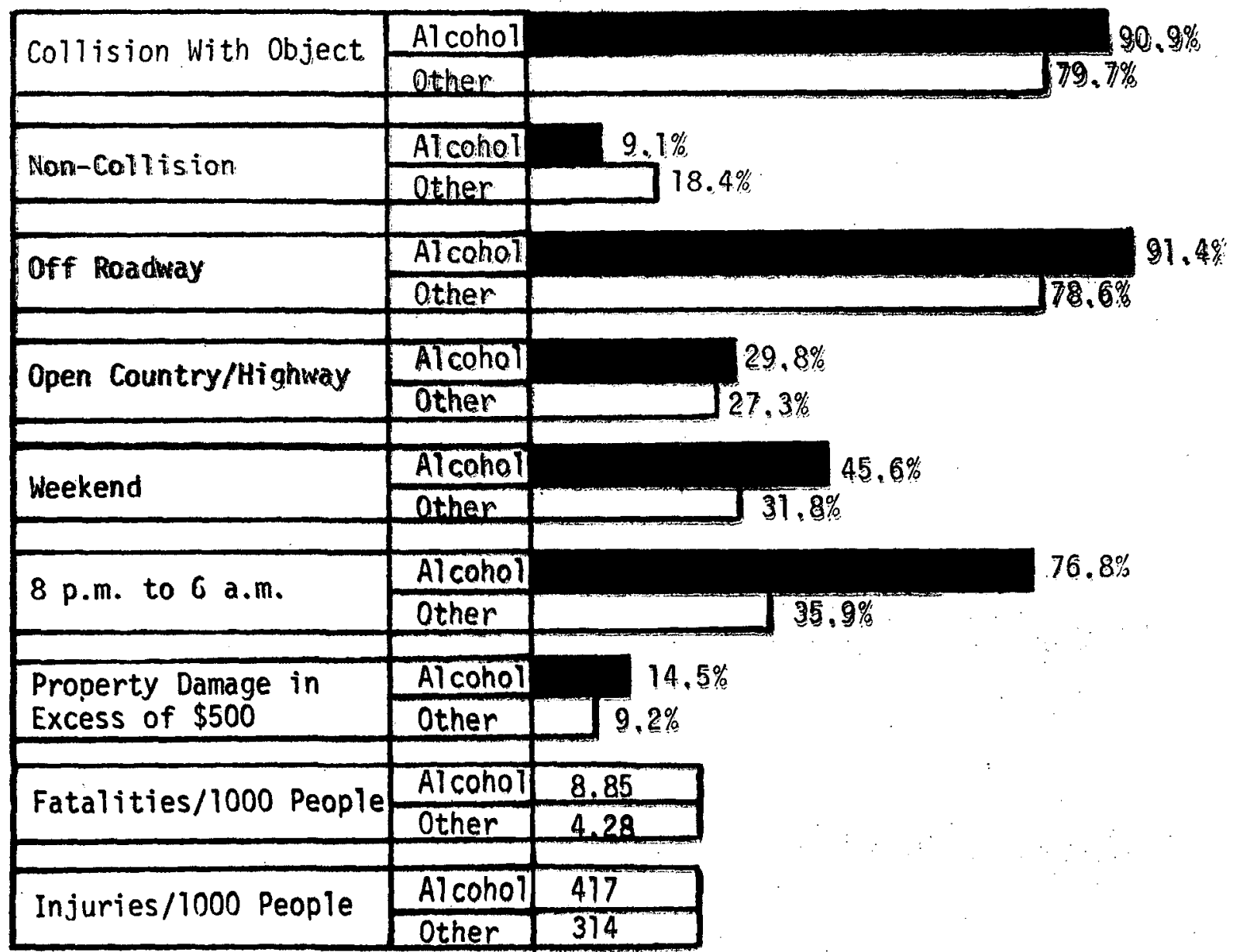

1. See Appendix F, Tables F-15 through F-22.

In summary, Dade County single vehicle accidents are more likely to be off-road object collisions, which occur in open country/highway areas, at night, and on weekends than other types of accidents. If consideration is restricted to alcohol involved single vehicie accidents, the tendency toward the above accident configuration is even stronger. Single vehicle accidents also tend to be more severe in terms of injury and property damage than other types of accidents, with severity increasing further if alcohol is involved. For example, the fatality rates per 1000 involved people are $1.03,4.28$, and 8.85 for non-single vehicle accidents. single vehicle accidents with no alcohol involvement, and single 
FIGURE 4-1. SUMMARY OF PRIMARY DIFFERENCES BETWEEN TYPES OF FATAL AND OTHER (NON-FATAL) DADE COUNTY SINGLE VEHICLE ACCIDENTS ${ }^{1}$

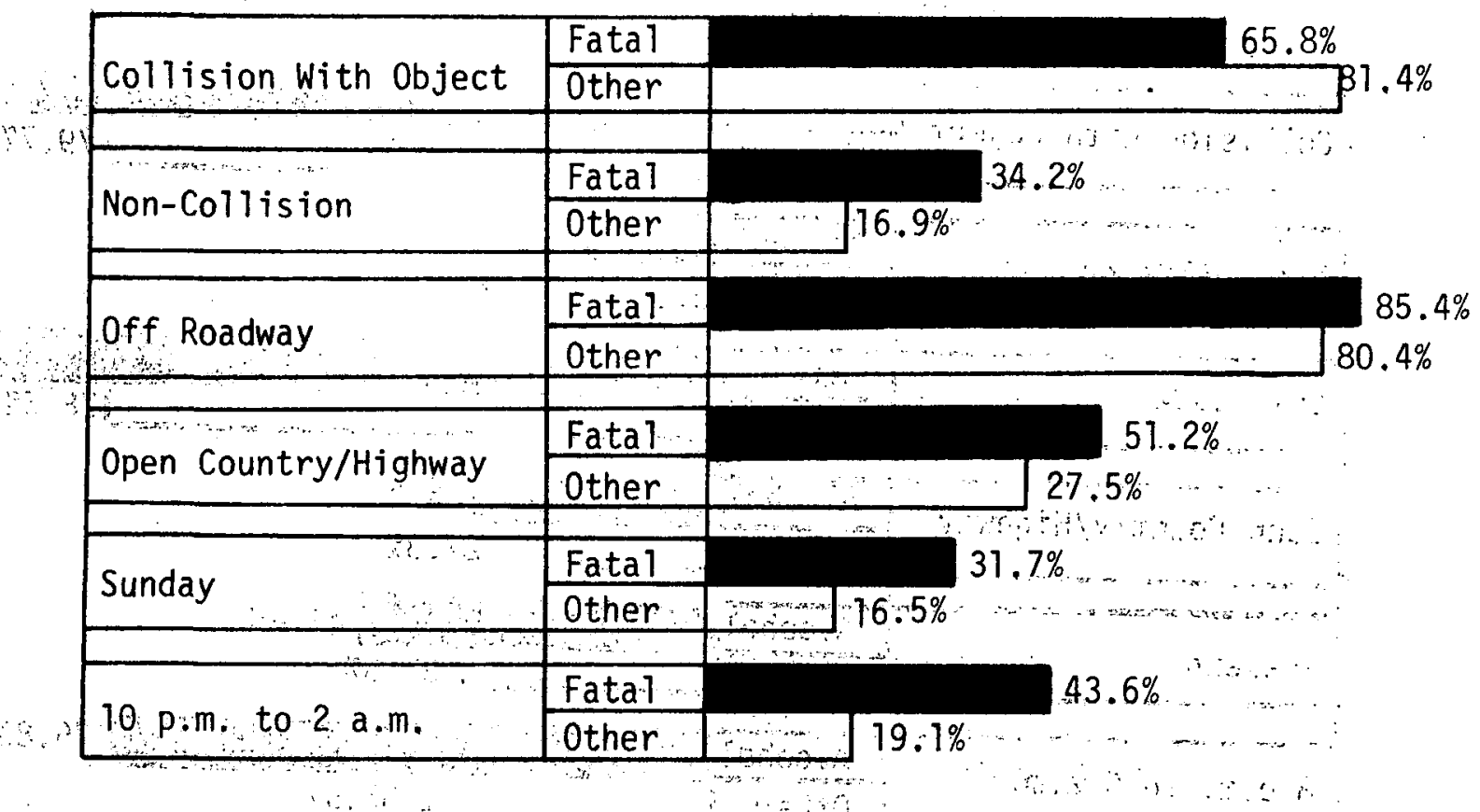

1 See Appendix F, Tables F-10 through F-14.

Accident type characteristics for accidents in which there is some evidence that the driver was under the influence of alcohol are compared in Figure 4-2. Although generaliy similar, detailed distributions show that somewhat more atcohol involved accidents are object collisions, off roadway, and in open country/highway. areas than non-alcohol accidents. As expected, Jarge percentages of alcohol involved accidents occur on the weekend and/or during the nighttime. The alcohol involved accidents are clearly more severe in terms of both injuries and non'vehicle property: damage.

It stiould be noted at this point that caution must be used in interpreting the results of Figure $4-2$. This is due to the possible bias introduced by police officers reporting alcohol involvement when lconfronted wi th a severe, off road object collision. There may be a tendency to more actively seek and identify arcohol invol vement' in such circumstances. 
FIGURE 4-2. SUMMARY OF PRIMARY DIFFERENCES BETWEEN TYPES OF ALCOHOL INVOLVED AND OTHER (NON-ALCOHOL INVOLVED) DADE COUNTY SINGLE VEHICLE ACCIDENTS ${ }^{\dagger}$

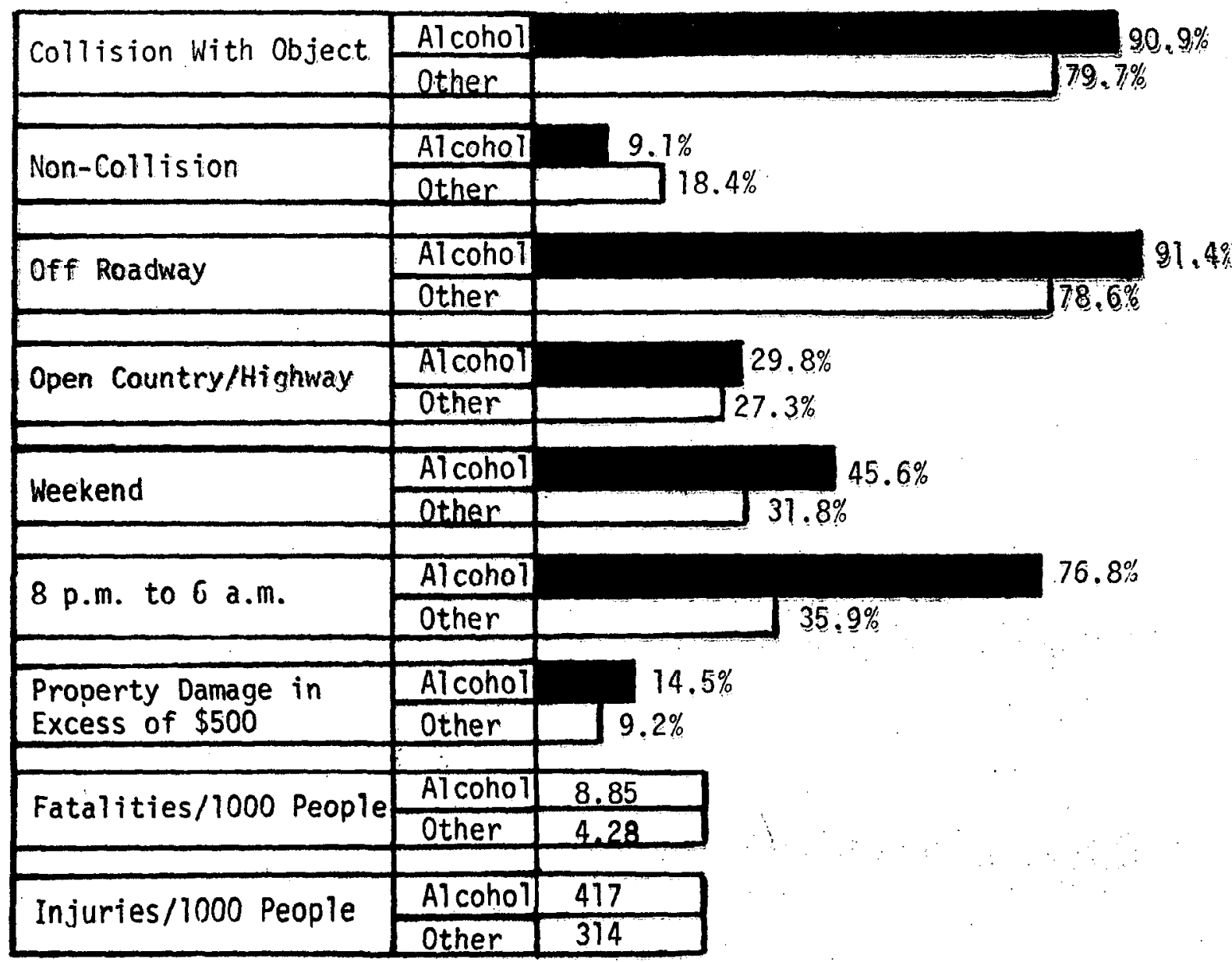

1

See Appendix F, Tables F-15 through F-22.

In summary, Dade County single vehicle accidents are more likely to be off-road object collisions, which occur in open country/highway areas, at night, and on weekends than other types of accidents. If consideration is restricted to alcohol involved single vehicle accidents, the tendency toward the above accident configuration is even stronger. Single vehicle accidents also tend to be more severe in terms of injury and property damage than other types of accidents, with severity increasing further if aicohol is involved. For example, the fatality rates per 1000 involved people are $1.03,4.28$, and 8.85 for non-single vehicle accidents, single vehicle accidents with no alcohol involvement, and single 
vehicle accidents with alcohol involvement, respectively. Fatal single vehicle accidents are more often non-collision (e.g., rollover), open country/highway area accidents than non-fatal single vehicle accidents, thus suggesting higher speeds. Alcohol involvement in the fatal single vehicle accidents is apparent in that some evidence of consumption on the part of the driver is indicated in $24.4 \%$ of the fatal accidents as compared to $14.2 \%$ for non-fatal accidents,

\subsubsection{REPRESENTATIVENESS OF THE IN-DEPTH SINGLE VEHICLE ACCIDENT SAMPLE BY ACCIDENT CHARACTERISTICS}

A summary comparison of the in-depth single vehicle and Dade County single vehicle data sets with respect to selected accident characteristics is presented in Table 4-2. Since both data sets cover the same time period, the in-depth data constitute a sample from the population of single vehicle accidents summarized in the County data. Some characteristics are not compared due to probable bias resulting from differences in interpretation and on-scene interaction between police officers and project field investigators. In the specific case of injuries and fatalities, no comparisons were made because the in-depth sample contains practically all of the fatal single vehicle accidents which happened in the County during the data collection period.

TABLE 4-2. SUMMARY OF PRIMARY DIFFERENCES BETWEEN DADE COUNTY SINGLE VEHICLE AND IN-DEPTH SINGLE VEHICLE ACCIDENT CHARACTERISTICS ${ }^{1}$

\begin{tabular}{|l|c|c|}
\hline \multicolumn{1}{|c|}{ Characteristic } & $\begin{array}{l}\text { Dade County Single } \\
\text { Vehicle Accidents }\end{array}$ & $\begin{array}{c}\text { In-Depth Single } \\
\text { Vehicle Accidents }\end{array}$ \\
\hline Collision With Object & $81.3 \%$ & $83.5 \%$ \\
Non-Collision & $17.1 \%$ & $16.1 \%$ \\
Occupants/Vehicle & 1.50 & 1.53 \\
Off Roadway Location & $80.4 \%$ & $92.0 \%$ \\
Weekend & $33.8 \%$ & $40.8 \%$ \\
8 p.m. to 6 a.m. & $42.0 \%$ & $49.9 \%$ \\
\hline
\end{tabular}

1 See Tables F-1 through F-3 and F-5 through F-6 of Appendix F. 
Although the detailed distributions show some differences within specific types of accidents, both the in-depth and County data exhibit about the same percentages of collision with object and non-collision accidents. Table 4-2 also indicates that while the number of occupants per vehicle is about the same in both cases, the in-depth sample has more off roadway accidents than the County data. As might be expected, the in-depth sample has a higher percentage of weekend accidents than the county population and more night time ( $8 \mathrm{p} . \mathrm{m}$. to $6 \mathrm{a} . \mathrm{m}$.$) accidents than the$ County. This most likely reflects the increased willingness of the police to hold accident scenes during periods of relatively low traffic volume.

In summary, al though calculated chi-square values indicate statistically significant differences between the in-depth sample and the County population of single vehicle accidents with respect to accident types, the similarities are believed to be strong enough to make the in-depth data set a practically representative sample for selected purposes. The apparent sample biases were most likely introduced by the circumstances in which police officers felt it appropriate to hold accident scenes; that is, in low traffic volume situations. With respect to accident type and location, additional bias may have stemmed from variations between the way police officers and in-depth team members classified accidents. Since the in-depth sample is basically a "convenience" sample, some differences are to be expected.

\subsubsection{ACCIDENT CHARACTERISTICS OF THE IN-DEPTH SINGLE VEHICLE SAMPLE}

The single vehicle accidents investigated in this study involved impacts with objects, vehicle rollovers and other crash configurations, on and off the roadway. The distribution of these crash occurrences, the type and location of objects impacted, and the resulting damage and injuries are presented in this section. Also included, is a description of various roadway departure parameters such as direction, speed and angle. Additional information regarding the events leading to the various crash configurations is presented within the framework of the causal mechanism analysis given in Section 5.0 CAUSAL FACTORS.

\section{Crash Configuration and Severity}

A listing of the number of accidents in which a given crash configuration occurred at least once, is given in Table 4.3. Transient objects include parked vehicles, construction equipment and other movable objects. The configuration "other" consists of crash occurrences such as fires and truck jackknifing. A majority (78.5\%) 
of the accidents involve an impact with a fixed object off the roadway, thus indicating the most significant event in single vehicle accidents. Vehicle rollovers, particularly off the roadway, are also of sufficient frequency to be considered as a major problem.

A significant number (168) of these accidents have more than one crash occurrence. The crash configurations for the three most severe impacts, given in Table 4-4, indicate that a wide variety of impact sequences can occur. As might be expected, rollovers are more frequentiy encountered in crash occurrences subsequent to an initial impact. A more detailed description of the various impact sequences is presented in $n_{i}$ Table F-23 in Appendix F.

TABLE 4-3. CRASH OCCURRENCE BY CONFIGURATION AND LOCATION'

\begin{tabular}{|c|c|c|r|r|}
\hline Crash & \multicolumn{3}{|c|}{ On Roadway } & \multicolumn{2}{c|}{ Off Roadway } \\
\cline { 2 - 5 } Configuration & $n$ & $\%$ & \multicolumn{1}{c|}{$n$} & \multicolumn{1}{c|}{$\%$} \\
\hline Struck Fixed Object & 2 & 0.3 & 478 & 78.5 \\
Struck Transient Object & 17 & 2.8 & 28 & 4.6 \\
Vehicle Rollover & 32 & 5.3 & 109 & 17.9 \\
Other Configuration & 10 & 1.6 & 6 & 1.0 \\
\hline
\end{tabular}

1 Entries are number of accidents having at least one crash occurrence of the indicated configuration (i.e., a given accident may have more than one crash occurrence). Percentages are calculated as a percent of the total accidents (609).

TABLE 4-4. CRASH CONFIGURATION BY IMPACT SEQUENCE

\begin{tabular}{|l|r|r|r|r|r|r|r|r|}
\hline \multirow{2}{*}{\begin{tabular}{c} 
Crash \\
\cline { 2 - 8 } Configuration
\end{tabular}} & \multicolumn{2}{|c|}{ First } & \multicolumn{2}{|c|}{ Second } & \multicolumn{2}{|c|}{ Third } & \multicolumn{2}{|c|}{ Total } \\
\cline { 2 - 9 } & \multicolumn{1}{|c|}{$\%$} & $n$ & $\%$ & $n$ & $\%$ & $n$ & $\%$ \\
\hline Object-On Rd, & 19 & 3.1 & 1 & 0.6 & 0 & 0.0 & 20 & 2.5 \\
Rollover-On Rd. & 22 & 3.6 & 10 & 6.0 & 0 & 0.0 & 32 & 4.0 \\
Other-On Rd. & 8 & 1.3 & 2 & 1.2 & 0 & 0.0 & 10 & 1.2 \\
Object- Off Rd. & 491 & 80.6 & 122 & 72.6 & 20 & 60.6 & 633 & 78.1 \\
Rollover-Off Rd & 65 & 10.7 & 32 & 19.0 & 12 & 36.4 & 109 & 13.5 \\
Other-Off Rd. & 4 & 0.7 & 1 & 0.6 & 1 & 3.0 & 6 & 0.7 \\
\hline Total & 609 & 100.0 & 168 & 100.0 & 33 & 100.0 & 810 & 100.0 \\
\hline
\end{tabular}

A description of the specific objects impacted is also presented in Table F-24. A summary listing of these objects, given in Table $4-5$, indicates that redirection devices $(30.2 \%)$, poles and supports 
$(20.7 \%)$, bridge structures $(14.9 \%)$ and trees (9.2\%) account for approximately 75 percent of the objects impacted. This distribution of objects does, to a certain extent, demonstrate the nature of the roadsides in the study area.

TABLE 4-5. TYPE OF OBJECTS IMPACTED

\begin{tabular}{|c|c|c|c|c|c|c|}
\hline \multirow[t]{2}{*}{$\begin{array}{l}\text { Type object } \\
\text { Impacted }\end{array}$} & \multicolumn{2}{|c|}{$\begin{array}{l}\text { First } \\
\text { Impacts }\end{array}$} & \multicolumn{2}{|c|}{$\begin{array}{c}\text { Subsequent } \\
\text { Impacts }\end{array}$} & \multicolumn{2}{|c|}{$\begin{array}{l}\text { Total } \\
\text { Impacts }\end{array}$} \\
\hline & $n$ & $\%$ & $n$ & $\%$ & $n$ & $\%$ \\
\hline $\begin{array}{l}\text { Trees } \\
\text { Poles and Supports } \\
\text { Bridge Structures } \\
\text { Ditch/Canal } \\
\text { Ground/Pavement } \\
\text { Curbs } \\
\text { Redirection Devices } \\
\text { E/A Devices } \\
\text { Fences/Walls/Buildings } \\
\text { Parked Vehicles } \\
\text { Construction Objects } \\
\text { Other Objects }\end{array}$ & $\begin{array}{r}47 \\
112 \\
65 \\
27 \\
4 \\
19 \\
155 \\
10 \\
11 \\
14 \\
19 \\
27\end{array}$ & $\begin{array}{r}9.2 \\
22.0 \\
12.8 \\
5.3 \\
0.8 \\
3.7 \\
30.4 \\
2.0 \\
2.2 \\
2.8 \\
3.7 \\
5.3\end{array}$ & $\begin{array}{r}32 \\
9 \\
7 \\
3 \\
42 \\
0 \\
8 \\
1 \\
3 \\
2\end{array}$ & $\begin{array}{r}9.1 \\
16.1 \\
22.4 \\
6.3 \\
4.9 \\
2.1 \\
29.4 \\
0.0 \\
5.6 \\
0.7 \\
2.1 \\
1.4\end{array}$ & $\begin{array}{r}60 \\
135 \\
97 \\
36 \\
11 \\
22 \\
197 \\
10 \\
19 \\
15 \\
22 \\
29\end{array}$ & $\begin{array}{r}9.2 \\
20.7 \\
14.9 \\
5.5 \\
1.7 \\
3.4 \\
30.2 \\
1.5 \\
2.9 \\
2.3 \\
3.4 \\
4.4\end{array}$ \\
\hline Total Objects & 510 & 100.0 & 143 & 100.0 & 653 & 100.0 \\
\hline
\end{tabular}

A further understanding of the roadsides involved in these accidents can be obtained from the location of the objects struck. In a large number of cases the vehicle initially departs the roadway and then impacts a roadside object. The location (clearance from the pavement edge) of these roadside objects is given in Table 4-6. First impacts with objects on the same side of the roadway as the initial departure are the only object locations included. It is interesting to note that over $70 \%$ of these objects were located within 12 feet of the pavement edge. The overall driver AIS for rigid object impacts within and beyond $12^{\prime}$ of the roadway is presented in Table F-24a of Appendix F. Although no adjustment for impact speed was made, the results indicate a reduction in injuries for objects beyond 12 feet.

An obviousiy important aspect of these accidents is the resulting damage and injuries. A detailed description of vehicle damage and occupant injuries for various crash configurations is presented in Appendix F in Tables F-25 through F-27. The distribution of damage extents as measured by the Vehicle Deformation Index (see Appendix B) is presented in Figure 4-3. Although the majority $(61.8 \%)$ of the impacts are minor, a fairly wide distribution of damage extents is apparent. 
TABLE 4-6. LOCATION OF OBJECTS' ${ }^{1}$ IMPACTED

\begin{tabular}{|l|c|c|c|}
\hline $\begin{array}{l}\text { Distance Off } \\
\text { Roadway (Ft.) }\end{array}$ & $n$ & $\begin{array}{c}\text { Relative } \\
\text { Frequency } \\
\%\end{array}$ & $\begin{array}{c}\text { Cumulative } \\
\text { Frequency } \\
\%\end{array}$ \\
\hline 0 thru 2 & 26 & 6.7 & 6.7 \\
3 thru 6 & 107 & 27.4 & 34.1 \\
7 thru 12 & 147 & 37.6 & 71.7 \\
13 thru 20 & 56 & 14.4 & 86.7 \\
21 thru 30 & 28 & 7.2 & 93.3 \\
31 thru 50 & 14 & 3.6 & 96.9 \\
over 50 & 12 & 3.1 & 100.0 \\
\hline Total & 390 & 100.0 & - \\
\hline
\end{tabular}

1 The only object locations included are first impacts on the same side of the roadway as the initial departure.

FIGURE 4-3. DAMAGE EXTENT AS MEASURED BY THE VEHICLE DEFORMATION INDEX (VDI ${ }^{7}$ )

\begin{tabular}{|c|c|}
\hline $\begin{array}{c}\text { VDI } \\
\text { Extent }\end{array}$ & $\begin{array}{c}\text { Percent of Impacts } \\
\text { With Indicated Extent of Damage }{ }^{2}\end{array}$ \\
\hline $0-1$ & \\
$2-3$ & $34.4 \%$ \\
$4-5$ & $2.3 \%$ \\
$6-9$ & $1.5 \%$ \\
\hline
\end{tabular}

1

See Appendix B

2. See Appendix F, Table F-25

The overall driver injury severity as measured by the Abbreviated Injury Scale (see Appendix $B$ ), which is presented in Figure 4-4, also demonstrates a good distribution of injury severities. Over $19 \%$ of the drivers receive substantial injuries (AIS $\geqslant 2$ ), including the 4.4\% fatalities. A similar distribution holds for passengers except that the severity is generaliy somewhat less. A comparison of driver injury severity for accidents involving a rollover and those with object impacts only is given in Figure 4-5. This clearly demonstrates 
that the likelihood of being injured and injured seriously is greater in rollover accidents. The percentage of fatalities in rollovers is, however, slightly smaller.

FIGURE 4-4. DRIVER INJURY SEVERITY AS MEASURED BY THE ABBREVIATED INJURY SCALE (AIS ${ }^{\dagger}$ )

\begin{tabular}{|c|c|}
\hline $\begin{array}{c}\text { Injury } \\
\text { Severity } \\
\text { (AIS) }\end{array}$ & $\begin{array}{l}\text { Percent of Accidents in which the Drivęr } \\
\text { Received the Indicated Injury Severity }\end{array}$ \\
\hline 0 ( No Injury) & $32.8 \%$ \\
1 & \\
2 & $8.7 \%$ \\
$3-5$ & $6.6 \%$ \\
$6-8$ (Fatal) & $4.4 \%$ \\
\hline
\end{tabular}

1

See Appendix B

2

See Appendix F, Table F-26

FIGURE 4-5. DRIVER INJURY SEVERITY (AIS ${ }^{1}$ ) VS. ROLLOVER INVOLVEMENT

\begin{tabular}{|c|c|c|}
\hline AIS & $\begin{array}{l}\text { Rollover } \\
\text { Involved }\end{array}$ & $\begin{array}{l}\text { Percent of Accidents With Indicated Driver } \\
\text { Injury Severity }\end{array}$ \\
\hline \multirow{2}{*}{0} & No & $37.9 \%$ \\
\hline & Yes & $11.5 \%$ \\
\hline \multirow{2}{*}{1} & No & $42.7 \%$ \\
\hline & Yes & $68.5 \%$ \\
\hline \multirow{2}{*}{2} & No & $7.8 \%$ \\
\hline & Yes & $10.0 \%$ \\
\hline \multirow{2}{*}{$3-5$} & No & \\
\hline & Yes & $6.9 \%$ \\
\hline \multirow{2}{*}{$6-8$} & No & $4.8 \%$ \\
\hline & Yes & \\
\hline
\end{tabular}

See Appendix B 


\section{Departure Description}

Since the majority of these single vehicle accidents involve an off-roadway impact, a description of the vehicle dynamics during the roadway departure would appear to be important. The first variable considered is the speed of the vehicle prior to the initiation of the accident sequence. Regression equations estimating the relationship between average pre-crash travel speed and the posted speed limit for curves and straight roadways are presented in Figure 4-7. In general travel speeds (relative to the posted speed limit) are higher on curves and are substantially above the limit on facilities with a low posted speed. Statistical parameters for these and all other curves presented in this section are given in Table F-28 of Appendix F.

The design of roadsides (width, slope, protective devices) should, in part, be based upon roadway departure parameters. The directions (right or left) of departure from the roadway for various alignments are presented in Figure 4-6. Cases involving trucks and motorcycles, or roadway configurations of a complex nature (e.g. reverse curves) are excluded from this and subsequent analyses of departure parameters. An important result indicated in this table is that left side departures comprise a substantial portion (43.8\%) of the roadway departures. It also appears significant that nearly $28 \%$ of the departures occur on curves.

FIGURE 4-6. ROADWAY DEPARTURE DIRECTION

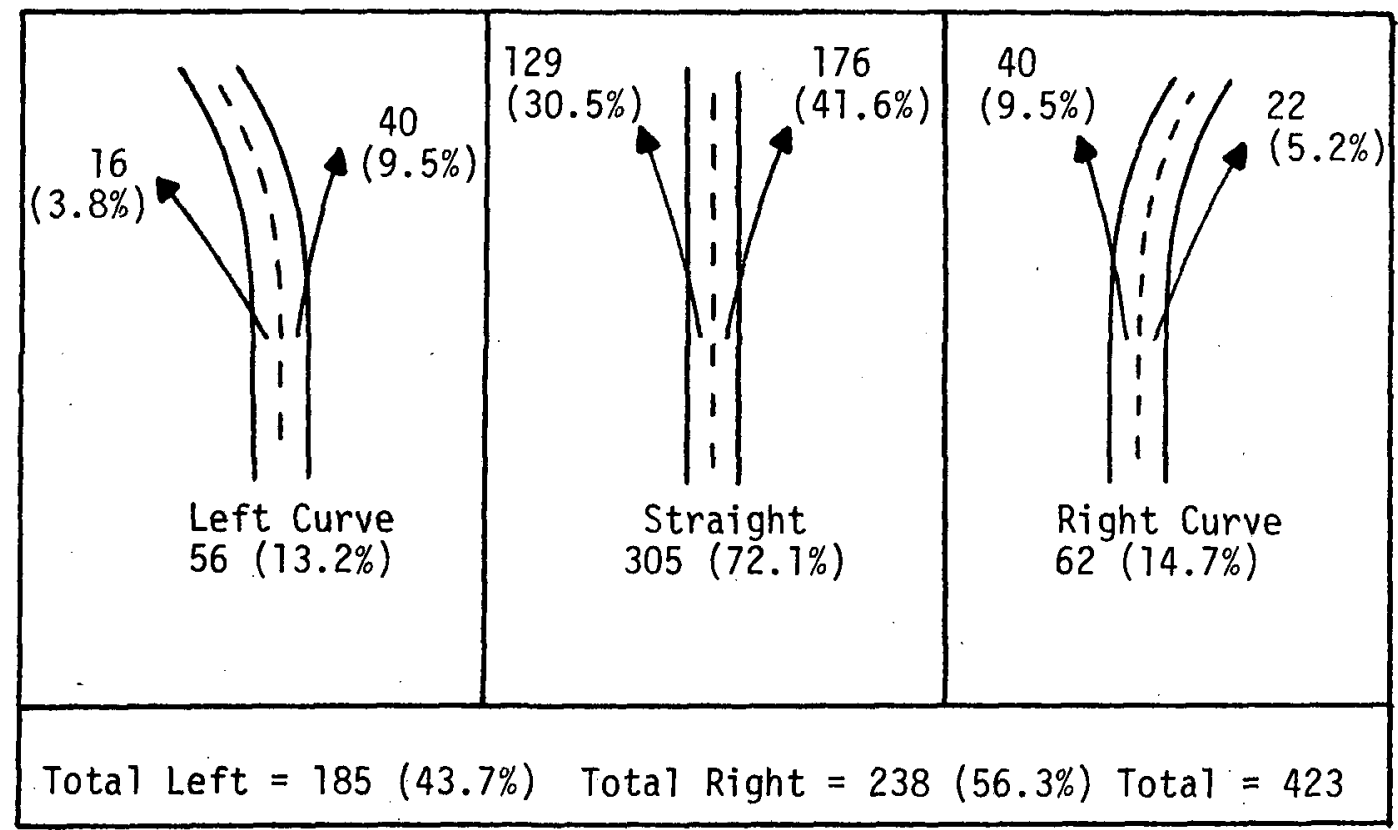


FIGURE 4-7

PRE-CRASH SPEED VERSUS POSTED SPEED LIMIT ${ }^{\top}$

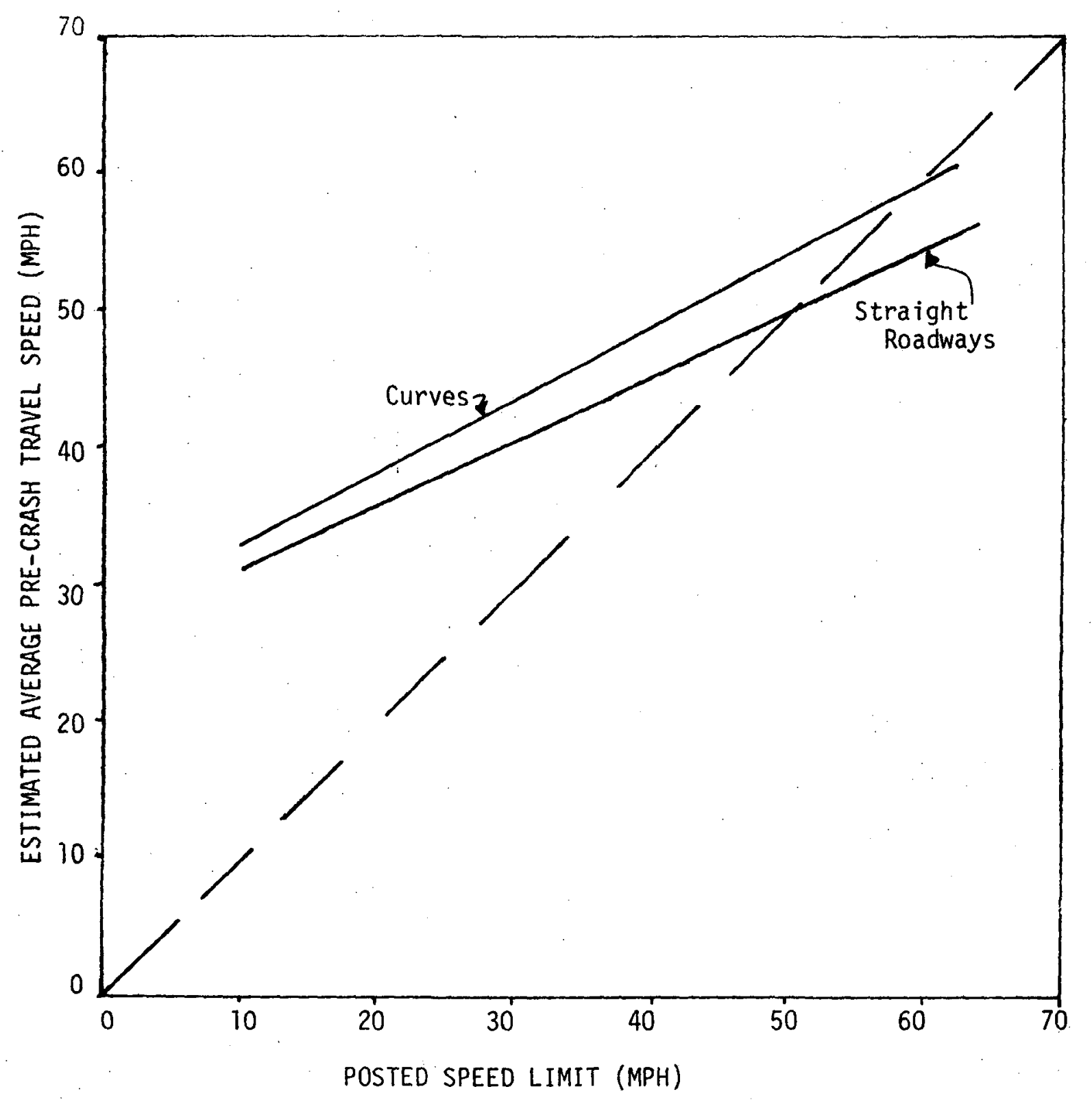

1 See Appendix F, Table F-28 
Vehicle departure speeds and angles (relative to the roadway) as a function of the posted speed limit are presented in Figures 4-8 and 4-9. Only those cases in which both the speed and angle were known are included. This includes 135 right side departures and 127 (74 of which are median departures) left side departures. As might be expected, more of the right side departure speeds and angles are unknown. This is due to the relatively large number of shallow angle, unintentional right side departures, wherein physical evidence adequate to establish departure angle was not available. Note that a horizontal line in Figures 4-8 and 4-9 indicates that no significant relationship with posted speed was identified even though a reasonable sample size was available for analysis. The heights of the horizontal lines are simply: the observed average value of the indicated ordinate variable.

Another important factor to be considered in roadside design is the expected speed and angle of vehicles at various distances from the roadway. A number of off-road points where speed or angle and distance from the roadway could be determined are included in this study. These points include impact points, curb crossings, maximum departure distances and other points of interest. Values of these off-road speeds and angles are given in Appendix F, Table F-29.

Significant relationships are identified for both off-road speed and off-road angle subsequent to departures from straight roadways. These are presented in Figures 4-10 and 4-11. The rapid drop in speed as a function of departure distance (Figure 4-10) would indicate that wide clear roadsides could substantialiy reduce accident severity: The posted speed limit does not appear to have a significant effect upon off-road speeds for left departures even though the actual departure speed is somewhat influenced by posted speed (Figure 4-8).

Off-road angles for straight roadways, as indicated in Figure 4-11, increase substantially with distance from the roadway. This rate of increase appears to be larger for high-speed facilities. Both of these phenomena may, of course, be indicative of the study area roadside characteristics rather than basic driver/vehicle behavior patterns.

\subsection{DRIVER CHARACTERISTICS}

Selected general, behavioral, and injury related characteristics of accident involved drivers are summarized and compared in this section. The tables and figures presented report statistics for several data sets: the in-depth sample of 609 single vehicle accidents, all drivers involved in reported single vehicle accidents 
FIGURE $4-8$

DEPARTURE SPEED VS. POSTED SPEED LIMIT'

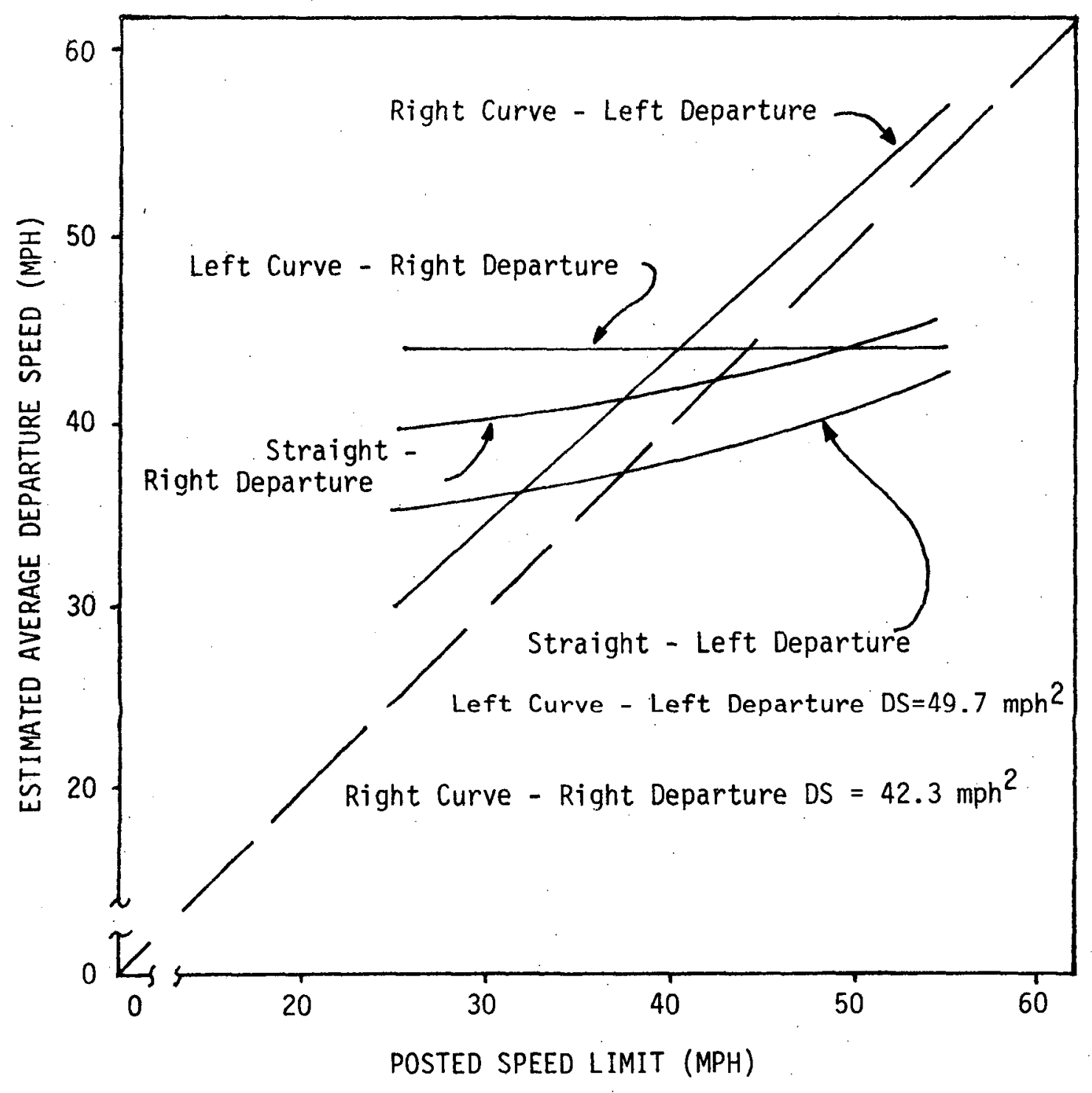

1 See Appendix F, Table F-28

2 sample size insufficient for regression analysis $(n \leq 10)$. Number shown is average departure speed. 
FIGURE 4-9

DEPARTURE ANGLE VS. POSTED SPEED LIMIT'

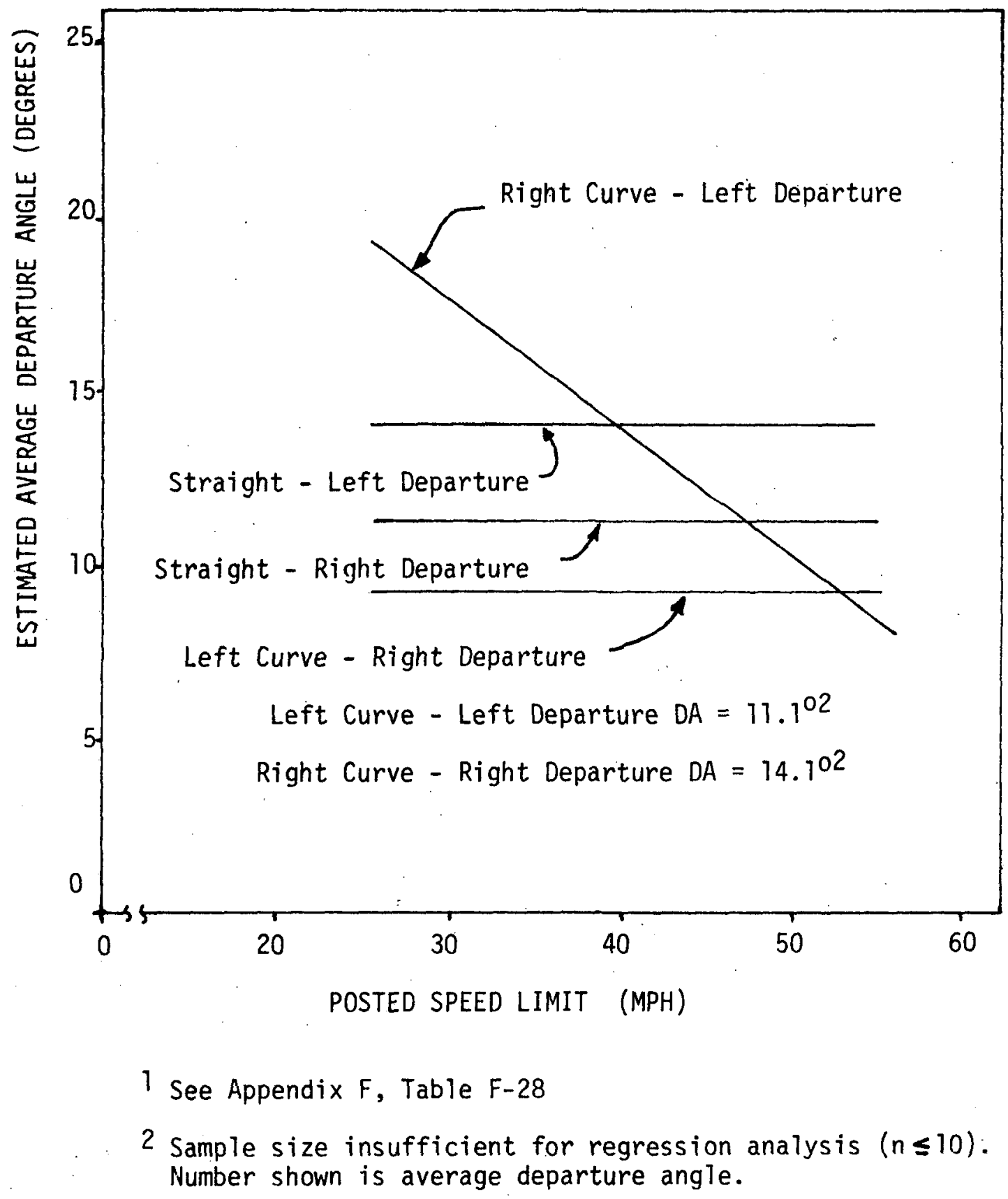


FIGURE 4-10

OFF-ROAD SPEED VS. POSTED SPEED AND DEPARTURE DISTANCE

FOR STRAIGHT ROADWAYS

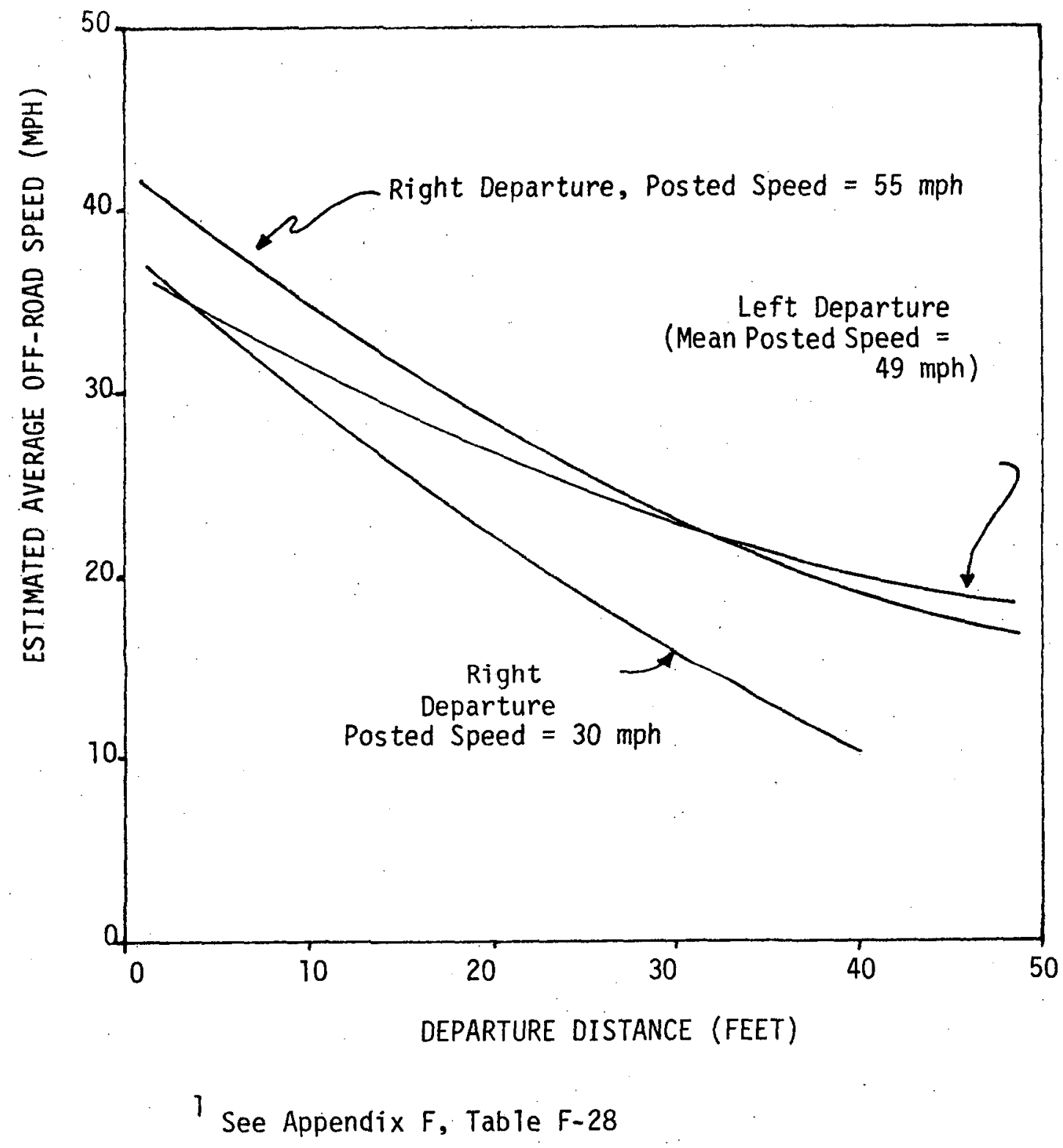


FIGURE 4-11

OFF-ROAD ANGLE VS. POSTED SPEED AND DEPARTURE DISTANCE FOR STRAIGHT ROADWAYS

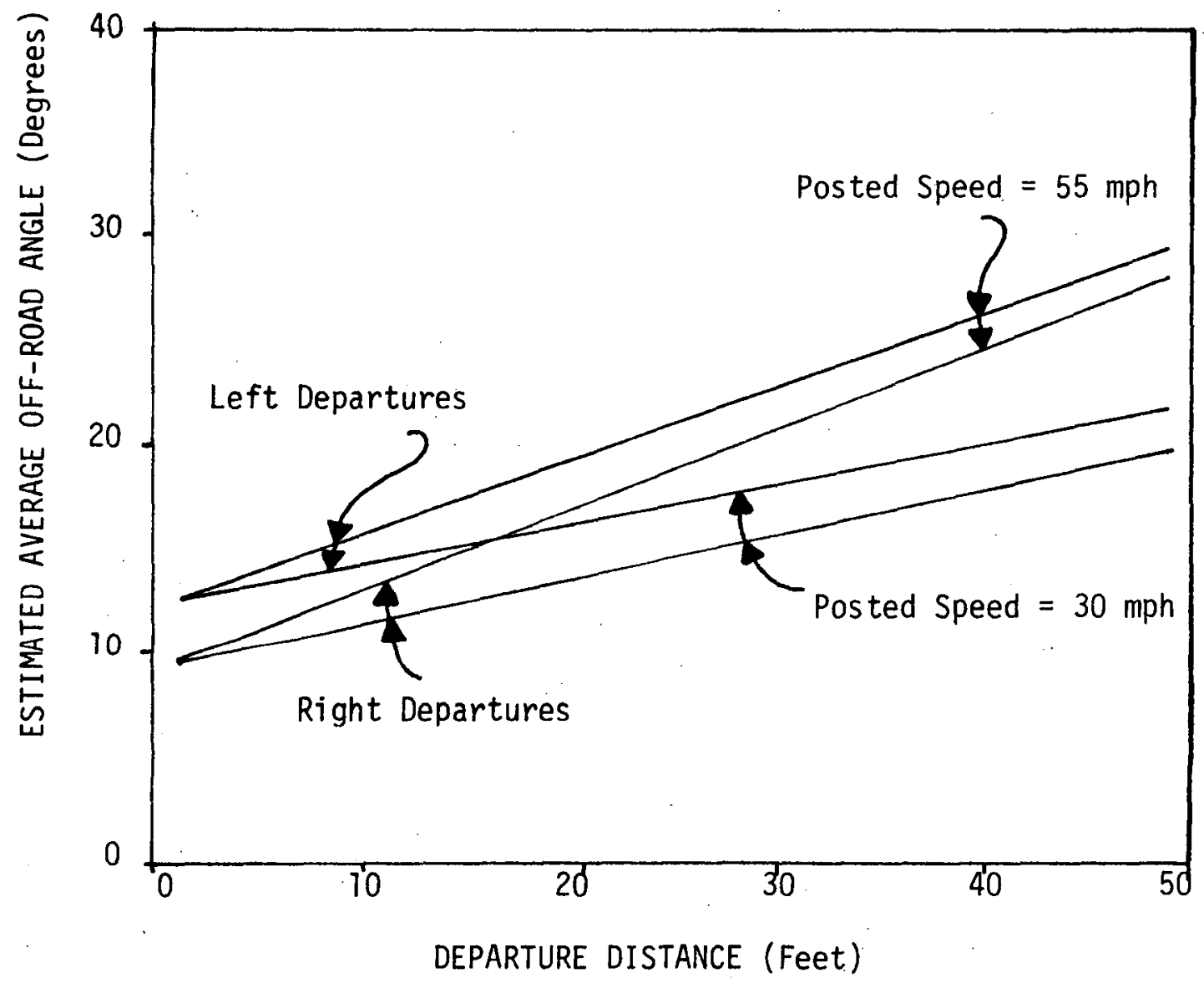

1 See Appendix F, Table F-28 
in Dade County during the period for which in-depth data were collected (approximately thirteen months), a sample of 1 out of 5 of the remaining drivers involved in non-single vehicle accidents in Dade County, and all Dade County licensed drivers on file as of October, 1974. The Dade County accident data were taken from the Public Safety Department accident files and the licensed driver data from the Florida Department of Highway Safety and Motor Vehicles driver license file.

As explained in the beginning of Section 4.1, the total counts for each data set may vary between the detailed tables of Appendix $F$ because of the elimination of "unknown" or "not stated" categories.

\subsubsection{COMPARISONS OF SINGLE VEHICLE ACCIDENT AND NON-SINGLE VEHICLE ACCIDENT DRIVER CHARACTERISTICS}

The primary differences between Dade County single vehicle accidents and other county accidents in terms of selected driver characteristics are presented in Table 4-7. As indicated drivers involved in single vehicle accidents are more likely to be young males than drivers involved in other types of accidents. More single vehicle accident drivers are also identified as having some physical defect. Although not shown, the predominant defects are "fatigue" and "apparently as leep" which account for $49 \%$ of all defects identified for single vehicle accident drivers. This is consistent with the fact that alcohol is cited as a contributing cause in more single vehicle accidents (Table 4-7), and with the previous observation that single vehicle accidents tend to occur at night and on weekends (see Table 4-1). Combining excessive speed with the effects of alcohol and fatigue most likely account for the significantiy greater percentage of single vehicle accidents which occur when the pre-accident driver/vehicle action is simply going straight.

The single vehicle driver fatality rate shown in Table 4-7 is approximately eleven times that for other accident types. Similarly, the single vehicle driver injury rate is more than twice that for other accident types. The higher injury/fatality rates are in part explained by the lower use of restraints and higher percentage of ejections for single vehicle accident drivers. It is interesting to note that both the driver injury rate and fatality rate are slightly higher than the overall rates for single vehicle accidents (see Table 4-1). This indicates that single vehicle accident drivers may be more likely to be injured/killed than the other people (e.g. passengers) involved in the single vehicle accidents. It is possible however, that single vehicle accidents where passengers are present are less severe than those in which the driver is the only occupant of the vehicle. As would be expected, the rates for drivers are lower than the overall rates in other types of accidents. 
TABLE 4-7. SUMMARY OF PRIMARY DIFFERENCES BETWEEN. DADE COUNTY SINGLE VEHICLE AND NON-SINGLE VEHICLE ACCIDENT DRIVER CHARACTERISTICS

\begin{tabular}{|l|c|c|}
\hline Characteristic & $\begin{array}{c}\text { other } \\
\text { Accidents }\end{array}$ & $\begin{array}{c}\text { Single Vehicle } \\
\text { Accidents }\end{array}$ \\
\hline General: & & \\
Under 25 Years 01d & $25.8 \%$ & $38.7 \%$ \\
Male & $69.8 \%$ & $78.9 \%$ \\
Physical Defects & $1.0 \%$ & $5.1 \%$ \\
\hline Behavior: & & \\
Pre-Accident Driver/ & & \\
Vehicle Action - & \\
Going Straight & $53.0 \%$ & $74.6 \%$ \\
Stopped or Parked & $14.1 \%$ & $.3 \%$ \\
Contributing Cause - & $44.1 \%$ & $6.7 \%$ \\
None Specified & $2.3 \%$ & $27.8 \%$ \\
Excessive Speed & $2.4 \%$ & $14.2 \%$ \\
Alcohol & $32.5 \%$ & $26.9 \%$ \\
\hline Restraint Use & & \\
Injury: Fatalities/1000 Drivers & 0.48 & 5.58 \\
Injuries/1000 Drivers & 167 & 384 \\
Ejection & $.7 \%$ & $6.0 \%$ \\
\hline
\end{tabular}

1 See Appendix F, Tables F-30 through F-40.

\subsubsection{COMPARISON OF FATAL AND ALCOHOL INVOLVED SINGLE VEHICLE DRIVER CHARACTERISTICS}

Comparisons of Dade County fatal vs. non-fatal and alcohol involved vs. non-alcohol involved single vehicle accidents by selected driver characteristics are presented in Figures 4-12 and 4-13. The definitions of a fatal accident and an alcohol involved accident are given in Section 4.1.2. As indicated previous7y, approximately $.7 \%$ of the single vehicle accidents involved a fatality and $14.3 \%$ involved a driver suspected or proven to have been drinking.

Fatal vs. non-fatal accident drivers are compared in Figure 4-12. As shown, nearly one-half of the drivers in fatal single vehicle accidents are under 25 years old. The largest difference 
appears in the $20-24$ year old group which accounts for $34.1 \%$ of the fatal accident drivers as compared to $22.6 \%$ of the drivers involved in other types of accidents. Although there are no sex differences, slightly more white drivers are involved in fatal single vehicle accidents. The remainder of Figure 4-12 shows that the previously observed tendency for single vehicle accident drivers to be under the influence of alcohol, traveling at excessive speeds while proceeding straight ahead, unrestrained, and ejected is simply exaggerated when oniy fatal accident drivers are considered.

FIGURE 4-12. SUMMARY OF PRIMARY DIFFERENCES BETWEEN FATAL AND OTHER (NON-FATAL) DADE COUNTY SINGLE VEHICLE ACCIDENT DRIVER CHARACTERISTICS ${ }^{\top}$

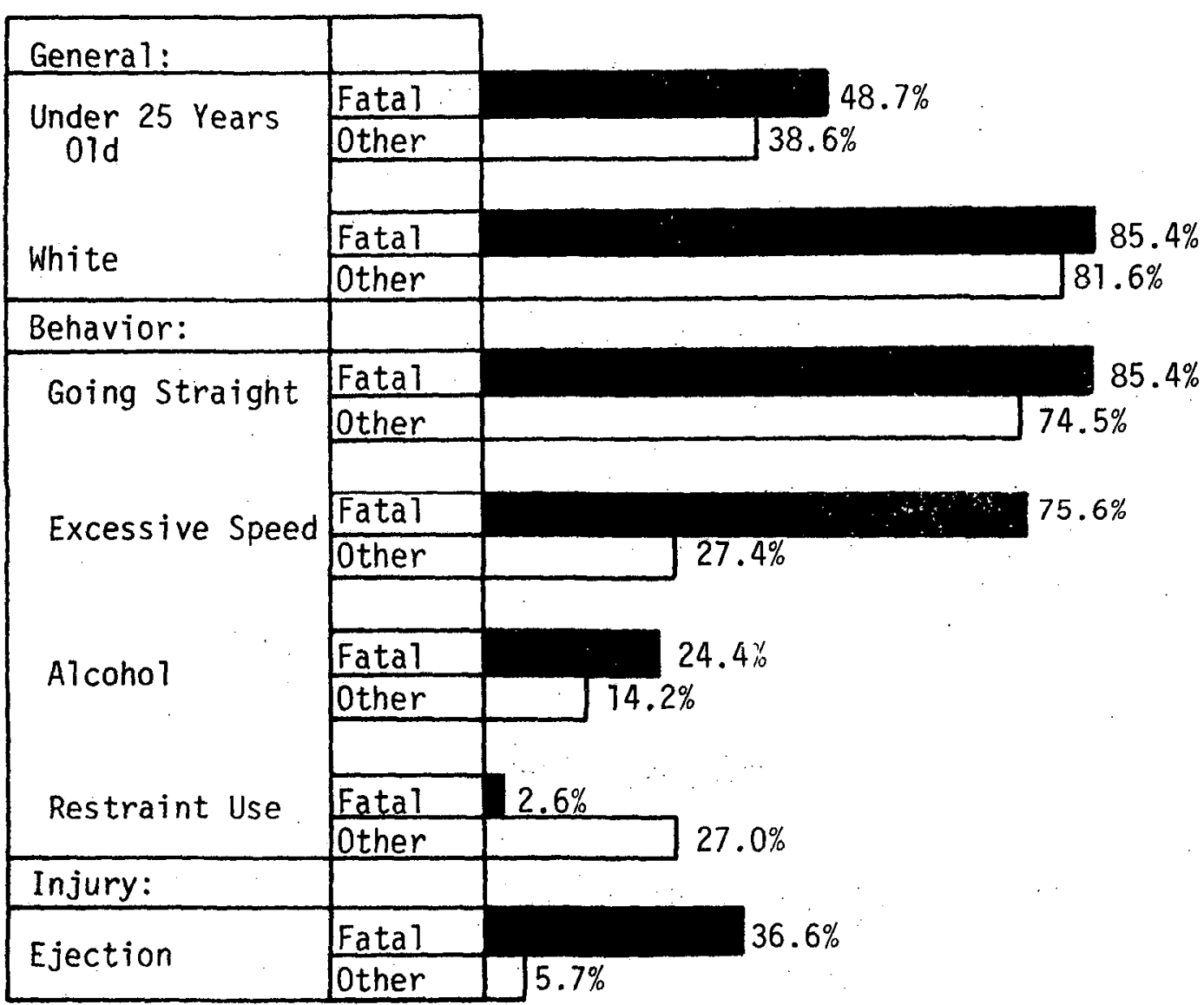

1 See Appendix F, Tables F-41 through F-48 
Selected characteristics of single vehicle accident drivers for which there is some evidence that the driver was under the influence of alcohol are compared in Figure 4-13. As expected, alcohol involved drivers tend to be older males. The observed difference in age is due entirely to the under 20 year old group which accounts for $7.3 \%$ of the alcohol involved drivers as compared to $17.6 \%$ for the other single vehicle accident drivers. The differences in the behavioral characteristics of the alcohol involved drivers tend to follow those of fatal accident drivers but are less pronounced. The interaction of excessive speed and alcohol, however, is again very apparent. The higher fatality/injury rates for alcohol involved drivers is consistent with the excessive speed behavior.

FIGURE 4-13. SUMMARY OF PRIMARY DIFFERENCES BETWEEN ALCOHOL INVOLVED AND OTHER (NON-ALCOHOL) DADE COUNTY SINGLE VEHICLE ACCIDENT DRIVER CHARACTERISTICS

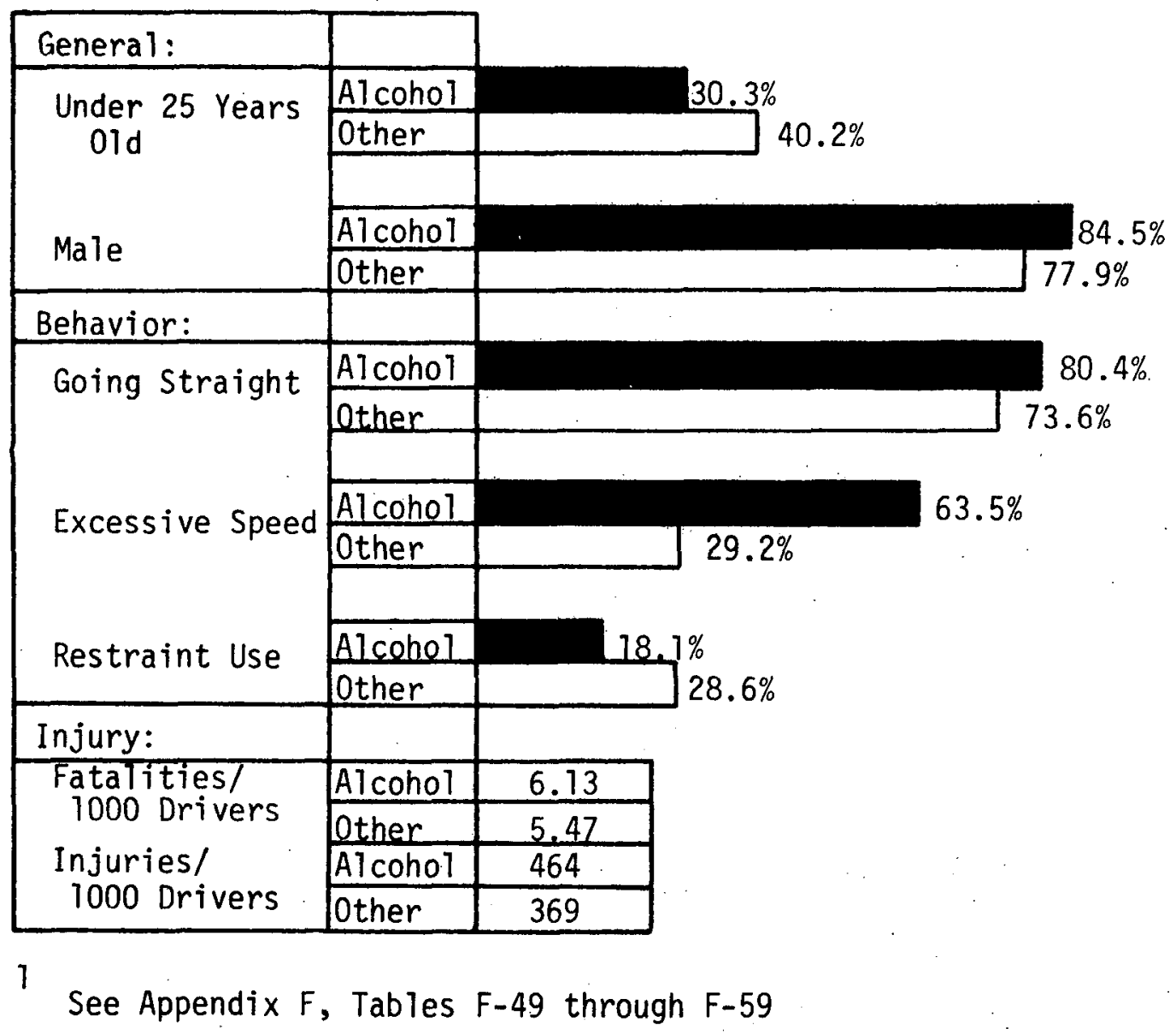




\subsubsection{REPRESENTATIVENESS OF THE IN-DEPTH SINGLE VEHICLE ACCIDENT DRIVER SAMPLE}

The representativeness of the in-depth sample of single vehicle accident drivers can be examined by comparing the in-depth age, sex, race, restraint use, and ejection distributions presented in Tables $F-30,31,32,39$, and 40 of Appendix $F$ to the comparable distributions for the County population of single vehicle accidents. Comparisons are not made for other factors due to differences in the interpretation of categories between the two data sets.

The in-depth age, sex, race, and ejection distributions are very similar to the County single vehicle distributions, there being no difference larger than $5 \%$. The only notable difference is in the restraint use distributions where the in-depth sample has a higher percentage of restraint non-use $(82.9 \%)$ than the County population $(73.1 \%)$. It is strongly suspected that this difference is due to more careful scene examination of the in-depth field investigators.

It should be noted that Chi-Square tests on the sex and race sample distributions do indicate statistically significant differences from the County population distributions. However, since there was no difference larger than $4.5 \%$ the in-depth sample can still be considered reasonably representative of the County population. In fact, the comparisons of age, race, and sex indicate the in-depth data represent a better sample of single vehicle accident drivers than they do a sample of single vehicle accident types as discussed in Section 4.1.3.

\subsubsection{IDENTIFICATION OF HIGH RISK SINGLE VEHICLE ACCIDENT DRIVERS}

Comparisons identifying high risk drivers with respect to age, sex, race and driving record are summarized in Table 4-8. As shown by the involvement ratios (\% of accidents $/ \%$ of driver population), drivers under 25 years of age are greatly overrepresented in both single vehicle accidents and other types of accidents. The overrepresentation of young drivers is strongest in single vehicle accidents, including the 25 - 29 year old category. If only fatal single vehicle accidents are considered, the overinvolvement of the under 25 group is even more pronounced (i.e., an involvement ratio of 2.45 vs. 1.94 for single vehicle accidents in general). Similar observations hold for the overrepresentation of male drivers and nonwhite drivers. It appears that the most appropriate target group for human countermeasures is young males, particularly with respect to single vehicle accidents. Although they account for a relatively 
small percentage, the non-white drivers should also be considered.

TABLE 4-8. INVOLVEMENT RATIOS AND COAVICTION RECORD BY DRIVER AGE, SEX, AND RACE

\begin{tabular}{|c|c|c|c|c|c|}
\hline Charact. & $\begin{array}{l}\text { Licensed } \\
\text { Drivers (s) }\end{array}$ & $\begin{array}{l}\text { Single Veh. } \\
\text { Involvement } \\
\text { Ratio }\end{array}$ & $\begin{array}{l}\text { Other Acc. } \\
\text { Involvement } \\
\text { Ratio }\end{array}$ & $\begin{array}{l}\text { Mean Con } \\
\text { Per Year } \\
\text { Lic. }(\boldsymbol{\mu})\end{array}$ & $\begin{array}{l}\text { jictions } \\
\text { In-Dep. }(\bar{x})\end{array}$ \\
\hline $\begin{array}{l}\text { Age : } \\
0-19 \\
20-24 \\
25-29 \\
30-39 \\
40-49 \\
50-59 \\
60+\end{array}$ & $\begin{array}{l}7.6 \\
12.3 \\
12.9 \\
19.0 \\
16.7 \\
14.8 \\
16.7\end{array}$ & $\begin{array}{r}2.11 \\
1.85 \\
1.22 \\
1.01 \\
.77 \\
.57 \\
.32\end{array}$ & $\begin{array}{l}1.24 \\
1.33 \\
1.02 \\
1.01 \\
1.01 \\
.87 \\
.73\end{array}$ & $\begin{array}{l}.33 \\
.47 \\
.37 \\
.33 \\
.30 \\
.25 \\
.27\end{array}$ & $\begin{array}{r}1.32 \\
1.21 \\
.66 \\
.90 \\
.69 \\
.48 \\
.47\end{array}$ \\
\hline $\begin{array}{l}\text { Sex: } \\
\text { Male } \\
\text { Female }\end{array}$ & $\begin{array}{l}56.6 \\
43.4\end{array}$ & $\begin{array}{r}1.39 \\
.49\end{array}$ & $\begin{array}{r}1.23 \\
.70\end{array}$ & $\begin{array}{l}.42 \\
.18\end{array}$ & $\begin{array}{r}1.07 \\
.51\end{array}$ \\
\hline $\begin{array}{l}\text { Race: } \\
\text { White } \\
\text { Black } \\
\text { Others }\end{array}$ & $\begin{array}{r}88.2 \\
11.1 \\
.7\end{array}$ & $\begin{array}{l}.93 \\
1.52 \\
2.14\end{array}$ & $\begin{array}{r}.93 \\
1.49 \\
1.86\end{array}$ & $\begin{array}{l}.30 \\
.47 \\
.19\end{array}$ & $\begin{array}{r}.89 \\
1.08 \\
.79\end{array}$ \\
\hline
\end{tabular}

1 See Appendix F, Tables F-60 through F-63.

Average traffic convictions per year, average convictions involving an accident per year, and average "points" per year for various types of drivers are described in Table F-63. The data are summarized for al1 Dade County licensed drivers and for the single vehicle accident drivers in the in-depth sample. The averages for each individual driver are calculated by dividing the total number of items (e.g., convictions) appearing on the individual's Florida driver license record up to the date of the in-depth accident (or date on which driver license data tape was obtained) by the time between the aforementioned date and the earliest entry date on the record. The summary data presented in Table F-63 includes the average of the individual driver averages for the population of a 11 Dade County licensed drivers (uvalues), the average of the individual driver averages in the single vehicle in-depth sample ( $x$ values), and the standard deviation of the individual driver averages in the in-depth sample (s values). The population and in-depth sample averages for convictions per year are presented in Table 4-8 for illustration and further discussion. For example, the average of the average convictions per year for all in-depth sample drivers under 20 years of age was 1.32 . 
As can be seen from Table 4-8, the difference between the traffic conviction records of the base population of a 11 county drivers and those drivers involved in the in-depth sample is quite great. In fact, the hypothesis that the population mean of the single vehicle accident population is the same as that for county drivers at large would be rejected at the $\alpha=.01$ level of significance for all categories of drivers presented. Thus there is a significant overrepresentation of drivers with poor traffic violation records in single vehicle accidents. The implications of these differences are obvious. For example, eliminating drivers with an average of three or more convictions per year would have reduced the number of accidents in the in-depth sample by approximately $5 \%$, two or more convictions per year by approximately $14 \%$, and 1.5 or more by approximately 23\%. Assuming the results hold for a 11 Dade County single vehicie accidents, the total accident reduction for the indicated cut-off points would be 290,812 , and 1348 accidents respectively. Similar results hold when considering convictions involving an accident or "points" per year.

It is interesting to note that although drivers classified as "Other" with respect to race have the highest involvement ratios, they also have the lowest conviction rate. The reason for this anomaly is unclear.

\subsubsection{IN-DEPTH SAMPLE DRIVER CHARACTERISTICS}

Certain driver characteristics identified during the in-depth sample study which cannot be conveniently compared to base population drivers are, however, of some interest. Selected in-depth characteristics are summarized in Table 4-9 and Figure 4-14. The driver's trip destination and purpose along with the driver's familiarity with the area and route traveled shown in Table 4-9 indicate that the majority of single vehicle accidents occur on a familiar roadway while the driver is returning home from a social trip. Only a small number of cases involve low-mileage drivers. The percentage of drivers who have one month or less experience with the case vehicle (22.8\%) may, however, be significant. The majority of drivers have completed high school and a significant percentage have some advanced educational experience $(32.6 \%)$. The low percentage of drivers fully employed and high percentage living with family or friends may be explained in part by the fact that approximately $18 \%$ are attending school on a full or part time basis.

Although blood alcohol levels were determined by actual test in only 87 of the in-depth drivers, estimates were made by the field investigators in 579 cases as shown in Table F-69 of Appendix F. 
TABLE 4-9. SUMMARY OF IN-DEPTH DRIVER CHARACTERISTICS ${ }^{1}$

\begin{tabular}{|c|c|}
\hline Characteristic & $\begin{array}{c}\text { Percent of } \\
\text { Drivers }\end{array}$ \\
\hline $\begin{array}{l}\text { Trip Destination: } \\
\text { Residence } \\
\text { Trip Purpose: } \\
\text { Social }\end{array}$ & $\begin{array}{l}64.1 \% \\
53.0 \%\end{array}$ \\
\hline $\begin{array}{l}\text { Familiarity/Experience: } \\
\text { Area } \\
\text { Route } \\
\text { Vehicle ( } \leq 1 \text { month) } \\
\text { Yearly Mileage }(\leq 5000)\end{array}$ & $\begin{array}{l}88.4 \% \\
86.7 \% \\
22.8 \% \\
13.8 \%\end{array}$ \\
\hline $\begin{array}{l}\text { Personal Characteristics: } \\
\text { High School Graduate } \\
\text { Employed Full Time } \\
\text { Living With Family/Friends } \\
\text { Single } \\
\text { Admitted Orinking } \\
\text { Thought to Have Been Drinking }\end{array}$ & $\begin{array}{l}68.8 \% \\
75.0 \% \\
34.4 \% \\
44.8 \% \\
40.1 \% \\
42.7 \%\end{array}$ \\
\hline
\end{tabular}

1 See Appendix F, Tables F-64 through F-69.

The estimated percentage of drivers that had been drinking (42.7\%) does not differ significantly from percentage of drivers who admitted drinking at the time of interview (40.1\%). These percentages are, however, substantially greater than the percentage $(14.2 \%)$ of drivers reported to have been drinking by police officers for Dade County single vehicle accidents in general (see Table 4-7). The differences are most likely due to more extensive interviewing by research personnel at the scene and a possible reluctance of police officers to report alcohol involvement unless it is very obvious and/or contributed to the cause of the accident. In any case, police reported alcohol involvement should generally be considered as understated.

The speeding behavior of the in-depth drivers is summarized in Figure 4-14. As shown, the percentage of accidents in which pre-crash speed exceeds posted speed decreases substantially as posted speed increases. This does not imply, however, that excessive speed is not a contributing cause of single vehicle accidents which occur on high speed highways. 
FIGURE 4-14. PERCENT OF ACCIDENTS IN WHICH PRE-CRASH SPEED EXCEEDS POSTED SPEED LIMIT

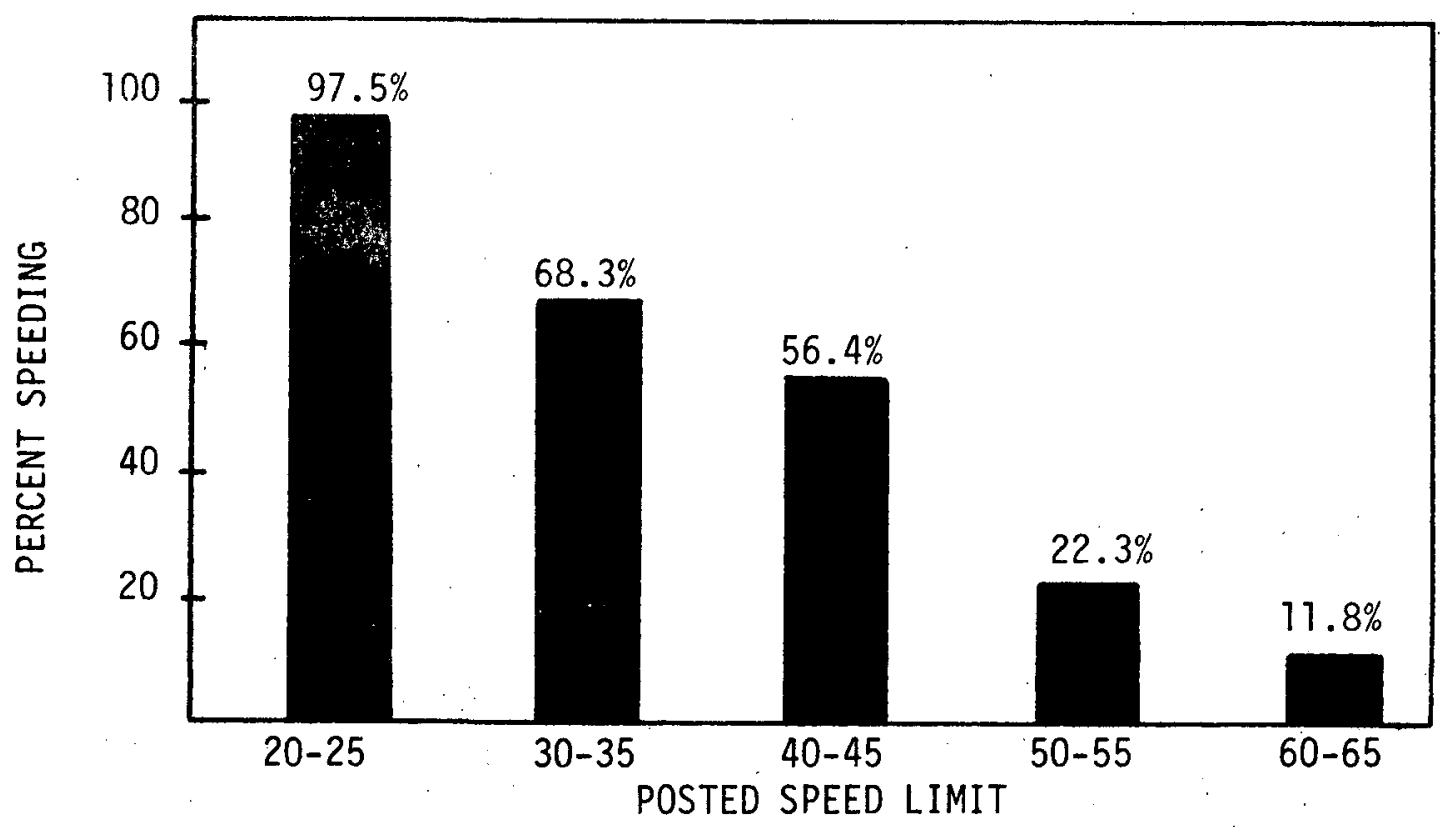

\subsection{VEHICLE CHARACTERISTICS}

Selected characteristics of accident involved vehicles are discussed in this section. The tables report statistics for several data sets: the in-depth sample of 609 single vehicle accidents, a 11 vehicles involved in reported single vehicle accidents in Dade County during the period for which in-depth data were collected (approximately thirteen months), a sample of 1 out of 5 of the remaining vehicles involved in other accidents in Dade County, 1974, and a sample of 1445 Dade County motor vehicle inspection slips during the period January, 1973, through December, 1973. The Dade County accident data are taken from the Public Safety Departure accident files, the registered vehicle data from the Florida Department of Highway Safety and Motor Vehicles vehicle registration files, and the vehicle inspection data from the Division of Florida Highway Patrol, Vehicle Safety Inspection files.

As explained in the beginning of Section 4.1 , the total counts for each data set may vary between tables due to the elimination of "unknown" or "not stated" catagories. A1so, the limited information contained in the Public Safety Department accident tape files severely restricts the number of vehicle characteristics which can be compared. 
Notably missing are model year and weight data for accident involved vehicles.

\subsubsection{COMPARISON OF SINGLE VEHICLE ACCIDENT AND NON-SINGLE VEHICLE ACCIDENT VEHICLE CHARACTERISTICS}

The primary differences between Dade County single vehicle accidents and other County accidents in terms of selected vehicle characteristics are summarized in Table 4-10. The higher percentages of "trucks" and "motorcycles" in single vehicle accidents may be due to stability problems inherent in these types of vehicles. In the case of "trucks" the problem could be load induced, while for "motorcycles" the obvious fact is that two wheel vehicles are less stable than four wheel vehicles.

The condition of vehicles involved in single vehicle accidents is somewhat worse than that of vehicles involved in other accident types. Tire, brake, and steering problems are the most prevalent defects identified. Although fewer vehicles involved in single vehicle accidents have safety equipment installed, the difference is more than offset by the higher percentages of "motorcycles" and "trucks" (most of which are not required to have restraints) in this group. The higher severity of single vehicle accidents is again apparent in that a much larger percentage of vehicles involved in single vehicle accidents have damage in excess of $\$ 500$. This is consistent with the comparison of non-vehicle property damage previously made in Table 4-1.

\subsubsection{COMPARISON OF FATAL AND ALCOHOL INVOLVED SINGLE VEHICLE ACCIDENT VEHICLE CHARACTERISTICS}

Comparisons of Dade County fatal vs. non-fatal and alcohol involved vs. non-alcohol single vehicle accidents by selected vehicle characteristics are presented in Figure 4-15. The definitions of a fatal accident and an alcohol involved accident are given in Section 4.1.2. As indicated previously, approximately $.7 \%$ of the single vehicle accidents involve a fatality and $14.3 \%$ involve a driver suspected or proven to have been drinking.

Fatal accident vehicles differ from non-fatal accident vehicles primarily in that a greater percentage are motorcycle/scooters $(9.8 \%$ vs. $6.5 \%)$. Although not shown in Figure $4-15$, there are somewhat more: trucks and somewhat fewer identified defects in the fatal accident vehicle group. The differences, however, are slight. 
TABLE 4-10. SUMMARY OF PRIMARY DIFFERENCES BETWEEN DADE COUNTY SINGLE VEHICLE AND NON-SINGLE VEHICLE ACCIDENT VEHICLE CHARACTERISTICS ${ }^{1}$

\begin{tabular}{|l|c|c|}
\hline \multicolumn{1}{|c|}{ Characteristic } & $\begin{array}{c}\text { Other } \\
\text { Accidents }\end{array}$ & $\begin{array}{c}\text { Single Vehicle } \\
\text { Accidents }\end{array}$ \\
\hline Truck_Trailer/Pick-up/ & & \\
Van' & $9.9 \%$ & $13.5 \%$ \\
Motorcycle/Scooter & $1.0 \%$ & $6.5 \%$ \\
No Safety Equipment & $14.7 \%$ & $18.8 \%$ \\
Installed & $.4 \%$ & $5.8 \%$ \\
Worn/Punctured Tires & $.5 \%$ & $2.2 \%$ \\
Defective Brakes & $.1 \%$ & $1.2 \%$ \\
Steerive Wheel Assembly/ & & $31.4 \%$ \\
Vehicle Damage In Excess & $17.1 \%$ & \\
of $\$ 500$ & &
\end{tabular}

1 See Appendix F, Tables F-70 through F-74

2 Only vans with commercial tags, other vans are considered to be passenger cars.

As would be expected, the alcohol involved driver is more likely to be driving a passenger car. Equivalently, he is less likely to be driving a motorcycle/scooter $(2.4 \%$ vs. $7.2 \%)$ or a truck $(7.0 \%$ vs. $14.6 \%$ ). There are also fewer identified defects for alcohol involved vehicles, perhaps because a police officer does not examine a vehicle driven by an alcohol involved driver as thoroughly as he would another vehicle. In either case, worn or punctured tires account for the majority of the identified defects.

FIGURE 4-15. SUMMARY OF PRIMARY DIFFERENCES BETWEEN FATAL VS. NON-FATAL ACCIDENT AND ALCOHOL INVOLVED VS. NON-ALCOHOL ACCIDENT VEHICLE CHARACTERISTICS 1

\begin{tabular}{|c|c|c|c|}
\hline \multirow[b]{2}{*}{ Motorcycle/Scooter } & Fatal & $9.8 \%$ & \multirow[b]{3}{*}{$90.4 \%$} \\
\hline & Other & $6.5 \%$ & \\
\hline \multirow{2}{*}{ Passenger Car } & Alcohol & & \\
\hline & Other & & \multirow[t]{3}{*}{$77.3 \%$} \\
\hline \multirow{2}{*}{ Vehicle Defects } & Alcohol & $5.6 \%$ & \\
\hline & Other & $13.1 \%$ & \\
\hline
\end{tabular}

1 See Appendix F, Tables F-75 through F-80. 


\subsubsection{REPRESENTATIVENESS OF THE IN-DEPTH SINGLE VEHICLE ACCIDENT VEHICLE SAMPLE}

The representativeness of the in-depth sample of single vehicle accident vehicles can be examined by comparing the in-depth single vehicle and Dade County single vehicle data sets in Tables F-70 and F-71 of Appendix F. Comparisons were not made for other characteristics due to differences in interpretations between the two data sets.

The in-depth and County vehicle types are quite similar, there being no difference larger than $5.1 \%$. The in-depth sample has somewhat greater safety equipment installation (90\%) as compared to the County single vehicle accident population ( $81.2 \%)$. This is most likely due to the slightly larger percentage of passenger cars $(84.4 \%$ vs. $79.3 \%$ ) in the in-depth sample and a more careful scene examination by the in-depth field investigators.

The observed differences with respect to vehicle type and safety equipment installations are not felt to be practically significant. Although the number of comparison variables is small there is no reason to suspect that the in-depth sample is not a reasonable representation of the vehicles in the County single accident population.

\subsubsection{IDENTIFICATION OF OVERINVOLVED SINGLE VEHICLE ACCIDENT VEHICLE CHARACTERISTICS}

Comparisons identifying overinvolvement with respect to vehicle type and vehicle defects are presented in Table 4-11.

The involvement ratios for vehicle type are calculated by dividing the percentage of accidents involving the indicated vehicle type by the corresponding percentage of registered vehicles of that type. Motorcycle/scooters appear to be greatly overinvolved in single vehicle accidents and underinvolved in other types of accidents. The overinvolvement of trucks and buses in both types of accidents is quite apparent and may be due to higher driven mileage rates. This is not the case for motorcycles/scooters. Passenger cars still account for the majority of single vehicle accident vehicles $(79.3 \%)$, even though they are somewhat underinvolved.

The involvement ratios for the various vehicle defects are calculated by dividing the percentage of total defects identified on police reports for the indicated defect, by the corresponding percentage of total defects identified as causes for rejection during annual Dade County motor vehicle inspections. Thus the indicated involvement ratios compare the vehicle defects which caused rejection of inspected vehicles to those defects identified for accident involved vehicles. 
One or more vehicle defects were identified for $41.4 \%$ of the vehicle inspections as compared to $11.9 \%$ of the vehicles involved in single vehicle accidents and $1.4 \%$ for other accident involved vehicles. Note that the motor vehicle inspection defect percentages do not in general reflect the condition of vehicles on the roadway nor do the accident involved defect percentages necessarily reflect the condition of vehicles at the time of the accident. Within these limitations, however, "involvement ratios" do indicate vehicle defect areas which should receive careful attention. For example, the high involvement ratio for steering defects in single vehicle accidents (9.7) might well indicate inadequate inspection procedures and/or questionable defect identification at the time of the accidents. The involvement ratios indicate primary emphasis should be given to improving inspection/ accident reporting procedures in the areas of steering, brakes, and tire conditions.

TABLE 4-11. INVOLVEMENT RATIOS BY VEHICLE TYPE AND DEFECTS

\begin{tabular}{|l|cc|}
\hline \multirow{2}{*}{ Characteristic } & \multicolumn{2}{|c|}{ Involvement Ratios } \\
\cline { 2 - 3 } & $\begin{array}{c}\text { Single Vehicle } \\
\text { Accidents }\end{array}$ & $\begin{array}{c}\text { Other } \\
\text { Accidents }\end{array}$ \\
\hline Vehicle Type: & .89 & .99 \\
Passenger Car & 1.62 & 1.19 \\
Truck & 2.67 & 2.67 \\
Bus & 3.42 & .53 \\
Motorcycle/Scooter & & .12 \\
\hline Rejection Item/Defect: & .04 & 5.20 \\
Lights and Turn Signals & 9.70 & .07 \\
Steering & .00 & 1.53 \\
Windshield Wipers & 2.48 & 6.67 \\
Tires & 3.48 & 1.71 \\
Foot Brakes & 1.70 & \\
Other & & \\
\hline
\end{tabular}

1 See Appendix F, Tables F-81 and F-82

\subsubsection{IN-DEPTH SAMPLE VEHICLE CHARACTERISTICS}

Certain factors relating to the condition of the case vehicles were evaluated for the in-depth sample. The results are summarized in Table 4-12. A substantial number of vehicles appear to have tires of mixed sizes. This could possibly contribute to instability and loss of control. Defects in the brakes, steering, and suspension 
appear in only a small percentage of the cases. The integrity of the exhaust system is generally satisfactory.

TABLE 4-12. SUMMARY OF IN-DEPTH VEHICLE CHARACTERISTICS ${ }^{\top}$

\begin{tabular}{|l|c|}
\hline \multicolumn{1}{|c|}{ Characteristic } & $\begin{array}{c}\text { Percentage of } \\
\text { Vehicles }\end{array}$ \\
\hline Mixed Tire Sizes & $21.3 \%$ \\
Unsatisfactory: & \\
One minute brake test & $5.3 \%$ \\
Steering condition & $1.0 \%$ \\
Suspension & $1.3 \%$ \\
Exhaust System Integrity & $5.9 \%$ \\
Vehicle Weight 3500 Ib. & $53.1 \%$ \\
\hline
\end{tabular}

1 See Appendix F, Tables F-83 through F-88

\subsection{ENVIRONMENTAL CHARACTERISTICS}

Characteristics of the accident environment are presented in this section. The tables and figures report statistics for various data sets: the in-depth sample of 609 single vehicle accidents, conditions reported for all single vehicle accidents in Dade County during the period for which data were collected (approximately thirteen months), and a sample of four out of ten of the remaining non-single vehicle accidents in Dade County. The County data are taken from the Public Safety Department accident tape files. The total counts for each data set may vary between tables because of the elimination of the "unknown" or "not stated" categories as discussed in the beginning of Section 4.1 .

\subsubsection{COMPARISON OF SINGLE VEHICLE ACCIDENT AND NON-SINGLE VEHICLE ACCIDENT ENVIRONMENTAL CHARACTERISTICS}

Dade County single vehicle accident and other accident environmental conditions are compared in Table 4-13. The area description percentages appear to indicate that single vehicle accidents are more likely to occur in open highway areas than other kinds of accidents. Roadway configurations other than straight and level apparently 
contribute to the occurrence of single vehicle accidents as evidenced by the roadway description variables. A somewhat higher percentage of single vehicle accidents in which the road surface is wet and/or slippery indicates that road surface condition may also be a contributing factor. The greater percentage of single vehicle accidents which occur on individual roadways is consistent with the previously observed tendency for single vehicle accidents to occur in open highway areas.

Table 4-1 shows that more single vehicle accidents occur at night than do other accident types. This fact is also apparent from the ambient light condition percentages shown in Table 4-13. It is interesting to note that $25.8 \%$ of the single vehicle accidents which occur after dark, occur on unlighted streets as compared to only $13.2 \%$ for other types of accidents which occur after dark. Thus, lack of street lighting combined with previously observed factors such as alcohol, speed, and road geometry may contribute to the occurrence of single vehicle accidents.

TABLE 4-13. SUMMARY OF PRIMARY DIFFERENCES BETWEEN DADE COUNTY SINGLE VEHICLE AND NON-SINGLE VEHICLE ACCIDENT ENVIRONMENTAL CHARACTERISTICS

\begin{tabular}{|l|c|c|}
\hline \multicolumn{1}{|c|}{ Characteristic } & $\begin{array}{c}\text { Other } \\
\text { Accidents }\end{array}$ & $\begin{array}{c}\text { Single Vehicle } \\
\text { Accidents }\end{array}$ \\
\hline $\begin{array}{l}\text { Area Description: } \\
\text { Lccal Street } \\
\text { Traffic Contro1 (None } \\
\text { or Posted Speed Only) }\end{array}$ & 46.0 & 31.7 \\
\hline Roadway Description: & 49.2 & 78.1 \\
Undivided & 35.8 & 41.9 \\
Curve & 2.4 & 14.1 \\
Leve1 & 94.8 & 87.9 \\
Wet/S1ippery Surface & 14.9 & 17.5 \\
\hline Ambience: & & 33.7 \\
Dark (Street Lighted) & 17.7 & 11.7 \\
Dark (Street Not Lighted) & 2.7 & \\
\hline
\end{tabular}

1 See Appendix F, Tables F-89 through F-95. 


\subsubsection{COMPARISON OF FATAL AND ALCOHOL INVOLVED SINGLE VEHICLE ACCIDENT ENVIRONMENTAL CHARACTERISTICS}

Comparisons of selected environmental characteristics present in fatal vs. non-fatal single vehicle accidents are presented in Figure 4-16. Similar comparisons between accidents in which there is some evidence that the driver had been drinking and those in which alcohol is not involved are presented in Figure 4-17. The definitions of a fatal accident and an alcohol involved accident are given in Section 4.1.2. As indicated previously, approximately $0.7 \%$ of the single vehicle accidents involve a fatality and $14.3 \%$ involve a driver suspected or proven to have been drinking.

FIGURE 4-16. SUMMARY OF PRIMARY DIFFERENCES BETWEEN FATAL AND OTHER (NON-FATAL) DADE COUNTY SINGLE VEHICLE ENVIRONMENTAL CHARACTERISTICS ${ }^{1}$

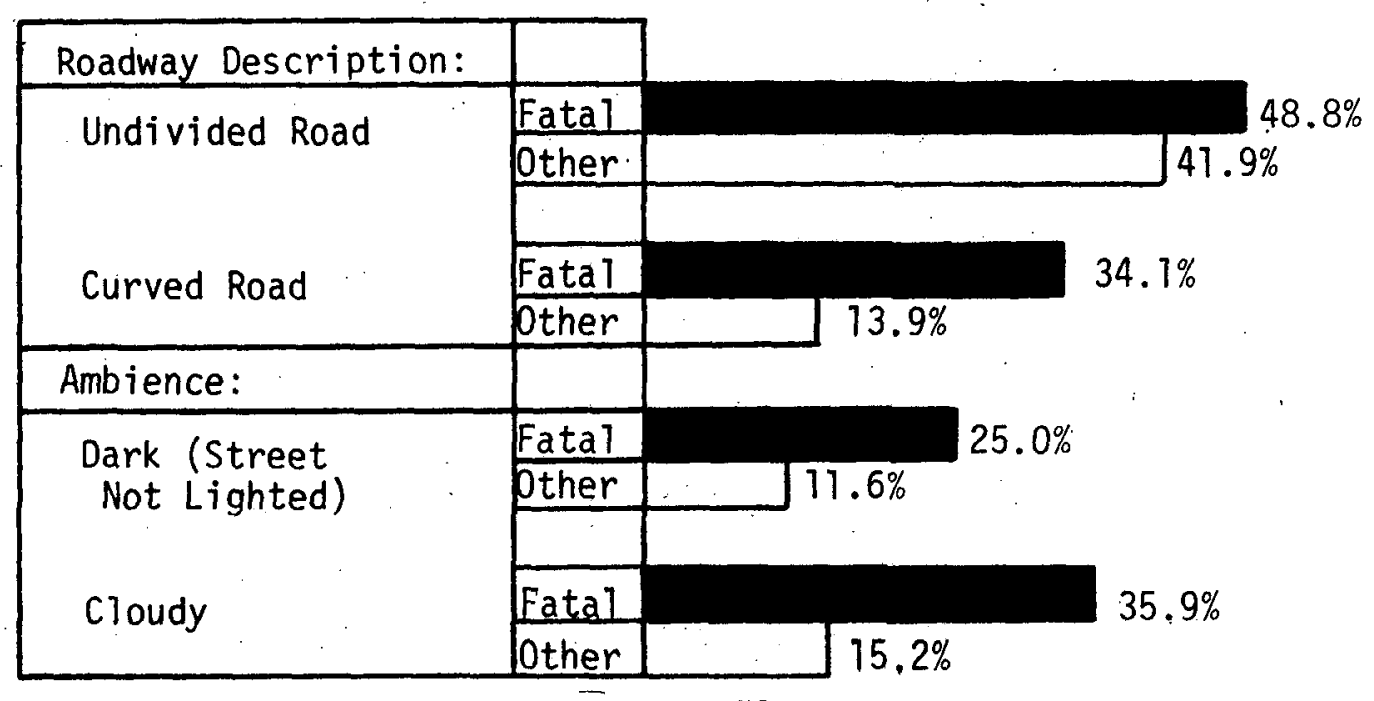

1 See Appendix F, Tables F-96 through F-100.

The only notable differences between fatal and non-fatal accidents are summarized in Figure 4-16. The higher percentages of fatal accidents which occur on undivided, curved, and unlighted roadways after dark is simply an exaggeration of the tendency observed for single vehicle accidents in general. Unlighted curves appear to be a potentially significant problem in fatal accidents.

The percentage of fatal single vehicle accidents (35.9\%) which occur during cloudy weather appears unusualiy high as compared to $15.4 \%$ for single vehicle accidents in general and $15.8 \%$ for other types of accidents. Since only $12.8 \%$ of the fatal single vehicle accidents occur on a wet or slippery road surface, it is unlikely 
that the high percentage is due to misclassifications between the "cloudy" and "rain" weather categories. Examination of the other available environmental data failed to provide a possible explanation for the observed phenomenon.

The primary differences between alcohol involved and non-alcohol involved accidents are summarized in Figure 4-17. As shown, alcohol consumption in conjunction with certain driving tasks such as negotiating a curve may contribute to accident causation. However, the relatively low percentage of alcohol involved accidents occurring on wet/slippery road surfaces appears to run counter to this concept.

FIGURE 4-17. SUMMARY OF PRIMARY DIFFERENCES BETWEEN ALCOHOL INVOLVED AND OTHER (NON-ALCOHOL) DADE COUNTY SINGLE VEHICLE ACCIDENT ENVIRONMENTAL CHARACTERISTICS ${ }^{1}$

\begin{tabular}{|c|c|c|c|}
\hline \multicolumn{4}{|l|}{ Roadway Description: } \\
\hline \multirow{2}{*}{ Curved Road } & Alcohol & $19.2 \%$ & \\
\hline & Other & $13.2 \%$ & \\
\hline \multirow{2}{*}{ Wet/Slippery Surface } & A]cohol & $9.3 \%$ & . \\
\hline & Other & $18.9 \%$ & \\
\hline \multicolumn{4}{|l|}{ Ambience: } \\
\hline \multirow{2}{*}{ Dark (Street Lighted) } & Alcohol & & $62.8 \%$ \\
\hline & Other & $28.9 \%$ & \\
\hline \multirow{2}{*}{$\begin{array}{c}\text { Dark (Street Not } \\
\text { Lighted) }\end{array}$} & Alcohol & $18.0 \%$ & \\
\hline & Other & $10.6 \%$ & \\
\hline
\end{tabular}

1 See Appendix F, Tables F-101 through F-105.

Perhaps this is a consequence of a tendency for alcohol involved drivers not to drive in rainy weather. As would be expected, most a) cohol involved accidents occur after dark (80.8\%) and on lighted streets $(62.8 \%)$. 


\subsubsection{REPRESENTATIVENESS OF THE IN-DEPTH SINGLE VEHICLE ACCIDENT SAMPLE WITH RESPECT TO ENVIRONMENTAL CHARACTERISTICS}

The representativeness of the in-depth sample in terms of selected environmental characteristics can be examined by comparing single vehicle accident data sets. A summary of these comparisons are presented in Table 4-14. The in-depth sample appears somewhat overrepresented in terms of rain, wet surface, and curve accidents while underrepresented in terms of daylight and undivided roadway accidents.

TABLE 4-14. SUMMARY OF PRIMARY DIFFERENCES BETWEEN DADE COUNTY SINGLE VEHICLE AND IN-DEPTH SINGLE VEHICLE ENVIRONMENTAL CHARACTERISTICS 1

\begin{tabular}{|l|c|c|}
\hline \multicolumn{1}{|c|}{ Characteristic } & $\begin{array}{c}\text { Dade County Single } \\
\text { Vehicle Accidents }\end{array}$ & $\begin{array}{c}\text { In-Depth Single } \\
\text { Vehicle Accidents }\end{array}$ \\
\hline Roadway Description: & & \\
Undivided & $41.9 \%$ & $28.9 \%$ \\
Curve & $14.0 \%$ & $27.9 \%$ \\
Wet Surface & $14.0 \%$ & $23.5 \%$ \\
\hline Ambience: & & \\
Daylight & $50.9 \%$ & $43.2 \%$ \\
Rain & $11.0 \%$ & $18.5 \%$ \\
\hline
\end{tabular}

1 See Appendix F, Tables F-91 thorugh F-95.

The rain, wet surface, and daylight differences are in part explained by the time of occurrence differences noted in Section 4.1.3. The curve difference can be attributed to the fact that the in-depth sample includes almost ail the fatal single vehicle accidents which happened in the county and the observation in Figure 4-16 that a large percentage of fatal accidents occur on curves. The undivided roadway difference is primarily due to the relatively large percentage of expressway accidents $(67.5 \%)$ in the in-depth sample. Note that this percentage is not directly comparable to the figures in Table F-89 of Appendix $F$ since many if not most Dade County expressway accidents are classified under state numbered roads by police agencies. Since approximately $68.2 \%$ of Dade County single vehicle accidents occur on roadways other than "Local Streets", the in-depth sample bias toward expressways may not be as strong as it first appears. The high percentage of in-depth sample expressway accidents is primarily due to varying levels of police agency cooperation during the course of the study. 


\subsubsection{IDENTIFICATION OF OVERINVOLVED SINGLE VEHICLE ACCIDENT ENVIRON- MENTAL CHARACTERISTICS}

There is little available information which inventories the environmental characteristics of the study area. That information which is available is generally not reported on the same basis as the accident involved characteristics. Thus it was not possible to identify high "risk" environmental conditions by computing involvement ratios.

\subsubsection{IN-DEPTH SAMPLE ENVIRONMENTAL CHARACTERISTICS}

Data were collected in the in-depth sample for various environmental variables. Although many of these characteristics are not directly comparable to other data sets, they are of some general interest for descriptive purposes. Selected characteristics are summarized in Table 4-15.

TABLE 4-15. SUMMARY OF IN-DEPTH ENVIRONMENTAL CHARACTERISTICS ${ }^{1}$

\begin{tabular}{|l|c|}
\hline Characteristic & Percent of Accidents \\
\hline Area Description: & \\
Freeway/Open Highway & $39.9 \%$ \\
Commercial Area & $41.5 \%$ \\
\hline Roadway Description: & \\
Freeway/Parkway/Expressway & $67.5 \%$ \\
Two-Way (Divided) & $71.1 \%$ \\
Fu11 Access Control & $66.2 \%$ \\
12' Average Lane Width & $61.0 \%$ \\
Asphalt & $79.5 \%$ \\
Pre-Crash Level of Service = A & $61.1 \%$ \\
\hline Roadway Conditions: & \\
Even Surface Contour & $94.4 \%$ \\
Traveled Surface Texture & $74.4 \%$ \\
Dry and Clean & $73.6 \%$ \\
\hline Ambient Conditions: & \\
Not Raining & $81.0 \%$ \\
Dark & $52.9 \%$ \\
\hline
\end{tabular}

See Appendix F, Tables F-106 through F-118. 
The largest single categories for site description and type of area are freeway/open highway and commercial, respectively. The preponderance of "expressway" accidents is apparent from the roadway description variables. The condition of the roadway surface at the time of the in-depth sample accidents is generally good. No particular anomalies are apparent in the data. 


\subsection{CAUSAL FACTORS}

A causal factor may be described as any situation, condition or action which precipitates or contributes to the causation of an accident, or which affects the severity of the consequences of a crash occurrence. Causal factors include human conditions and failures, vehicle characteristics and defects, and permanent and transient environmental conditions and situations.

The determination of the causal mechanism of a crash occurrence and $i$ ts attendant consequences is extremely important since this provides the basic explanation of why the event actually occurred, not merely what happened during the accident. In addition to the determination of specific human, vehicular and environmental factors as contributing to the causation or severity of an accident, it is also essential to determine their frequency of occurrence and to identify where and when these failures took place. A better understanding of the total causal mechanism can be obtained if each causal factor and the corresponding failure can be correlated with a particular event in the overall accident sequence. It is also essential to understand the precise nature and the extent of the various causal mechanisms in order to identify those areas in which the development of countermeasures may be effective in reducing the frequency of occurrence and/or the consequences of single vehicle accidents.

The classification of causal factors was carried out during the review and analysis phase of this study described in Section 2.3 REVIEW AND ANALYSIS. The causal factor model utilized was designed primarily to assist in the development of a clear understanding of the total causal mechanisms for accident causation and damage/injury production. A detailed description of this causal factor classification scheme and its relationship to the events in the accident sequence is presented in the following sections. The major causal factors identified during the on-scene investigation and the review and analysis process are included within this overall classification scheme.

\section{1 THE SINGLE VEHICLE ACCIDENT MODEL}

The classification and understanding of causal mechanisms may be facilitated by first considering what is involved in a single vehicle accident. A simplified conceptual model of potential single vehicle accidents, which was utilized throughout this study, is presented in Figure 5-1. This model provides the basic framework for the classification of causal factors as well as the description of events in the accident sequence. 
FIGURE 5-1 SINGLE VEHICLE ACCIDENT MODEL

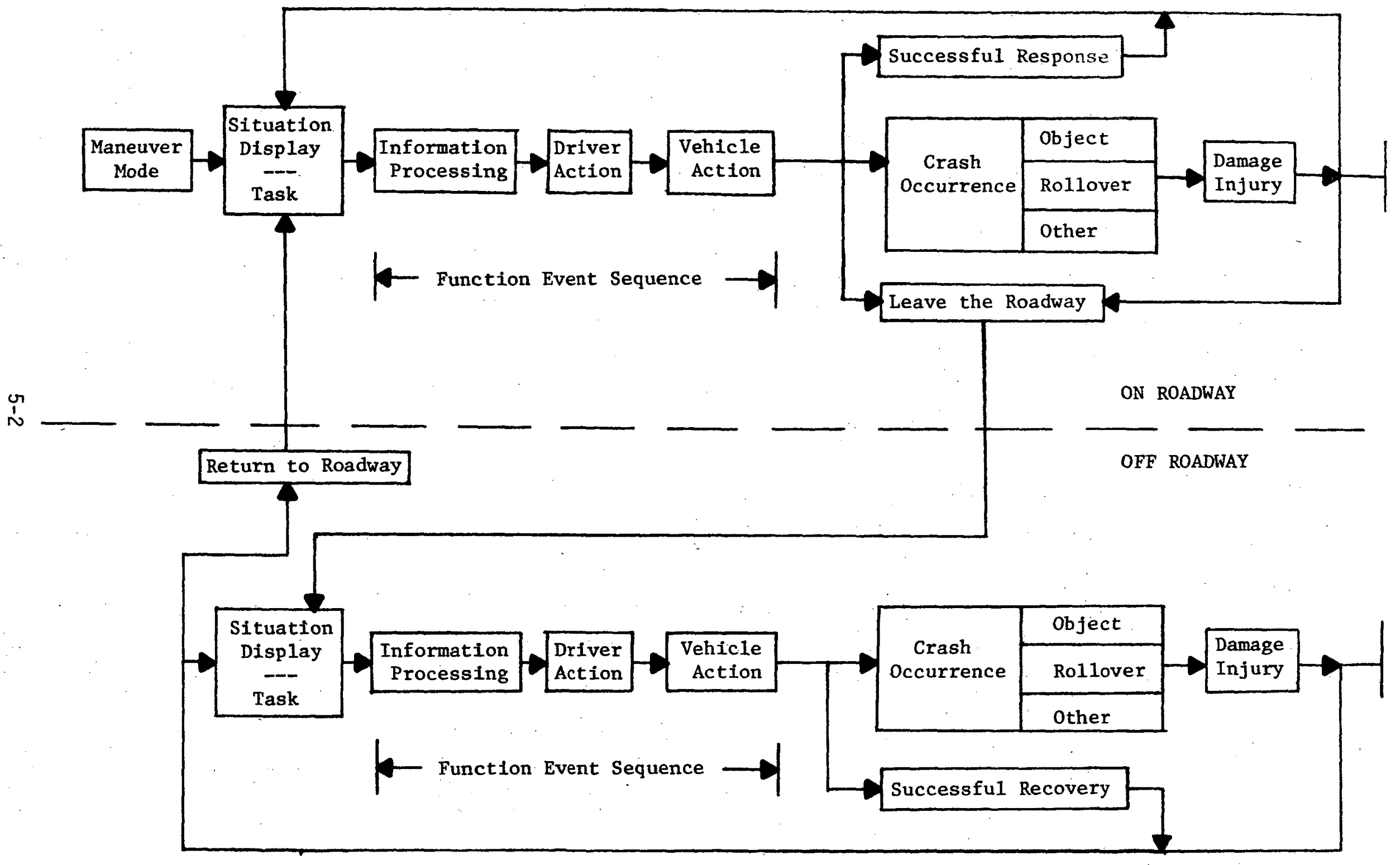


Normal driving may be considered as a continuous series of situation displays or tasks presented to the driver, followed by correct information processing, appropriate driver actions and adequate vehicle responses which result in successful responses. A non-successful response indicates the existence of a failure, and corresponding causal factor(s), in one or more of the events comprising the function event sequence. This may result in an on-roadway crash occurrence, or in the vehicle leaving the roadway. In those situations where the vehicle does leave the roadway, a new task or situation display is presented, followed by a subsequent function event sequence which may result in a successful recovery or in a failure and consequent crash occurrence off the roadway. As indicated in Figure 5-1, a series of impacts or crash occurrences may also take place during a single vehicle accident.

A general description of each segment of the model is presented in Figure 5-2 and in the following discussions. Included with this general discussion of the single vehicle accident model is a specific description of the accident sequences encountered in this study.

\subsubsection{PRE-ACCIDENT MANEUVER MODE}

The first item considered in establishing the framework for the potential accident sequence is the pre-accident driver/vehicle maneuver mode. These maneuvers, as indicated in Figure 5-2, include; going straight, negotiating a curve, turning at an intersection, passing, decelerating or stopping, and other miscellaneous maneuvers. The distribution of maneuver modes preceding the 609 single vehicle accidents analyzed in this study is given in Table 5-1. It is interesting to note that in over 85 percent of the accidents the initial maneuver mode itself consisted of nothing more complicated than either going straight $(50.7 \%)$ or negotiating a curve $(35.0 \%)$. This indicates that the execution of complex maneuvers (e.g. passing) does not constitute the basic problem in initiating single vehicle accidents.

TABLE 5-1 PRE-ACCIDENT MANEUVER MODE

\begin{tabular}{|l|r|r|}
\hline MANEUVER MODE & N & $\%$ \\
\hline Going Straight & 309 & 50.7 \\
Negotiating Curve & 213 & 35.0 \\
Intersection Turn & 16 & 2.6 \\
Passing Maneuver & 23 & 3.8 \\
Decelerating/Stopping & 23 & 3.8 \\
Other Maneuver & 25 & 4.1 \\
\hline Total & 609 & 100.0 \\
\hline
\end{tabular}


FIGURE 5-2

PRE-ACCIDENT EVENT SEQUENCE

\begin{tabular}{|c|c|c|c|c|}
\hline $\begin{array}{l}\text { Pre-Accident } \\
\text { Maneuver Mode }\end{array}$ & Task & $\begin{array}{l}\text { Information } \\
\text { Processing }\end{array}$ & $\begin{array}{l}\text { Driver } \\
\text { Action }\end{array}$ & $\begin{array}{c}\text { Resultant } \\
\text { Driver/Vehicle } \\
\text { Action }\end{array}$ \\
\hline $\begin{array}{l}\text { Going Straight } \\
\text { Curve Negotiation } \\
\text { Intersection Curve } \\
\text { Passing } \\
\text { Decelerating } \\
\text { Other Maneuver }\end{array}$ & $\begin{array}{l}\text { Maintain Course } \\
\text { Vehicle Control } \\
\text { Vehicle Avoidance } \\
\text { Obstacle Avoidance } \\
\text { Hazard Response }\end{array}$ & $\begin{array}{l}\text { Search } \\
\text { Identification } \\
\text { Evaluation } \\
\text { Decision }\end{array}$ & $\begin{array}{l}\text { None } \\
\text { Steer } \\
\text { Swerve } \\
\text { Brake } \\
\text { Accelerate } \\
\text { Combinations }\end{array}$ & $\begin{array}{l}\text { No Response } \\
\text { Loss of Control } \\
\text { Intentional } \\
\text { Departure } \\
\text { Unintentional } \\
\text { Departure } \\
\text { Other Action }\end{array}$ \\
\hline
\end{tabular}




\subsubsection{SITUATION DISPLAY OR TASK}

Since a driver is continuously confronted with new situations which require proper responses for successful accident avoidance, the initiation of a potential accident may be considered as the situation display presented to the driver. During a given accident sequence, the driver may also be confronted with subsequent situation displays, each possibly requiring a different type of response. The specific situation displays considered in this study are given in detail in the Human Form in Appendix A.

For the purposes of causal factor classification, the initial situation display can best be considered as the general task presented to the driver. This allows for a more realistic evaluation of the driver's response to specific situations. The descriptions of each task considered in this study are as follows:

Task

(1) Maintain Course:

(2) Vehicle Control:

(3) Vehicle Avoidance:

(4) Obstacle Avoidance:

(5) Hazard Response:

\section{Description}

The task is simply to maintain the proper travel path through performance of the routine maneuvers regularly required in normal driving. The driver is not confronted with any unique hazard or situation.

The primary task is to properiy respond to a vehicle problem and, if possible, maintain control of the vehicle. Vehicle problems would include fires, steering loss, blowouts, wheel loss and other vehicular failures.

The initial task is to avoid collision with another moving vehicle which may be traveling slower, decelerating, or maneuvering into the case vehicle's travel path. A corollary task would be to perform this avoidance maneuver without precipitating a single vehicle accident.

This task is essentially the same as Vehicle Avoidance except that all objects on the roadway other than moving vehicles are considered. Parked or disabled vehicles, pedescyclists, animals, accident debris and other objects would be included in this category.

The task is, if possible, to respond successfully to pavement defects, water puddles and other unusual roadway hazards which may not be properly classified as objects to be avoided. 
All of the preceding tasks, except Maintain Course, should also be considered as causal factors since these unusual problems and situations tend to initiate accident sequences. These tasks may be best classified as precipitating causal factors, rather than contributing factors, even though their existence would not always lead to a crash occurrence.

The initial tasks presented to the drivers in this study are given in Table 5-2. In over 70 percent of the cases, the driver was not confronted with any unique problem and his basic task was simply to Maintain Course, indicating the existence of other substantial causal factors. It should be noted, however, that in nearly 30 percent of the cases, the accident was precipitated, at least in part, by some real and unusual problem. This indicates that vehicle problems and roadway and traffic conditions are important factors in accident causation.

In $103(16.9 \%)$ of the cases, Vehicle Avoidance was identified as the major task confronting the driver. Within this task there were frequently corollary precipitating factors such as driver inattention and poor roadway sight distance, as well as the vehicle avoidance task produced by adverse traffic conditions and errors by other drivers. A portion of these cases might then properly be considered as being in the same general task category as Maintain Course.

TABLE 5-2 TASK PRESENTED TO THE DRIVER

\begin{tabular}{|l|r|r|}
\hline TASK & $\mathrm{N}$ & $\%$ \\
\hline MAINTAIN COURSE & 434 & 71.3 \\
VEHICLE CONTROL & & \\
Tire Failure & 16 & 2.6 \\
Steering Loss & 2 & 0.3 \\
Wheel Loss & 1 & 0.2 \\
Other (fires, etc.) & 14 & 2.3 \\
TOTAL & 33 & 5.4 \\
VEHICLE AVOIDANCE & 103 & 16.9 \\
& & \\
OBSTACLE AVOIDANCE & 12 & 2.0 \\
Stopped Vehicle & 2 & 0.3 \\
Pedestrian & 6 & 1.0 \\
Other Object & 20 & 3.3 \\
TOTAL & & \\
HAZARD RESPONSE & 0.2 \\
Surface Defect & 1 & 2.6 \\
Puddled Surface & 16 & 0.3 \\
Other & 19 & 3.1 \\
TOTAL & 609 & 100.0 \\
\hline TOTAL & & \\
\hline
\end{tabular}




\section{1,3, INFORMATION PROCESSING}

The next phase in a normal driving situation, or in an accident sequence, is information processing by the driver. The information input from the task or situation display presented to the driver must be adequately processed to indicate the proper driver response. The information processing consists of the following steps.

\section{(1) Search:}

(2) Identification:

(3) Evaluation:

(4) Decision:
The continuous monitoring of the driver's surroundings for the sensory (visual, auditory, etc.) input necessary for information processing.

The actual identification of situations, conditions or objects that should influence the driver's response.

The driver's assessment or understanding of an identified condition or situation, including the realization of these as potentiai hazards.

The driver's process in selecting the action or response based upon his identification and evaluation of a situation or condition.

These four events (information processing) along with the subsequent driver action and vehicle action comprise the six phases of the function event sequence.

\subsubsection{DRIVER ACTION}

Following the information processing phase, which culminates in the driver's decision as to the appropriate response to the task or situation display, is the driver action phase of the function event sequence. This is defined as the driver's physical implementation of the action or response dictated by the decision process. As indicated in Figure 5-2, driver responses would include; no response, simple steering, swerving, braking, accelerating, combinations, and other miscellaneous actions.

The identified driver responses to each task encountered in this study are given in Table 5-3. In 100 cases (16.4\%) the driver essentialiy made no response. This was primarily due to some state or condition of the driver inhibiting effective action.

Subsequent presentation of driver/vehicle actions will indicate that many of the swerving (abrupt steering), braking and swerve/brake 
combination maneuvers were incorrect, significantly delayed or excessive in magnitude, thus resulting in a loss of control or an unintentional departure from the roadway.

\subsubsection{VEHICLE ACTION}

Vehicle action, which is the final phase of the function event sequence, is defined as the actual response of the vehicle to the driver's action. The vehicle action may not necessarily correspond precisely with the driver actions listed in Figure 5-2, due to occurrence of vehicle action failures, The physical response of the vehicle is, of course, dependent upon basic vehicle characteristics and defects, and the roadway condition and configuration.

The description of vehicle action may be more meaningful when considered in combination with driver action. One useful method for describing the resultant driver/vehicle actions consists of placing these actions into the following broad categories which are particularly applicable to single vehicle accidents.

Action

(1) None:

(2) Loss of Control:

(3) Intentional Departure:

(4) Unintentional

Departure:

(5) Other/Unknown:

\section{Description}

Due to the lack of a significant driver (or vehicle) response, the vehicle continues on its previous course. This may result in an on-roadway crash occurrence or in the vehicle leaving. the roadway.

The driver has lost control of the vehicle (e.g. rotation) due to improper driver action, faulty vehicle response or some adverse environmental condition. This may also result in an on-roadway crash occurrence or in the vehicle leaving the roadway.

The driver intentionally departs the roadway based upon his decision process.

The driver has unintentionally departed the roadway, but the vehicle is still essentially under control. Braking, steering or other maneuvers could be effected by the driver.

Driver/vehicle actions that do not constitute loss of control but result in a roadway departure. 
TABLE 5-3

DRIVER RESPONSE TO TASK

\begin{tabular}{|c|c|c|c|c|c|c|c|c|c|c|c|c|}
\hline \multicolumn{13}{|c|}{ TASK } \\
\hline $\begin{array}{l}\text { Driver } \\
\text { Response }\end{array}$ & \multicolumn{2}{|c|}{$\begin{array}{l}\text { Maintain } \\
\text { Course }\end{array}$} & \multicolumn{2}{|c|}{$\begin{array}{l}\text { Vehicle } \\
\text { Control }\end{array}$} & \multicolumn{2}{|c|}{$\begin{array}{l}\text { Vehicle } \\
\text { Avoidance }\end{array}$} & \multicolumn{2}{|c|}{$\begin{array}{l}\text { Obstacle } \\
\text { Avoidance }\end{array}$} & \multicolumn{2}{|c|}{$\begin{array}{l}\text { Hazard } \\
\text { Response }\end{array}$} & \multicolumn{2}{|c|}{ TOTALS } \\
\hline 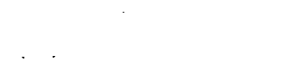 & $n$ & $\%$ & $n$ & $\%$ & $n$ & $\%$ & $n$ & $\%$ & $n$ & $\%$ & $n$ & $\%$ \\
\hline None & 97 & 22.4 & 1 & 3.0 & 0 & 0.0 & 2 & 10.0 & 0 & 0.0 & 100 & 16.4 \\
\hline Steer & 77 & 17.7 & 11 & 33.3 & 7 & 6.8 & 3 & 15.0 & 1 & 5.3 & 99 & 16.3 \\
\hline Swerve & 88 & 20.3 & 6 & 18.2 & 29 & 28.2 & 1 & 5.0 & 1 & 5.3 & 125 & 20.5 \\
\hline Brake & 38 & 8.8 & 2 & 6.1 & 10 & 9.7 & 8 & 40.0 & 6 & 31.6 & 64 & 10.5 \\
\hline Accelerate & 12 & 2.8 & 0 & 0.0 & 1 & 1.0 & 0 & 0.0 & 0 & 00.0 & 13 & 2.1 \\
\hline $\begin{array}{c}\text { Swerve/Steer } \\
\text { and Brake }\end{array}$ & 110 & 25.3 & 13 & 39.4. & 56 & 54.4 & 6 & 30.0 & 9 & 47.4 & 194 & 31.9 \\
\hline Other/Unknown & 12 & 2.8 & 0 & 0.0 & 0 & 0.0 & 0 & 0.0 & 2 & 10.5 & 14 & 2.3 \\
\hline TOTALS & 434 & 100.0 & 33 & 100.0 & 103 & 100.0 & 20 & 100.0 & 19 & 100.0 & 609 & 100.0 \\
\hline
\end{tabular}


TABLE 5.4

RESULTANT DRIVER/VEHICLE ACTION

\begin{tabular}{|c|c|c|c|c|c|c|c|c|c|c|c|c|}
\hline \multicolumn{13}{|c|}{ TASK } \\
\hline Action & \multicolumn{2}{|c|}{$\begin{array}{l}\text { Maintain } \\
\text { Course }\end{array}$} & \multicolumn{2}{|c|}{$\begin{array}{l}\text { Vehicle } \\
\text { Control }\end{array}$} & \multicolumn{2}{|c|}{$\begin{array}{l}\text { Vehicle } \\
\text { Avoidance }\end{array}$} & \multicolumn{2}{|c|}{$\begin{array}{l}\text { Obstacle } \\
\text { Avoidance }\end{array}$} & \multicolumn{2}{|c|}{$\begin{array}{l}\text { Hazard } \\
\text { Response }\end{array}$} & \multicolumn{2}{|c|}{ TOTALS } \\
\hline & $n$ & $\%$ & $n$ & $\%$ & $n$ & $\%$ & $n$ & $\%$ & $n$ & $\%$ & $n$ & $\%$ \\
\hline None & 16 & 3.9 & 2 & 6.1 & 5 & 4.9 & 8 & 40.0 & 0 & 0.0 & 31 & 5.7 \\
\hline $\begin{array}{l}\text { Loss of } \\
\text { Control }\end{array}$ & 126 & 28.8 & 19 & 57.6 & 15 & 14.6 & 6 & 30.0 & 19 & 100.0 & 185 & 30.4 \\
\hline $\begin{array}{l}\text { Intentional } \\
\text { Departure }\end{array}$ & 43 & 9.9 & 6 & 18.2 & 82 & 79.6 & 6 & 30.0 & 0 & 0.0 & 137 & 22.5 \\
\hline $\begin{array}{l}\text { Unintentional } \\
\text { Departure }\end{array}$ & 234 & 53.9 & 6 & 18.2 & 0 & 0.0 & 0 & 0.0 & 0 & 0.0 & 240 & 39.4 \\
\hline Other/Unknown & 15 & 3.5 & 0 & 0.0 & 1 & 1.0 & 0 & 0.0 & 0 & 0.0 & 16 & 2.6 \\
\hline TOTALS & 434 & 100.0 & 33 & 100.0 & 103 & 100.0 & 20 & 100.0 & 19 & 100.0 & 609 & 100.0 \\
\hline
\end{tabular}


The distribution of the resultant driver/vehicle actions in response to each task encountered in this study is presented in Table 5-4. The loss of control actions are primarily the result of driver (e.g. incorrect or excessive swerve/brake maneuvers) and vehicle action failures due to various human, vehicular and environmental causal factors which will be discussed later. The intentional departures are primarily due to driver decisions in response to vehicle avoidance tasks. The few intentional departures listed under Maintain Course are most frequently the result of driver indecision, poor judgement and reckless driving at freeway exits and at-grade intersections. The most frequent causes of unintentional departures are predisposing human conditions and poor roadway geometry which will be identified in the subsequent listings of causal factors. A portion of these unintentional departures were also caused by delayed or excessive driver responses as indicated in Section 5. 1.4. DRIVER ACTION.

\section{1.6. CRASH OCCURRENCE}

Successful driving requires proper actions throughout the function event sequence following each task or situation display. A failure in one or more of the events (search, identification, evaluation, decision, driver action or vehicle action) and/or the failure inherent in a particular task may result in a crash occurrence. A crash occurrence is defined as any action which damages or disables the vehicle or injures one or more of the vehicle occupants.

The understanding of the mechanism and causation of single vehicle accidents can be improved by the use of an orderly classification of crash occurrence configurations and locations. The possible results of any function event sequence following a given task or situation display on the roadway are as follows:

(1) Successful Response

(2) Crash Occurrence on the Roadway

(3) Leave the Roadway

The first possible result, a successful response is, of course, the desired result which is achieved in normal driving.

The second possible result, a crash occurrence on the roadway, implies the existence of a serious task presentation or a significant failure in the function event sequence. The categorization of these on-roadway crash occurrences by accident configuration is as follows:

Configuration

(1) Object (Fixed)

(2) Object (Transient)
Description

The vehicle strikes a fixed object which is permanently placed at that location.

The vehicle strikes an object which is not permanentiy located at that location. 
(3) Rollover

(4) Other
The vehicle rotates sufficiently so that the top or side strikes the surface of the ground.

Damage or disablement of the vehicle or injury to an occupant is produced by occurrences such as truck jackknifes, fires and the opening of vehicle doors.

The third possible result of an on-roadway event sequence is that the vehicle leaves the roadway. For the purposes of this study, the roadway is defined as the normal travel lanes, excluding the shoulders. Although leaving the roadway is not specificalily a crash occurrence, it is a consequence of extreme importance. This event not only separates on-roadway from off-roadway events but also initiates a new set of situation displays. Upon leaving the roadway, the driver, as indicated in Figure 5-1, is confronted with a new task and function event sequence. The nature of the roadside and the driver/vehicle response to this situation determine the resultant consequences of this excursion from the roadway.

When a vehicle leaves the roadway there are basically two potential results - a successful recovery or a crash occurrence. A successful recovery would involve the vehicle coming to a safe stop or returning to the roadway. A return to the roadway would then place the driver in a new on-roadway situation display and potential accident sequence. An off-roadway crash occurrence may be classified as striking an object (fixed or transient), a rollover, or other configuration in the same manner as that described for on-roadway crash occurrences.

The classification (by configuration and location) of the initial crash occurrences encountered in this study, which was presented in Tables 4-3 and 4-4 in the preceding section, is summarized in Table 5-5. The large number (560) of off-roadway crash occurrences indicates that causal mechanisms leading to a roadway departure are the primary precipitating factors in single vehicle accidents. It is also obvious that the nature and condition of the roadside is of primary importance in the causation of off-roadway crash occurrences. The two primary off-roadway crash configurations, impact with a fixed object (465) and rollovers (65), further substantiate the importance of the roadside in single vehicle accident causation.

Another method for evaluating crash occurrence production is to consider the effects of the original task presentation and the corresponding driver/vehicle response. The relationships between tasks and driver/vehicle actions were presented in Table 5-4. The resulting crash configurations for each driver/vehicle action is given in Table 5-5. A rollover appears to be the only major crash configuration that is significantly more frequent for a given driver/vehicle action and, as would be expected, occurs more frequently due to the driver/vehicle action, Loss of Control: 
The relationships between the resultant driver/vehicle action and the consequent crash configuration for each task presented to the driver are given in Appendix G, Tables G-1 through G-5. The task does not appear to have a significant influence upon the resulting crash configuration. One interesting result is, however, obtained from Table G-1 which contains the results for the task Maintain Course which was presented in 71 percent of the cases. Within this task, the resultant driver/ vehicle action was Unintentional Departure in 54 percent of the cases. Of these Unintentional Departures, 82 percent resulted in impacts with fixed roadside objects. This clearly identifies the most frequently occurring problem in single vehicle accidents - a driver simply allows the vehicle to drift off the roadway into a rigid roadside object.

\subsection{EVENT SEQUENCE FAILURES}

In the preceding section, the description of the single vehicle accident model and the specific accident sequences involved in this study have provided the basic framework for the classification and understanding of accident causation mechanisms. Task presentations are, as previously indicated, inherent precipitating causal mechanisms, whereas failures in the function event sequence are generally best described as contributing causal mechanisms. It is important to understand that the relationship between these event sequence failures and causal factors is essentially a cause and effect relationship. The cause can be identified as a specific human, vehicular and environmental causal factor and the effect as failure in a particular phase of the function event sequence.

A better description of the nature of failures in the event sequence and a more useful basis for classifying causal factors can be obtained if, in addition to the six events specifically identified as comprising the function event sequence, two more failure mechanisms are included. These are failures due to human predisposing states or.conditions, and failures due to environmental predisposing conditions or situations which directly contribute to accident causation but cannot be directly related to a specific phase of the event sequence.

This expanded concept of event sequence failures provides a more complete framework for the classification of causal factors which contribute to the causation of single vehicle accidents. The following categorization scheme for event sequence failures and corresponding causal factors is used throughout this study. 
TABLE 5-5

CRASH CONFIGURATION BY DRIVER/VEHICLE ACTION

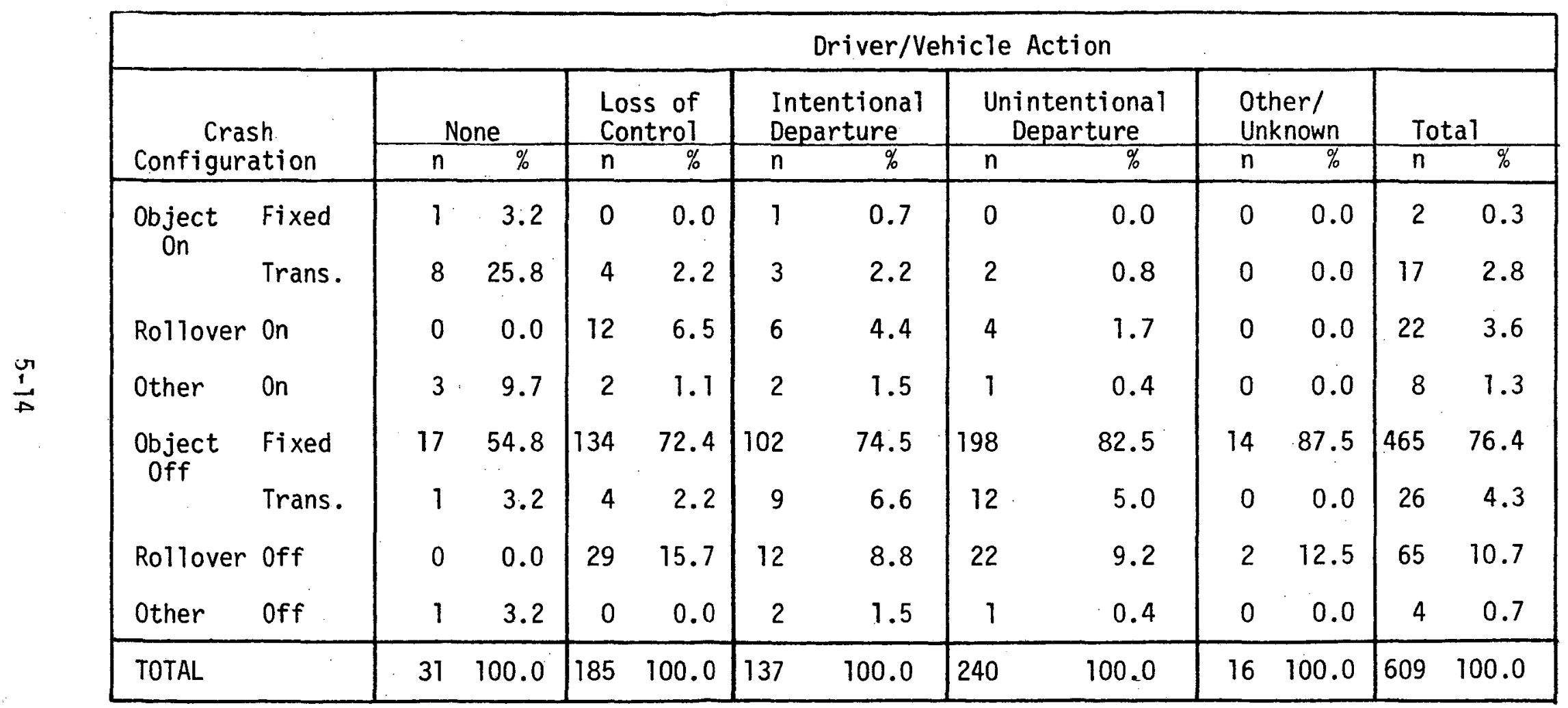


Event Failure

(1) Human Predisposition:

(2) Search:

(3) Identification:

(4) Evaluation:

(5) Decision:

(6) Driver Action:

\section{Causal Factor Description}

Human states or conditions which would interfere with the driver's response in two or more events in the sequence, or which would inhibit this performance throughout the accident sequence. Being under the influence of alcohol would be a typical causal factor in this category.

Factors which inhibit the driver's search or monitoring of his surroundings for the necessary input information. Included in these causal factors are human factors (e.g. inattention), vehicle factors (e.g. distraction by vehicle controls) and environmental factors (e.g. distraction by other vehicles).

Human, vehicular or environmental factors preventing or delaying the driver's clear identification of a potentially hazardous object, condition or situation. Poor vision or hearing, a dirty windshield, and inadequate lighting or sight distance are examples of causal factors in this category.

Causal factors which inhibit the driver's proper assessment or understanding of identified conditions or situations. These would include factors such as driver inexperience, inadequate signing and confusing or unusual highway design.

Factors contributing to an improper or delayed decision by the driver as to the proper action he should take. Factors typical of this category are driver indecision, poor judgement and inexperience.

Causal factors which inhibit the proper physical implementation of the driver's decision. Failures in driver action would include overreactions, as well as insufficient or delayed responses due to such causal factors as inexperience or inadequate physical capabilities. 
(7) Vehicle Action:

(8) Environmental Predisposition:
Vehicular and environmental causal factors interfering with the vehicle's response to the driver's action (e.g. a spinout may result from a steering input). Bald tires and wet pavement surfaces are typical examples of causal factors in this category.

Environmental causal factors that substantially prevent the proper response in one or more events in the sequence. A causal factor such as a narrow roadside would be included, since the function event sequence is essentially eliminated due to the lack of time and/ or space for any reasonable response.

The determination of failures in the event sequence was predicated upon the identification of causal factors producing these failures. The number of accidents having at least one failure (and therefore causal factors) in the indicated event is given in Table 5-6. These results indicate that a substantial number of failures occur in every phase of the function event sequence, and that more than one failure in an accident is a common occurrence. The number of accidents in which a failure in a particular event was listed at least once as the cause of a specific crash configuration is given in Table 5-7. The leaving the roadway "crash occurrences" were the result of failures well distributed throughout the event sequence, except for environmental predisposition. The most frequent actual crash occurrences, rollovers and striking objects off the roadway, were primarily the result of environmental predisposing factors and vehicle action failures, however, decision and driver action failures also contributed to a significant number of off-roadway, fixed-object impacts. These last results indicate that the nature of the highway roadside is a major contributing factor in the causation of off-roadway crash occurrences.

TABLE 5-6 FAILURES IN THE EVENT SEQUENCE WHICH CONTRIBUTED TO CAUSING THE ACCIDENT

\begin{tabular}{|l|c|c|}
\hline \multicolumn{1}{|c|}{ EVENT FAILURE } & $n$ & $\%$ \\
\hline Human Predisposition & 327 & 53.7 \\
Search & 258 & 42.4 \\
Identification & 19 & 19.5 \\
Evaluation & 189 & 31.0 \\
Decision & 137 & 22.5 \\
Driver Action & 329 & 54.0 \\
Vehicle Action & 293 & 48.7 \\
Environmental Predisposition & 275 & 45.2 \\
\hline
\end{tabular}

NOTE: Entries are the number of accidents having at least one failure of the indicated event. Percentages are calculated by dividing these numbers by the total number of accidents (609). 


\section{TABLE 5-7}

FAILURES IN THE EVENT SEQUENCE BY CRASH OCCURRENCE

\begin{tabular}{|c|c|c|c|c|c|c|c|c|c|c|c|c|c|c|c|c|}
\hline & \multicolumn{2}{|c|}{$\begin{array}{l}\text { Object } \\
\text { On } \\
n\end{array}$} & \multicolumn{2}{|c|}{$\begin{array}{c}\text { Rollover } \\
\text { On }\end{array}$} & \multicolumn{2}{|c|}{$\begin{array}{l}\text { Other } \\
\text { On }\end{array}$} & \multicolumn{2}{|c|}{$\begin{array}{l}\text { Leave } \\
\text { Roadway }\end{array}$} & \multicolumn{2}{|c|}{$\begin{array}{l}\text { Object } \\
\text { off }\end{array}$} & \multicolumn{2}{|c|}{$\begin{array}{l}\text { Rollover } \\
\text { Off }\end{array}$} & \multicolumn{2}{|c|}{$\begin{array}{l}\text { Other } \\
\text { Off }\end{array}$} & \multicolumn{2}{|c|}{ Total } \\
\hline $\begin{array}{l}\text { Human } \\
\text { Predisposition }\end{array}$ & 3 & 0.5 & 1 & 0.2 & 0 & 0.0 & 323 & 53.0 & 0 & 0.0 & 0 & 0.0 & 0 & 0.0 & 327 & 53.7 \\
\hline Search & 10 & 1.6 & 3 & 0.5 & 0 & 0.0 & 241 & 39.6 & 4 & 0.7 & 0 & 0.0 & 1 & 0.2 & 259 & 42.5 \\
\hline Identification & 8 & 1.3 & 3 & 0.5 & 0 & 0.0 & 103 & 16.9 & 5 & 0.8 & 0 & 0.0 & 0 & 0.0 & 119 & 19.5 \\
\hline Evaluation & 5 & 0.8 & 7 & 1.1 & 0 & 0.0 & 174 & 28.6 & 5 & 0.8 & 3 & 0.5 & 0 & 0.0 & 194 & 31.9 \\
\hline Decision & 3 & 0.5 & 8 & 1.3 & 1 & 0.2 & 104 & 17.1 & 20 & 3.3 & 8 & 1.3 & 0 & 0.0 & 144 & 23.6 \\
\hline Driver Action & 2 & 0.3 & 9 & 1.5 & 0 & 0.0 & 287 & 47.1 & 39 & 6.4 & 17 & 2.8 & 0 & 0.0 & 354 & 58.1 \\
\hline Vehicle Action & 0 & 0.0 & 26 & 4.3 & 2 & 0.3 & 213 & 35.0 & 30 & 4.9 & 61 & 10.0 & 3 & 0.5 & 335 & 55.0 \\
\hline $\begin{array}{l}\text { Environmental } \\
\text { Predisposition }\end{array}$ & 4 & 0.7 & 8 & 1.3 & 1 & 0.2 & 15 & 2.5 & 206 & 33.8 & 53 & 8.7 & 9 & 1.5 & 296 & 48.6 \\
\hline
\end{tabular}

NOTE: Entries in each column are the number of accidents in which a particular failure was identifled at least once as the cause of the indicated crash occurrence. Percentages in each column are calculated by dividing the column numbers by the total number of accidents (609). 


\subsection{CAUSAL FACTOR CLASSIFICATION}

The classification of causal factors is, as previously indicated, based upon the potential single vehicle accident model and the possible failures which may occur within this sequence. The general classification scheme is summarized in Figure 5-3. Specific causal factors are initially classified as to whether they contribute to accident causation or to damage or injury production. Those accident causation factors identified as tasks presented to the driver (see Table 5-2) are considered as precipitating causal factors and have not been further classified.

The causal factors identified as contributing to accident causation by producing failures in the event sequence are classified in several manners. As indicated in Figure 5-3, the frequency of occurrence and the relevance of each causal factor is identified. The relevance is essentially the degree of certainty assigned to a given causal factor based upon a team evaluation of its influence upon accident causation. The three categories of relevance or degree of certainty are as follows:

\section{Relevance $\quad$ Degree of Certainty}

(1) Certain

$95-100 \%$

(2) Probable

$80-95 \%$

(3) Possible

$50-80 \%$

$$
0-50 \% \text { (not 1isted) }
$$

It should be stressed that the accident causation factors listed in the following section are those which were identified in the field investigation and/or the review and analysis process. Only those factors which were judged to have a reasonable degree of probability (50 percent or greater) of contributing to accident causation were listed. In addition to the low-probability causal factors, other possible causal mechanisms may not have been revealed in the field investigation or the review process, and therefore would also not be included in the causal factor listings.

Each causal factor is also classified as being human, vehicular or environmental in origin. Causal factors in each of these three classifications were also subset into more specific categories. The complete listing of specific causal factors considered in this study is given in the Human, Vehicle and Environmental Causal Factors Lists in Appendix B.

The human accident causation factors were subset in the following categories.

As leep/Unconscious

Physical Deficiency

Menta] Deficiency

Driving Deficiency
Total or Partial

Permanent or Temporary 
FIGURE 5-3

CAUSAL FACTORS CLASSIFICATION MODEL

IA. TASK PRESENTATION (Precipitating Causal Factor)

IB. EVENT SEQUENCE FAILURES

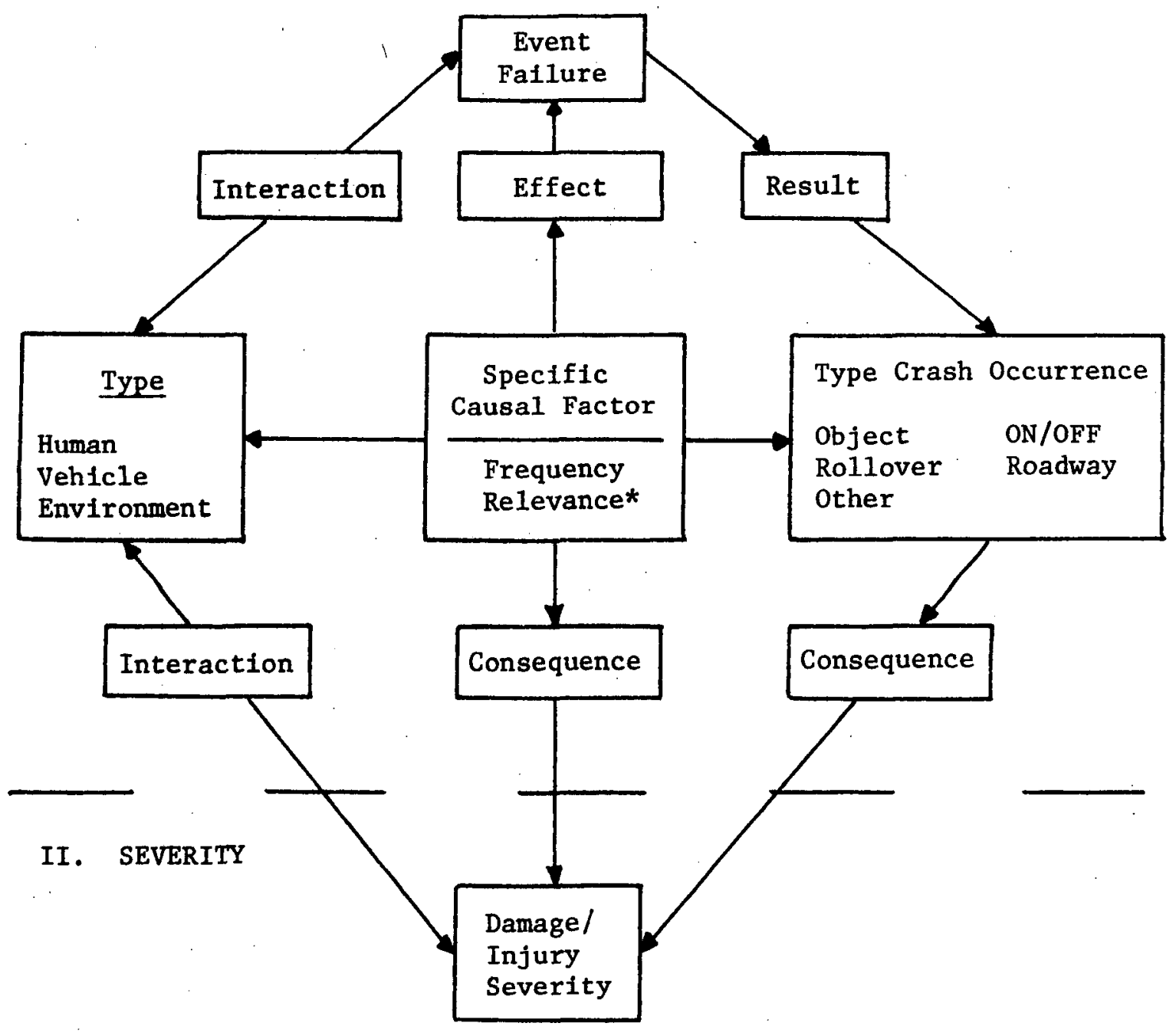

* (Certain, Probable or Possible) 
The specific causal factors resulting in the driver being Asleep/ Unconscious (Total or Partial) are also the same as those producing a temporary physical deficiency. Included in human causal factors are items such as: fatfgue (Asleep), inadequate motor response (Physical Deficiency), emotional instability (Mental Deficlency) and inexperience (Driving Deficiency).

The vehicular causal factors are divided into the following categories.

General Vehicle Characteristics/Defects

Driver Interaction

Vehicle Response

Vehicle causal factors include: instability (General Characteristic), vision obstructions (Driver Interaction) and faulty brakes (Vehicle Response).

Environmental causal factors include highway design parameters and specific highway components, as well as roadway conditions, defects and hazards, traffic conditions, ambient factors, and roadside hazards. The general categories are as follows:

Sight Distance

Horizontal Alignment

Roadway Cross Section

Intersection/Interchange Design

Pavement Surface

Roadway Lighting

Traffic Control Devices
Ambient Conditions

Roadway Traffic and Hazards

Shoulders

Roadside Conditions

Roadside Hazards

Protective Devices

Many of the environmental causal factors are simply listed as a highway design parameter or component. This implies that the design parameter (e.g. degree of horizontal curvature) or component (e.g. pavement texture) has been judged to be inappropriate or in a defective condition, and has contributed to the causation of the accident. The existence of an object (tree, pole, etc.) struck by a vehicle is not listed as an environmental causal factor. Although its existence is essentialiy the cause of its being struck, listing it as a causal factor would be redundant with the data presented in Section 4. SINGLE VEHICLE ACCIDENT CHARACTERISTICS.

Another important method for classifying an accident causation factor is by the failure it initiates in the function event sequence. These failures and their relationship to the corresponding causal factors have been described in Section 5.2 EVENT SEQUENCE FAILURES.

Causal factors are also classified by the type and location of the resultant crash occurrence. The categorization of crash configurations has been presented in Section 5. 1.6. CRASH OCCURRENCE. 
Vehicular and environmental causal factors which have contributed to accident causation have each received one other classification. Vehicular causal factors have been classified as being either a defect or a characteristic. In the evaluation of vehicular causal mechanisms, it is useful to determine whether the causal factor is associated with a particular defect or is essentially the result of an inherent characteristic of that vehicle. The identification and evaluation of potential countermeasures is also benefited by the distinction of maintenance, repair and inspection criteria versus vehicle design and construction problems. The definition of characteristic and defect for causal factor classification is as follows :

\section{Characteristic:}

Defect:
A design feature, an operating behavior or a component which is normally existent in this particular model vehicle. (e.g. wheel base)

A vehicle component which is damaged, excessively worn, inoperative or in such condition that it does not properly fulfill its intended function. (e.g. worn tires)

Environmental causal factors are also classified in a manner similar to that utilized for vehicular factors. Each causal factor, which is essentially a roadway design feature, component, or condition is identified as being permanent or transient in nature. The definition of permanent and transient is as follows:

Permanent:

A non-varying condition or situation, or a fixed feature or component of the roadway. (e.g. degree of horizontal curvature)

Transient:

Conditions, situations or features of the roadway which are not permanent due to construction, maintenance, ambient factors or traffic conditions. (e.g. wet surface)

This identification of environmental causal factors as being permanent of transient is, of course, beneficial for the development of countermeasures, as well as helpful in providing a better understanding of causal mechanisms.

The causal factors which influence the severity of damage or injury production only were also classified in several fashions. Initially the causal factor was categorized as increasing or decreasing either damage or injuries. It was then identified as being human, vehicular or environmental in nature. The relevance of these causal factors influencing severity was also included, in the classification scheme in the same manner as for accident causation factors. The majority of these causal factors were deleted from the data since their influence upon damage/injury production could be assessed in a quantitative manner. 


\section{4 CAUSAL FACTORS CONTRIBUTING TO ACCIDENT CAUSATION}

A11 causal factors (except Tasks) identified as contributing to the causation of the single vehicle accidents investigated in this study are presented in Appendix G. The listings of a 71 specific human, vehicular and environmental causal factors are given in Tables G-6, G-7 and $G-8$, respectively. The relevance attributed to each causal factor is also identified in these tables.

These causal factors are the mechanisms which produced the event sequence failures and subsequent crash occurrences described in Tables 5-6 and 5-7. A summary of these two tables, along with the number of causal factors producing each type of failure, is presented in Table 5-8. In a few cases, a given type failure occurred more than once, thus producing more than one crash occurrence. For example, in a given case, a Decision failure may lead to the crash occurrence Leaving the Roadway, and then a second Decision failure may cause an impact with a Fixed object. As also indicated in Table 5-8, more than one causal factor may be identified as producing a given event sequence failure. An example would be Alcohol and Fatigue leading to the failure Human Predisposition.

TABLE 5-8 EVENT SEQUENCE FAILURES BY NUMBER OF ACCIDENTS, CRASH OCCURRENCES AND CAUSAL FACTORS

\begin{tabular}{|l|c|c|c|}
\hline $\begin{array}{c}\text { Event } \\
\text { Fequence }\end{array}$ & $\begin{array}{c}\text { Accidents } \\
\text { Having Ope } \\
\text { Failure }\end{array}$ & $\begin{array}{c}\text { Crash Occurrences } \\
\text { Produced By } \\
\text { Failure }\end{array}$ & $\begin{array}{c}\text { Causal Factors } \\
\text { Producing } \\
\text { Failure }\end{array}$ \\
\hline Human Predisposition & 327 & 327 & 462 \\
Search & 258 & 259 & 275 \\
Identification & 119 & 119 & 135 \\
Evaluation & 189 & 194 & 315 \\
Decision & 137 & 144 & 155 \\
Driver Action & 329 & 354 & 424 \\
Vehicle Action & 293 & 335 & 556 \\
Environmental Predisposition & 275 & 297 & 341 \\
\hline
\end{tabular}

1 See Table 5-6

2 See Table 5-7

The distribution by type (human, vehicular or environmental) of the causal factors producing event failures is preșented in Table 5-9. It is particularly interesting to note that environmental causal factors were identified as the major cause of driver evaluation failures. This would indicate a strong driver/environment interaction in producing these failures. Environmental factors were also quite important in the causation of vehicle action failures. 
TABLE 5-9. DISTRIBUTION OF CAUSAL FACTORS BY TYPE FOR EACH EVENT SEQUENCE FAILURE

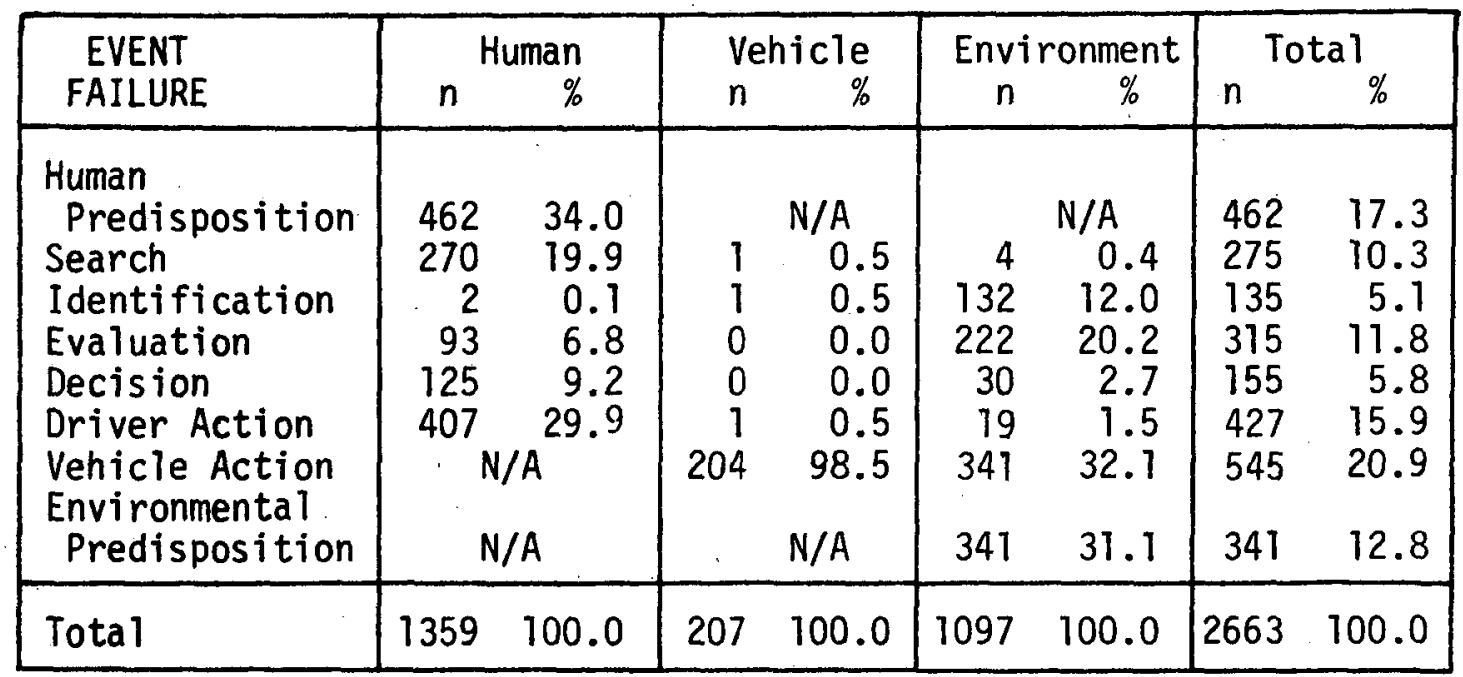

As indicated in Table 5-9, of the total number (2663) of accident causation factors identified, 1359 were human, 207 were vehicular and 1097 were environmental in nature. The relative contributions to accident causation are, as presented in Figure $5-4,51.0 \%$ human, $7.8 \%$ vehicular and $41.2 \%$ environmental. As would be expected, human errors and environmental factors are the dominate causal mechanisms for these single vehicle accidents. Another important characteristic of these accidents is illustrated in Figure 5-5. An average of over four causa. factors was identified as contributing to the causation of each accident, including 2.23 human and 1.80 environmental factors. This indicates that the total causal mechanism in a given accident is complex and dependent upon a number of interrelated human, vehicular and environmental factors.

FIGURE 5-4 CAUSAL FACTORS BY TYPE.

\begin{tabular}{|c|c|cc|}
\hline TYPE & $N$ & PERCENT OF TOTAL \\
\hline Human & 1359 & & $51.0 \%$ \\
\hline Tehicular & 207 & $7.8 \%$ & $47.2 \%$ \\
\hline Environmental & 1097 & & 47 \\
\hline
\end{tabular}

FIGURE 5-5 CAUSAL FACTORS PER ACCIDENT

\begin{tabular}{|c|c|c|}
\hline TYPE & $N$ & NUMBER PER ACCIDENT \\
\hline Human & 1359 & 2.23 \\
\hline Vehicular & 207 & .34 \\
\hline Environmental & 1092 & 11.80 \\
\hline IOTAL & 2663 & \\
\hline
\end{tabular}


The distribution of each type of causal factor by relevance, given in Table 5-10, demonstrates that nearly 60 percent of the identified causal factors were considered as certain or probable. It should be noted, however, that those listed as possible were still considered to be in the 50 to 80 percent probability range. It should also be recalled that the human conditions and errors, vehicle characteristics and defects, and environmental conditions and situations are 1 isted as causal factors only if a strong causal relationship can be identified. The existence of a human condition (e.g. alcohol) or a poor environmental condition was not included unless it was specifically identified as contributing to accident causation.

TABLE 5-10 CAUSAL FACTORS BY TYPE AND RELEVANCE

\begin{tabular}{|l|rr|rr|rr|rr|}
\hline \multirow{2}{*}{ Relevance } & \multicolumn{2}{|c|}{ Human $^{2}$} & \multicolumn{2}{|c|}{ Vehicular } & \multicolumn{2}{|c|}{ Envi ronmental } & \multicolumn{2}{|c|}{ Total } \\
\hline Certain & 89 & 6.5 & 36 & 17.4 & 44 & 4.0 & 169 & 6.3 \\
Probable & 748 & 55.0 & 83 & 40.1 & 557 & 50.8 & 1388 & 52.1 \\
Possible & 522 & 38.4 & 88 & 42.5 & 497 & 45.2 & 1106 & 41.5 \\
\hline Total & 1359 & 100.0 & 207 & 100.0 & 1097 & 100.0 & 2663 & 100.0 \\
\hline
\end{tabular}

A summary of the causal factor distributions in Table G-6 through G-8 in Appendix $G$ is presented in Tables 5-11 through 5-14. As indicated in Table 5-11, the human causal factors most frequently identified were: Inattention (17.1\%), Alcohol $(17.0 \%)$, Speeding (14.1\%), Driver Overreaction $(13.5 \%)$, Poor Judgement $(13.2 \%)$, Fatigue $(7.6 \%)$, and Inexperience $(3.7 \%)$. These percentages indicate the relative importance of each specific problem within the set of human factors. The magnitude of each problem is shown in Table 5-11a which gives the number/percentage of accidents in which at least one human causal factor of each type was identified. Tables 5-12a and 5-13a provide similar information for vehicular and environmental factors.

Instability against rollover (30.4\%), inadequate Tire Tread Depth $(23.2 \%)$, and other tire related problems $(25.6 \%)$ comprise the majority of the vehicular causal factors listed in Table 5-12. The identification of these causal factors as either a basic characteristic (36.2\%) or a vehicle defect $(63.8 \%)$, presented in Tables G-9 and G-10 in Appendix $G$, indicates that except for instability, the causal factors are basically vehicle defects.

A summary of Table G-8, presenting the number of environmental causal factors in each general category, is given in Table 5-13. A 1ist of the most frequently identified specific causal factors is given in Table 5-14. The percentage of the total environmental causal factors, along with the more meaningful percentage of accidents in which these 
specific factors contributed to accident causation, is also given in Table 5-14. The identification of the specific environmental causal factors as being permanent or transient in nature is presented in Tables G-11 and G-12. A summary of the causal factor categories as permanent or transient, given in Table 5-15, indicates that transient problems due to construction and maintenance activities were of significant importance.

The human, vehicular and environmental causal factors listed in Tables G-6 through G-8 have also been classified with respect to the resulting event sequence failure and the consequent crash occurrence configuration. For each crash occurrence configuration, including leaving the roadway, the specific causal factors are listed which contributed to each event sequence failure resulting in that particular configuration. These results may be found in Appendix $G$ in Tables G-14 through G-54. Of the 56 possible Tables (7 crash configurations by 8 event sequence failures), several combinations have no listed causal factors. The specific table number for each combination with identified causal factors is given in Table G-13. The classification of each causal factor by type (human, vehicular or environmental) and relevance is also presented in Tables G-14 through G-54.

A summary of vehicle characteristics and defects producing event failures and specific crash occurrence configurations is presented in Tables G-55 and G-56. Rollovers are produced by vehicle action failures caused primarily by vehicle characteristics, with some contribution from defects. Leaving the roadway, the most frequent configuration, was the result of vehicle action failures due to defects. Environmental causal factors classified as permanent or transient have also been summarized in Tables G-57 and G-58. Transient factors (e.g. wet roadway surface) were more frequently represented in the production of vehicle action failures and leaving the roadway crash occurrence configurations. A discussion of specific human, vehicular, and environmental causal factors producing particular event sequence failures and crash configurations is presented in Section 5.6 CAUSAL FACTORS SUMMARY.

\subsection{CAUSAL FACTORS INFLUENCING DAMAGE OR INJURY SEVERITY}

In addition to the causal factors which precipitate accident events, there are other causal mechanisms which influence only the severity of vehicle damage or occupant injury during the crash occurrence. A description of the damage incurred during the various impact configurations and the injury level (overall AIS) sustained by the drivers involved in this study was presented in Section 4.1.3. ACCIDENT CHARACTERISTICS OF THE IN-DEPTH SINGLE VEHICLE ACCIDENT SAMPLE. It should be noted that the overall severity of these single vehicle accidents appears to be greater than that experienced in multiple vehicle crashes, thus increasing the importance of damage and injury causal mechanisms. 
TABLE 5-11

HUMAN CAUSAL FACTORS CONTRIBUTING TO ACCIDENT CAUSATION

\begin{tabular}{|c|c|c|c|c|c|c|}
\hline \multirow[b]{2}{*}{ CAUSAL FACTOR } & \multicolumn{6}{|c|}{ RELEVANCE } \\
\hline & \multicolumn{2}{|c|}{$\begin{array}{l}\text { Certain/ } \\
\text { Probable } \\
n\end{array}$} & \multicolumn{2}{|c|}{$\begin{array}{c}\text { Possible } \\
n\end{array}$} & \multicolumn{2}{|c|}{ Total } \\
\hline PHYSICAL DEFICIENCY (PERM.) & 3 & 0.2 & 9 & 0.6 & 12 & 0.9 \\
\hline $\begin{array}{l}\text { PHYSICAL DEFICIENCY (TEMP.)* } \\
\text { Injury/IIiness } \\
\text { Fatigue } \\
\text { Medication } \\
\text { Orugs } \\
\text { Alcohol } \\
\text { Other/Unknown }\end{array}$ & $\begin{array}{r}15 \\
57 \\
7 \\
15 \\
141 \\
5\end{array}$ & $\begin{array}{r}1.1 \\
4.2 \\
0.7 \\
1.1 \\
10.4 \\
0.4\end{array}$ & $\begin{array}{r}3 \\
46 \\
9 \\
13 \\
90 \\
1\end{array}$ & $\begin{array}{l}0.2 \\
3.4 \\
0.6 \\
1.0 \\
6.6 \\
0.1\end{array}$ & $\begin{array}{r}18 \\
103 \\
10 \\
28 \\
231 \\
6\end{array}$ & $\begin{array}{r}1.3 \\
7.6 \\
0.7 \\
2.7 \\
17.0 \\
0.4\end{array}$ \\
\hline TOTAL & 234 & 17.2 & 162 & 11.9 & 396 & 29.1 \\
\hline $\begin{array}{l}\text { MENTAL DEFICIENCY } \\
\text { Suicide Attempt } \\
\text { Emotional Stability } \\
\text { Emotional Upset } \\
\text { Panic }\end{array}$ & $\begin{array}{l}2 \\
1 \\
8 \\
5\end{array}$ & $\begin{array}{l}0.1 \\
0.1 \\
0.6 \\
0.4\end{array}$ & $\begin{array}{r}2 \\
3 \\
17 \\
3\end{array}$ & $\begin{array}{l}0.1 \\
0.2 \\
1.3 \\
0.3\end{array}$ & $\begin{array}{r}4 \\
4 \\
25 \\
8\end{array}$ & $\begin{array}{l}0.3 \\
0.3 \\
1.8 \\
0.6\end{array}$ \\
\hline TOTAL & 16 & 1.2 & 25 & 1.8 & 41 & 3.0 \\
\hline $\begin{array}{l}\text { DRIVING DEFICIENCY } \\
\text { Inexperience } \\
\text { Inattention } \\
\text { Distraction } \\
\text { Indecision } \\
\text { Poor Judgement } \\
\text { Reckless - Speeding } \\
\text { Reckless - Maneuvers } \\
\text { Overreaction }\end{array}$ & $\begin{array}{r}4 \\
166 \\
18 \\
3 \\
112 \\
123 \\
21 \\
134\end{array}$ & $\begin{array}{r}0.3 \\
12.2 \\
1.3 \\
0.2 \\
8.2 \\
9.1 \\
1.5 \\
9.9\end{array}$ & $\begin{array}{r}46 \\
67 \\
15 \\
4 \\
67 \\
69 \\
7 \\
50\end{array}$ & $\begin{array}{l}3.4 \\
4.9 \\
1.1 \\
0.3 \\
4.9 \\
5.1 \\
0.5 \\
3.7\end{array}$ & $\begin{array}{r}50 \\
233 \\
33 \\
7 \\
779 \\
192 \\
28 \\
184\end{array}$ & $\begin{array}{r}3.7 \\
17.1 \\
2.4 \\
0.5 \\
13.2 \\
14.1 \\
2.1 \\
13.5\end{array}$ \\
\hline TOTAL & 581 & 42.8 & 325 & 23.9 & 906 & 66.7 \\
\hline RESTRAINT NON-USE & 3 & 0.2 & 1 & 0.7 & 4 & 0.3 \\
\hline TOTAL HUMAN & 837 & 61.6 & 522 & 38.4 & 1359 & 100.0 \\
\hline
\end{tabular}

* Includes totaliy or partially asleep/unconscious. 
TABLE 5-11a

HUMAN CAUSAL FACTORS CONTRIBUTING TO ACCIDENT CAUSATION'

\begin{tabular}{|c|c|c|c|c|c|c|}
\hline \multirow[b]{2}{*}{ CAUSAL FACTOR } & \multicolumn{6}{|c|}{ RELEVANCE } \\
\hline & \multicolumn{2}{|c|}{$\begin{array}{l}\text { Certain/ } \\
\text { Probable } \\
n\end{array}$} & \multicolumn{2}{|c|}{ Possible } & \multicolumn{2}{|c|}{ Total } \\
\hline PHYSICAL DEFICIENCY (PERM.) & 3 & 0.5 & 8 & 1.3 & 11 & 1.8 \\
\hline $\begin{array}{l}\text { PHYSICAL DEFICIENCY (TEMP.) }{ }^{2} \\
\text { Injury/IIIness } \\
\text { Fatigue } \\
\text { Medication } \\
\text { Drugs } \\
\text { Alcohol } \\
\text { Other/Unknown }\end{array}$ & $\begin{array}{r}15 \\
57 \\
1 \\
15 \\
140 \\
5\end{array}$ & $\begin{array}{r}2.5 \\
9.4 \\
0.2 \\
2.5 \\
23.0 \\
0.8\end{array}$ & $\begin{array}{r}3 \\
46 \\
9 \\
13 \\
90 \\
1\end{array}$ & $\begin{array}{r}0.5 \\
7.6 \\
1.5 \\
2.1 \\
14.8 \\
0.2\end{array}$ & $\begin{array}{r}18 \\
103 \\
10 \\
28 \\
230 \\
6\end{array}$ & $\begin{array}{r}3.0 \\
16.9 \\
1.7 \\
4.6 \\
37.8 \\
1.0\end{array}$ \\
\hline $\begin{array}{l}\text { MENTAL DEFICIENCY } \\
\text { Suicide Attempt } \\
\text { Emotional Stability } \\
\text { Emotional Upset } \\
\text { Panic }\end{array}$ & $\begin{array}{l}2 \\
1 \\
8 \\
5\end{array}$ & $\begin{array}{l}0.3 \\
0.2 \\
1.3 \\
0.8\end{array}$ & $\begin{array}{r}2 \\
3 \\
17 \\
3\end{array}$ & $\begin{array}{l}0.3 \\
0.5 \\
2.8 \\
0.5\end{array}$ & $\begin{array}{r}4 \\
4 \\
25 \\
8\end{array}$ & $\begin{array}{l}0.7 \\
0.7 \\
4.1 \\
1.3\end{array}$ \\
\hline $\begin{array}{l}\text { DRIVING DEFICIENCY } \\
\text { Inexperience } \\
\text { Inattention } \\
\text { Distraction } \\
\text { Indecision } \\
\text { Poor Judgement } \\
\text { Reckless - Speeding } \\
\text { Reckless - Maneuvers } \\
\text { Overreaction }\end{array}$ & $\begin{array}{r}4 \\
166 \\
16 \\
3 \\
103 \\
121 \\
20 \\
127\end{array}$ & $\begin{array}{r}0.7 \\
27.3 \\
2.6 \\
0.5 \\
16.9 \\
19.9 \\
3.3 \\
20.9\end{array}$ & $\begin{array}{r}45 \\
67 \\
15 \\
4 \\
64 \\
69 \\
7 \\
43\end{array}$ & $\begin{array}{r}7.4 \\
11.0 \\
2.5 \\
0.7 \\
10.5 \\
11.3 \\
1.1 \\
7.1\end{array}$ & $\begin{array}{r}49 \\
233 \\
31 \\
7 \\
167 \\
190 \\
27 \\
170\end{array}$ & $\begin{array}{r}8.0 \\
38.3 \\
5.1 \\
1.2 \\
27.4 \\
37.2 \\
4.4 \\
27.9\end{array}$ \\
\hline RESTRAINT NON-USE & 3 & 0.5 & 1 & 0.2 & 4 & 0.7 \\
\hline TOTAL HUMAN & & & & & 576 & 94.6 \\
\hline
\end{tabular}

1 As a percentage of total accidents (609)

2 Includes totally or partially asleep/unconscious 
TABLE $5-12$

VEHICULAR CAUSAL FACTORS CONTRIBUTING TO ACCIDENT CAUSATION

\begin{tabular}{|c|c|c|c|c|c|c|}
\hline \multirow[b]{2}{*}{ CAUSAL FACTOR } & \multicolumn{6}{|c|}{ RELEVANCE } \\
\hline & & $\begin{array}{c}\text { tain/ } \\
\text { bable } \\
\%\end{array}$ & & $\underset{\%}{s i b l e}$ & $n^{T}$ & tal $\%$ \\
\hline $\begin{array}{l}\text { GENERAL CHARACTERISTICS/ } \\
\text { DEFECTS - Frame, Linkage } \\
\text { Load or Contents - Total }\end{array}$ & 7 & 3.4 & 5 & 2.4 & 12 & 5.8 \\
\hline $\begin{array}{l}\text { DRIVER INTERACTION - Vision } \\
\text { Exhaust or Accelerator - } \\
\text { Total }\end{array}$ & 2 & 1.0 & 4 & 1.9 & 6 & 2.9 \\
\hline $\begin{array}{l}\text { VEHICLE RESPONSE } \\
\text { General Handling } \\
\text { Stability - Rollover } \\
\text { Suspension } \\
\text { Steering } \\
\text { Brakes } \\
\text { Tire Tread Depth } \\
\text { Tire Condition/Damage } \\
\text { Other Tire Problems }\end{array}$ & $\begin{array}{r}0 \\
48 \\
0 \\
4 \\
2 \\
29 \\
16 \\
11\end{array}$ & $\begin{array}{r}0.0 \\
23.2 \\
0.0 \\
1.9 \\
1.0 \\
14.0 \\
7.7 \\
5.3\end{array}$ & $\begin{array}{r}3 \\
15 \\
3 \\
8 \\
5 \\
19 \\
1 \\
25\end{array}$ & $\begin{array}{r}1.4 \\
7.2 \\
1.4 \\
3.9 \\
2.4 \\
9.2 \\
0.5 \\
12.1\end{array}$ & $\begin{array}{r}3 \\
63 \\
3 \\
12 \\
7 \\
48 \\
17 \\
36\end{array}$ & $\begin{array}{r}1.4 \\
30.4 \\
1.4 \\
5.8 \\
3.4 \\
23.2 \\
8.2 \\
17.4\end{array}$ \\
\hline TOTAL RESPONSE & 110 & 53.1 & 79 & 38.0 & 189 & 91.2 \\
\hline TOTAL VEHICLE & 119 & 57.5 & 88 & 42.5 & 207 & 100.0 \\
\hline
\end{tabular}


TABLE $5-12 a$

VEHICULAR CAUSAL FACTORS CONTRIBUTING TO ACCIDENT CAUSATION*

\begin{tabular}{|c|c|c|c|c|c|c|}
\hline \multirow[b]{2}{*}{ CAUSAL FACTOR } & \multicolumn{6}{|c|}{ RELEVANCE } \\
\hline & & $\begin{array}{l}\text { in/ } \\
\text { b]e } \\
\%\end{array}$ & & ble & & al $\%$ \\
\hline $\begin{array}{l}\text { GENERAL CHARACTERISTICS/ } \\
\text { DEFECTS - Frame, Linkage } \\
\text { Load or Contents - Total }\end{array}$ & 7 & 1.0 & 4 & 0.7 & 11 & 1.6 \\
\hline $\begin{array}{l}\text { DRIVER INTERACTION - Vision } \\
\text { Exhaust or Accelerator - } \\
\text { Total }\end{array}$ & 2 & 0.3 & 3 & 0.5 & 5 & 0.8 \\
\hline $\begin{array}{l}\text { VEHICLE RESPONSE } \\
\text { General Handling } \\
\text { Stability - RolTover } \\
\text { Suspension } \\
\text { Steering } \\
\text { Brakes } \\
\text { Tire Tread Depth } \\
\text { Tire Condition/Damage } \\
\text { Other Tire Problems }\end{array}$ & $\begin{array}{r}0 \\
48 \\
0 \\
4 \\
2 \\
29 \\
16 \\
11\end{array}$ & $\begin{array}{l}0.0 \\
7.9 \\
0.0 \\
0.7 \\
0.3 \\
4.8 \\
2.6 \\
1.8\end{array}$ & $\begin{array}{r}3 \\
15 \\
3 \\
8 \\
5 \\
19 \\
0 \\
25\end{array}$ & $\begin{array}{l}0.5 \\
2.5 \\
0.5 \\
1.3 \\
0.8 \\
3.1 \\
0.0 \\
4.1\end{array}$ & $\begin{array}{r}3 \\
63 \\
3 \\
12 \\
7 \\
48 \\
16 \\
36\end{array}$ & $\begin{array}{r}0.5 \\
10.3 \\
0.5 \\
2.0 \\
1.1 \\
7.9 \\
2.6 \\
5.9\end{array}$ \\
\hline TOTAL VEHICLE & & & & & 163 & 26.8 \\
\hline
\end{tabular}

*As a percentage of total accidents (609) 
TABLE 5-13

ENVIRONMENTAL CAUSAL FACTOR CATEGORIES

CONTRIBUTING TO ACCIDENT CAUSATION

\begin{tabular}{|c|c|c|c|c|c|c|}
\hline \multirow[b]{2}{*}{$\begin{array}{l}\text { CAUSAL FACTOR } \\
\text { CATEGORIES }\end{array}$} & \multicolumn{6}{|c|}{ RELEVANCE } \\
\hline & & $\begin{array}{l}\text { ain/ } \\
\text { able }\end{array}$ & & ible & & tal \\
\hline Sight Distance & 11 & 1.0 & 27 & 2.5 & 38 & 3.5 \\
\hline Horizontal Alignment & 77 & 7.0 & 67 & 5.6 & 138 & 12.6 \\
\hline Roadway Cross Section & 12 & 1.1 & 28 & 2.6 & 40 & 3.6 \\
\hline Intersection/Interchange & 15 & 1.4 & 62 & 5.7 & 77 & 7.0 \\
\hline Pavement Surface & 37 & 2.8 & 14 & 1.3 & 45 & 4.1 \\
\hline Roadway Lighting & 12 & 1.1 & 61 & 5.6 & 73 & 6.7 \\
\hline Traffic Control Devices & 12 & 1.1 & 79 & 7.9 & 91 & 8.3 \\
\hline Ambient Conditions & 106 & 9.7 & 30 & 2.7 & 136 & 12.4 \\
\hline Roadway Traffic/Hazards & 14 & 1.3 & 11 & 1.0 & 25 & 2.3 \\
\hline Shoulders & 37 & 3.4 & 35 & 3.2 & 72 & 6.6 \\
\hline Roadside Conditions & 192 & 17.5 & 70 & 6.4 & 262 & 23.9 \\
\hline Roadside Hazards* & 36 & 3.3 & 8 & 0.7 & 44 & 4.0 \\
\hline Protective Devices & 46 & 4.2 & 10 & 0.9 & 56 & 5.1 \\
\hline TOTAL ENVIRONMENTAL & 601 & 54.8 & 496 & 45.2 & 1097 & 100.0 \\
\hline
\end{tabular}

* Does not include roadside objects struck. 
TABLE 5-13a

ENVIRONMENTAL CAUSAL FACTOR CATEGORIES

CONTRIBUTING TO ACCIDENT CAUSATION1

\begin{tabular}{|c|c|c|c|c|c|c|}
\hline \multirow[b]{2}{*}{$\begin{array}{l}\text { CAUSAL FACTOR } \\
\text { CATEGORIES }\end{array}$} & \multicolumn{6}{|c|}{ RELEVANCE } \\
\hline & & $\begin{array}{r}a i n / \\
\text { able } \\
\text { able }\end{array}$ & & sible & & $\operatorname{tal}_{\%}$ \\
\hline Sight Distance & 10 & 1.6 & 27 & 4.4 & 37 & 6.1 \\
\hline Horizontal Alignment & 47 & 7.7 & 48 & 7.9 & 95 & 15.6 \\
\hline Roadway Cross Section & 12 & 2.0 & 26 & 4.3 & 38 & 6.2 \\
\hline Intersection/Interchange & 10 & 1.6 & 47 & 7.7 & 57 & 9.4 \\
\hline Pavement Surface & 27 & 4.4 & 12 & 2.0 & 39 & 6.4 \\
\hline Roadway Lighting & 11 & 1.8 & 61 & 10.0 & 72 & 11.8 \\
\hline Traffic Control Devices & 8 & 1.3 & 66 & 10.8 & 74 & 12.1 \\
\hline Ambient Conditions & 92 & 15.1 & 28 & 4.6 & 120 & 19.7 \\
\hline Roadway Traffic/Hazards & 14 & 2.3 & 10 & 1.6 & 24 & 3.9 \\
\hline Shoulders & 37 & 6.1 & 32 & 5.3 & 69 & 11.3 \\
\hline Roadside Conditions & 175 & 28.7 & 68 & 11.2 & 243 & 39.9 \\
\hline Roadside Hazards ${ }^{2}$ & 34 & 5.6 & 7 & 1.1 & 41 & 6.7 \\
\hline Protective Devices & 37 & 6.1 & 11 & 1.8 & 48 & 7.9 \\
\hline TOTAL ENVIRONMENTAL & & & & & 489 & 80.3 \\
\hline
\end{tabular}

${ }^{1}$ As a percentage of total accidents (609)

${ }^{2}$ Does not include roadside objects struck 
TABLE $5-14$

ENVIRONMENTAL CAUSAL FACTORS MOST FREQUENTLY IDENTIFIED

\begin{tabular}{|l|c|c|c|}
\hline \multicolumn{1}{|c|}{ CAUSAL FACTOR } & N & $\begin{array}{c}\text { Percent of } \\
\text { Causal Factors }\end{array}$ & $\begin{array}{c}\text { Percent of } \\
\text { Accidents }\end{array}$ \\
\hline Inadequate Roadside Width & 205 & 18.7 & 33.7 \\
Wet or Puddled Roadway Surface & 121 & 11.0 & 19.9 \\
Excessive Horizontal Curvature & 79 & 7.2 & 13.0 \\
Absence of Signs & 51 & 4.6 & 8.4 \\
Pavement/Shoulder Discontinuity & 29 & 2.6 & 4.8 \\
Excessive Roadside Cross Slope & 27 & 2.5 & 4.4 \\
\hline
\end{tabular}

TABLE $5-15$

ENVIRONMENTAL CAUSAL FACTOR CATEGORIES CONTRIBUTING TO ACCIDENT CAUSATION

\begin{tabular}{|c|c|c|c|c|c|c|}
\hline \multirow{2}{*}{$\begin{array}{l}\text { CAUSAL FACTOR } \\
\text { CATEGORIES }\end{array}$} & \multirow{2}{*}{\multicolumn{2}{|c|}{$\begin{array}{c}\text { Permanent } \\
n\end{array}$}} & \multirow{2}{*}{\multicolumn{2}{|c|}{$\underset{n}{\text { Transient }} \%$}} & \multicolumn{2}{|c|}{ Total } \\
\hline & & & & & $n$ & $\%$ \\
\hline Sight Distance & 36 & 3.3 & 2 & 0.2 & 38 & 3.5 \\
\hline Horizontal ATignment & 97 & 8.8 & 41 & 3.7 & 138 & 12.6 \\
\hline Roadway Cross Section & 30 & 2.7 & 10 & 0.9 & 40 & 3.6 \\
\hline Intersection/Interchange & 68 & 6.2 & 9 & 0.8 & 77 & 7.0 \\
\hline Pavement Surface & 29 & 2.6 & 16 & 1.5 & 45 & 4.1 \\
\hline Roadway Lighting & 42 & 3.8 & 31 & 2.8 & 73 & 6.7 \\
\hline Traffic Control Devices & 69 & 6.3 & 22 & 2.0 & 91 & 8.3 \\
\hline Ambient Conditions & 0 & 0.0 & 136 & 12.4 & 136 & 12.4 \\
\hline Roadway Traffic/Hazards & 0 & 0.0 & 25 & 2.3 & 25 & 2.3 \\
\hline Shoulders & 39 & 3.6 & 33 & 3.0 & 72 & 6.6 \\
\hline Roadside Conditions & 232 & 21.1 & 30 & 2.7 & 262 & 23.9 \\
\hline Roadside Hazards & 35 & 3.2 & 9 & 0.8 & 44 & 4.0 \\
\hline Protective Devices & 47 & 4.3 & 9 & 0.8 & 56 & 5.7 \\
\hline TOTAL ENVIRONMENTAL & 724 & 66.0 & 373 & 34.0 & 1097 & 100.0 \\
\hline
\end{tabular}


The majority of the causal factors identified during the field investigation and the review and analys is process, as influencing the accident severity only, are amenable to quantitative analysis. This, of course, allows for a more reliable evaluation of their actual causal contribution to damage and injury severity. All human causal factors (restraint usage, speeding, etc.) and vehicular causal factors (restraint availability, weight, compartment integrity, etc.) identified as affecting severity have been deleted from the listing of specific causal

factors. The influence of these various factors is evaluated in section 6.0 and Section 7.0.

Only those environmental causal factors of an unusual nature which tended to increase the damage or injury severity have been retained. These causal factors, along with the associated relevance, are presented in Appendix $G$ in Tables G-59 and G-60. Faulty performance or redirection devices and breakaway supports and poor design of ditches were the most frequently identified environmental causal factors cited as increasing damage and injury severity. It should be noted that certain environmental factors involving protective devices, poles, curbs and other objects impacted not included in these tables have been evaluated and are presented in Section 6.0, in a more quantitative fashion.

\subsection{CAUSAL FACTORS SUMMARY}

As indicated previously, the total number (2663) of identified accident causation factors consisted of 1359 (51.0\%) Human, $207(7.8 \%)$ Vehicular and 1097 (47.2\%) Environmental causal factors. It should be noted that the percentage of environmental factors identified in this study is substantially larger than that reported by other major accident causation studies. This high involvement of environmental factors in single vehicle accidents, as compared to multiple vehicle accidents, is essentially dependent upon two major differences. The causation mechanisms for single vehicle on-roadway crash occurences and for leaving the roadway are more dependent upon driver/environment interactions rather than driver/driver interactions commonly involved in multiple vehicle accidents. The contribution to accident causation by the nature and characteristics of the roadside is also uniquely important in single vehicle accidents. The contribution of vehicular factors is not substantially different than that reported for multiple vehicle crashes.

Among the most frequently reported human causal factors were: Alcohol (17.0\%), Fatigue (7.6\%), Speeding (14.1\%), Inattention (17.1\%); Poor Judgement $(13.2 \%)$, and Inexperience $(3.7 \%)$. These human conditions and failures are similar to those consistently cited as contributing to multiple vehicle collisions. Another frequently occurring causal factor, Driver Overreaction (13.5\%), appears to be unusually significant in the causation of single vehicle accidents. The factors accounting for the remaining $13.8 \%$ of the human causal factors are also presented in Table 5-11.

The significant event precipitating the majority of the accidents 
investigated was the vehicle leaving the roadway. Although this action does not necessarily produce a crash occurrence, it is an essential and clearly definable phase in the accident event chain. The causation of this action was found to be due to a variety of event sequence failures, dependent to a large extent upon human conditions and failures. A description of the major causal factors leading to each event sequence failure is given in Tables G-61 through G-63.

Human predisposing factors (see Table G-32) such as Alcohol and Fatigue were major causes for the breakdown in the event sequence leading to the vehicle leaving the roadway. Other significant predisposing factors cited as producing this action were Driver Injury or IIIness, Drugs and Emotional Upset. Leaving the roadway due to search failures was primarily the result of human errors such as Inattention $(85.7 \%$ of the search failures leading to leaving the roadway) and Distraction $(12.7 \%)$.

Evaluation and decision failures due to human errors, although not as frequent as search failures, did contribute substantially to roadway departures. Poor Judgement was the most frequently cited human factor affecting these failures. Next to human predisposition, driver action failure due to human error was the most frequent cause for leaving the roadway. Speeding (44.8\%) and Driver Overreaction (38.6\%) were the major causal factors, with Reckless Maneuvers (7.7\%) and Inexperience (6.2\%) cited as being the only other significant factors producing these driver action failures and consequent leaving the roadway.

The predominate crash occurrence as a result of leaving the roadway was striking an object. Due to the nature of the roadsides encountered in this study, human failures were not generally the cause of this type of crash configuration, except for certain decision and driver action failures. Decision failures were almost entirely human errors predicated upon Poor Judgement by the driver. Although Overreaction was indicated as being the primary cause $(87.5 \%)$ of the driver action failures resulting in striking an object, it is interesting to note that Restraint NonUse by the driver was clearly indicated as the cause in three cases.

The second most frequent crash configuration was rollover off the roadway. The only significant human causal factor identified in this category was Driver Overreaction which generally resulted in a loss of control of the vehicle and subsequent rollover. The human causal factors identified as contributing to on-roadway crash occurrences were essentially the same as those listed for leaving the roadway.

Vehicular accident causation mechanisms consisted of Tasks presented to the driver, as well as other causal factors contributing to accident causation. As indicated in Table 5-2 vehicle problems precipitated 33 (5.4\%) of the 609 single vehicle accidents investigated. The most significant contributing vehicular causal factors (see Table 5-12) were Instability against rollover $(30.4 \%)$ and inadequate Tire Tread Depth $(23.2 \%)$. Since the determination of both of these causal factors is somewhat subjective, a more quantitative evaluation of these two problems would be helpful. In addition to inadequate tread depth, other tire related problems represent $25.6 \%$ of the vehicular causal factors, thus 
indicating an important area for study and countermeasure development.

The contribution of vehicular causal factors is, as indicated in Tables G-55 and G-56, essentially limited to vehicle action failures which result in leaving the roadway or rollovers on and off the roadway. Tire related defects are the dominate vehicular causal factors associated with leaving the roadway. The basic vehicle characteristic, Instability, is the major vehicular causal factor contributing to rollovers. Vehicular causal factors do not appear to have a significant role as a cause of striking roadside objects.

Environmental causal mechanisms have also been distinguished as Tasks or contributing causal factors. In $142(23.3 \%)$ of the accidents, environmental Tasks presented to the driver (see Table 5-2) were identified as precipitating the accident event. Of these, 103 consisted of avoiding another moving vehicle. This task was generally the result of traffic congestion over vertical crest curves and at access/egress points. Other significant tasks included the avoidance of parked or disabled vehicles and response to water puddles on the roadway surface.

The most frequently identified contributing environmental causal factors (see Table 5-14) were inadequate Roadside Width (18.7\%), Wet Surface conditions $(11.0 \%)$ and excessive Horizontal Curvature $(7.2 \%)$. With the possible exception of wet surface conditions, these appear to be problems uniquely important in the causation of single vehicle accidents. Two other significant causal factors identified were the Absence of Signs (4.6\%) and the existence of Pavement/Shoulder Drop-Offs $(2.6 \%)$.

The subtotals listed in Table 5-15 indicate that problems associated with Horizontal Alignment $(12.6 \%)$, Ambient Factors $(12.4 \%)$ and especial1y Roadside conditions (23.9\%) are particularly important in single vehicle accident causation. Although Roadside Hazards were specifically identified as only $4.0 \%$ of the accident causation factors, it should be noted that the existence of the specific roadside objects impacted were not 1isted as causal factors. The distribution of roadside objects struck was presented in Table 4-5. The wide distribution of environmental causal factors demonstrates that there are problems in virtually every phase of highway design, maintenance, construction and operation.

Although environmental causal factors played a role in on-roadway crash occurrences, their major influence was in contributing to Teaving the roadway and off-roadway crashes. Environmental factors which were responsible for nearly all of the identification failures resulting in roadway departures, included sight distance and roadway lighting problems. Darkness was not listed as a specific causal factor, although its importance in accident causation is recognized.

Roadway departures due to evaluation failures (see Table G-35) were substantialiy affected by environmental factors $(69.7 \%$ of the total 1 isted 
in this category). These included inadequacies in Horizontal Alignment, Access/Egress design, Intersection geometry and layout, and Traffic Control Devices and procedures. It should be emphasized that the human and environmental causal factors contributing to this failure are intimately related. The human problems listed (Judgement, Experience, etc.) may be, to a large extent, attributable to inconsistent roadways. Since improvement of this roadway might result in significant reduction in these "human" errors, this appears to be an important area for countermeasure development. Similar problems and relationships exist in the causation of roadway departures due to decision faitures.

Environmental factors are also quite important in contributing to vehicle action fajlures resulting in leaving the roadway (see Table G-38). Horizontal curvature, pavement surface texture and drainage, and wet surface conditions appear to be significant problems. Since the vehicular causal factor, inadequate tire tread depth, was also frequently identified in this event failure/crash occurrence combination, a relationship between these factors is, of course, suspected.

Upon leaving the roadway, accident avoidance is dependent upon a successful event sequence off the roadway. Environmental factors were identified as contributing to vehicle action failures resulting in both rollovers and striking objects off the roadway. These factors for both crash configurations consisted primarily of problems related to shoulder and roadside geometry and surface characteristics. Rollovers off the roadway were also produced by factors classified under environmental predisposition. These included excessive cross slope (25.3\%) and a variety of roadside objects that essentially made a rollover inevitable.

The major causes of the most common crash occurrence, striking an object off the roadway, were environmental predisposing conditions. The dominate condition identified, inadequate roadside width, presents a serious problem in that any event sequence actions leading to a successful recovery are essentially eliminated by lack of time or space.

As further indicated in Tables $G-57$ and $G-58$, environmental factors contributed primarily to vehicle action, evaluation and identification failures and to predisposing conditions which eliminated the function event sequence. These failures led most often to roadway departures which resulted in impacts with roadside objects and vehicle rollovers. of the total number (1097) of environmental causal factors identified as contributing to accident causation, $369(33.6 \%)$ were transient in nature. A review of the specific causal factors given in Tables G-11 and G-12 and the general categories presented in Table 5-15 indicates that construction and maintenance practices, as well as traffic operations and ambient factors, are important factors in accident causation. It should, however, be recognized that permanent features of the roadway (including the roadside) constitute the major environmental factor in the causation of single vehicle accidents. 
The identification of causal factors yielded an average of over four specific causal factors per accident. In addition to this large number of contributing factors evidently required to produce an accident, the relationships between these factors appears quite important. Certain accident causation mechanisms are obvious $7 y$ dependent, not just upon one factor, but upon the interaction between two or more specific causal factors.

The causal mechanisms influencing damage and injury production are often more difficult to determine on a case-by-case basis, but are generally more amenable to quantitative analysis. As previously described, all human and vehicular causal factors have been deleted from the specific listings, but are evaluated in Section 6.0 SELECTED ACCIDENT AND INJURY PRODUCING MECHANISMS and Section 7.0 MOTOR VEHICLE AND HIGHWAY SAFETY PROGRAM STANDARDS. Of the remaining environmental causal factors tending to increase damage and injury, the most significant are inadequate ditch cross section and poor performance of redirection devices. Other environmental factors involving protective devices, roadside characteristics, and the nature of objects impacted have also been deleted from the listings, but are presented quantitatively in Section 6.0 SELECTED ACCIDENT AND INJURY PRODUCING MECHANISMS. 


\subsection{SELECTED ACCIDENT AND INJURY PRODUCING MECHANISMS}

The purpose of this section is to present analyses of selected accident and injury producing mechanisms which are based on detailed data from the in-depth sample. Specific analyses related to impact attenuating devices, curbs, and rollover accidents are discussed.

\subsection{ANALYSES OF IMPACT ATTENUATING DEVICES}

The in-depth sample of 609 cases was analyzed to evaluate the effectiveness of breakaway light standards, energy absorbing devices (sand barrels and hydrocells), and guardrails in terms of injury reduction. The basic methodology involved developing regression models which relate average AIS to the presence or absence of a device and after adjusting for covariates such as restraint use, impact speed, etc., testing for the significance of the device term.

\subsubsection{THE EFFECTIVENESS OF BREAKAWAY SUPPORTS FOR LIGHT STANDARDS}

This analysis considered only cases involving passenger cars, vans, or pick-up trucks which struck light standards. For each such case the overall injury severity (AIS) of the driver, type of standard struck (breakaway or non-breakaway), speed at impact, vehicle weight, vehicle orientation (VDI direction), restraint use (yes or no), type of preceeding impacts if any, and the total number of subsequent impacts were recorded. However, if the driver AIS, type of standard, or speed at impact were unknown, or if there were curb or guardrail impacts prior to striking the light standard, the case was dropped from further consideration. This case selection procedure yielded 62 cases in which driver AIS and the remaining variables were known and could be used for further analysis. A similar attempt to build and analyze a file of front seat passengers resulted in too few cases for analysis.

Several models were examined using the BMDO2R Stepwise Regression program in order to determine whether the type of light standard significantly affects driver injury, after adjustment for impact severity (impact speed'), restraint use, etc. The model selected is

1

Many different functions of vehicle weight, impact speed, and distance traveled were examined as possible definitions of impact severity. None of the more complicated functions proved superior to impact speed or the square of impact speed as adjustments for impact severity. 


$$
\begin{aligned}
& \text { AIS } \left.=.32287+.00080 V^{2}-.00069 V^{2} T-.00060 V^{2} R \text { (Equation } 6-1\right) \\
& \text { where AIS = Estimated average driver AIS } \\
& V=\text { Vehicle speed at impact (mph) } \\
& T=\text { Type of light standard }(0=\text { rigid, } 1 \text { = breakaway }) \\
& R=\text { Driver restraint use }(0=\text { no, } 1=\text { yes })
\end{aligned}
$$

The statistical properties of this model, which are presented in Table $\mathrm{H}-\mathrm{l}$ of Appendix $\mathrm{H}$, indicate that all terms are highly significant. No other terms considered were significant when added to the above model.

The model is graphed in Figure 6-1 for various values of $R$ and $T$. The graphs demonstrate the effectiveness of the breakaway poles in that the reduction in the estimated average AIS as compared to rigid poles is substantial, in fact being slightly greater than that resulting from restraint use. Note that the effect of breakaway poles and restraint use depends on impact severity where severity is measured by the squared vehicle speed at impact. The higher impact severities result in greater relative effectiveness. The plot for breakaway pole/restrained drivers is omitted since the model gives a poor fit in this case (negative AIS values for impact speeds greater than $30 \mathrm{mph}$ ) due to insufficient data. The average AIS for the breakaway/restrained combination should be smal1, however, since all six observations of this type at impact speeds up to $40 \mathrm{mph}$ resulted in AIS $=0$ for the drivers.

FIGURE 6-1. DRIVER INJURY VS. IMPACT SPEED FOR LIGHT POLE COLLISIONS BY TYPE OF POLE AND RESTRAINT USE

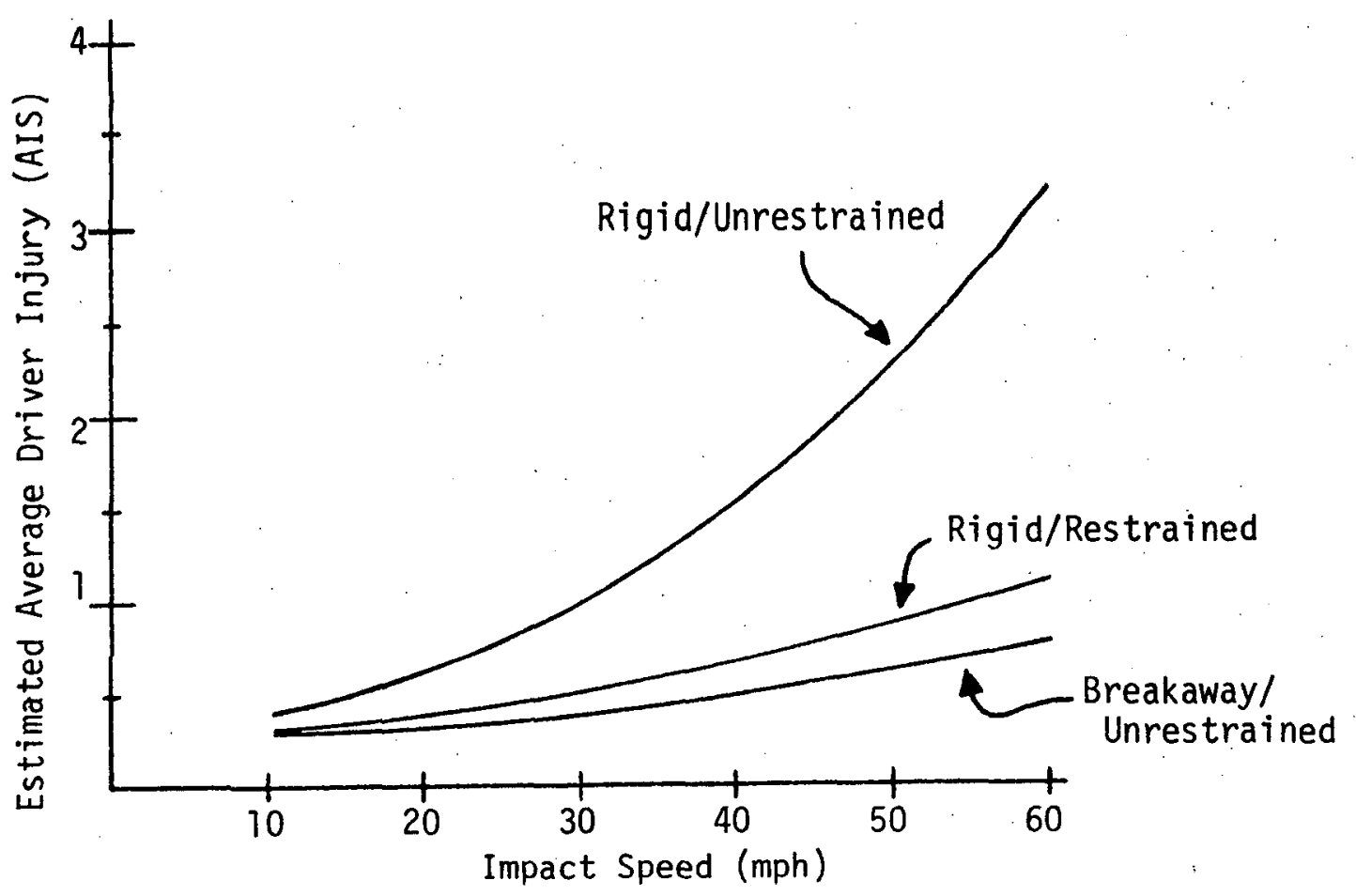


It should be noted that AIS is an ordinal scale and the meaning of averaging an AIS 0 with an AIS 6 to obtain an average of 3 is open to question. As the averages of sets of numbers increase, however, the magnitudes of the numbers in the sets generally increase. It is in this sense that the breakaway pole regression model should be interpreted.

The actual distributions of AIS values for various combinations of pole type, restraint use, and impact speed are shown in Table $\mathrm{H}-2$ of Appendix $H$. The effectiveness of the breakaway pole is again apparent. For example, $88.2 \%$ of the unrestrained drivers involved in high speed ( $\geq 35 \mathrm{mph}$ ) impacts with rigid poles sustain AIS injuries greater than zero as compared to $45.5 \%$ for unrestrained drivers impacting breakaway poles. Note also that only one of the 30 drivers (3.3\%) who impacted a breakaway pole and/or who wore restraints was seriously injured (AIS $\geq 2$ ).

\subsubsection{THE EFFECTIVENESS OF ENERGY ABSORBING DEVICES (SAND BARRELS AND HYDROCELLS) IN PROTECTING VEHICLES FROM IMPACT WITH RIGID OBJECTS}

This analysis considered only cases involving passenger cars, vans, or pick-up trucks which struck an unguarded utility pole, rigid light standard, bridge pier, tree (at least 6" in diameter), or an energy absorbing $(E / A)$ device guarding such objects. For each such case the overall injury severity (AIS) of the driver, type of object struck (E/A device or unguarded rigid object), speed at impact, restraint use (yes or no), vehicle weight, preceeding impacts (yes or no), and the number of subsequent impacts were recorded. If the driver AIS or speed at impact were unknown, or if there were preceeding or subsequent impacts, the case was dropped from further consideration. This case selection procedure yielded 90 cases in which driver AIS and the remaining variables were known and could be used for further analysis. A similar attempt to build and analyze a file of front seat passengers was unsuccessful in that there were no front seat passengers in vehicles which struck E/A devices.

Several models were examined using the BMD02R Stepwise Regression program in order to determine whether E/A devices significantly affect driver injury, after adjustment for impact severity (impact speed), vehicle weight, restraint use, etc. The model selected is

$$
\begin{aligned}
\text { AIS }= & 1.48888+.00126 \mathrm{~V}^{2}-.04194 \mathrm{~V} \cdot \mathrm{E}-.03016 \mathrm{~W} \text { (Equation 6-2) } \\
\text { where AIS } & =\text { Estimated average driver AIS } \\
V & =\text { Vehicle speed at impact (mph) }
\end{aligned}
$$




$$
\begin{aligned}
& E=\text { object contacted }(0=\text { unguarded rigid object, } \\
& 1=E / A \text { device) } \\
& W=\text { Vehicle weight (lbs. in hundreds) }
\end{aligned}
$$

The statistical properties of this model, which are presented in Table $\mathrm{H}-3$ of Appendix $\mathrm{H}$, indicate that all terms are highly significant with the exception of vehicle weight which is marginally significant at the $\alpha=$ .10 leve 1. No other terms considered were even marginally significant when added to the above model.

The model is graphed in Figure 6-2 for various values of $E$ and $W$. The graphs illustrate the estimated injury reduction possible from the use of E/A devices. Similar to the breakaway pole analysis, the effectiveness of the E/A devices increases as impact speed increases. The sample data also indicate some reduction in injuries as vehicle weight increases as shown by the graphs for vehicles which weigh approximately 2500 pounds versus those that weight 4500 pounds. It is interesting to note that restraint use has no significant affect in reducing driver injury for the data used in this analysis. This is possible due to the lack of distinction made between lap and shoulder use in conjunction with a predominance of frontal collisions in the data sets.

FIGURE 6-2, DRIVER INJURY VS, IMPACT SPEED FOR RIGID OBJECTS AND E/A DEVICES BY VEHICLE WEIGHT (IN LBS.)

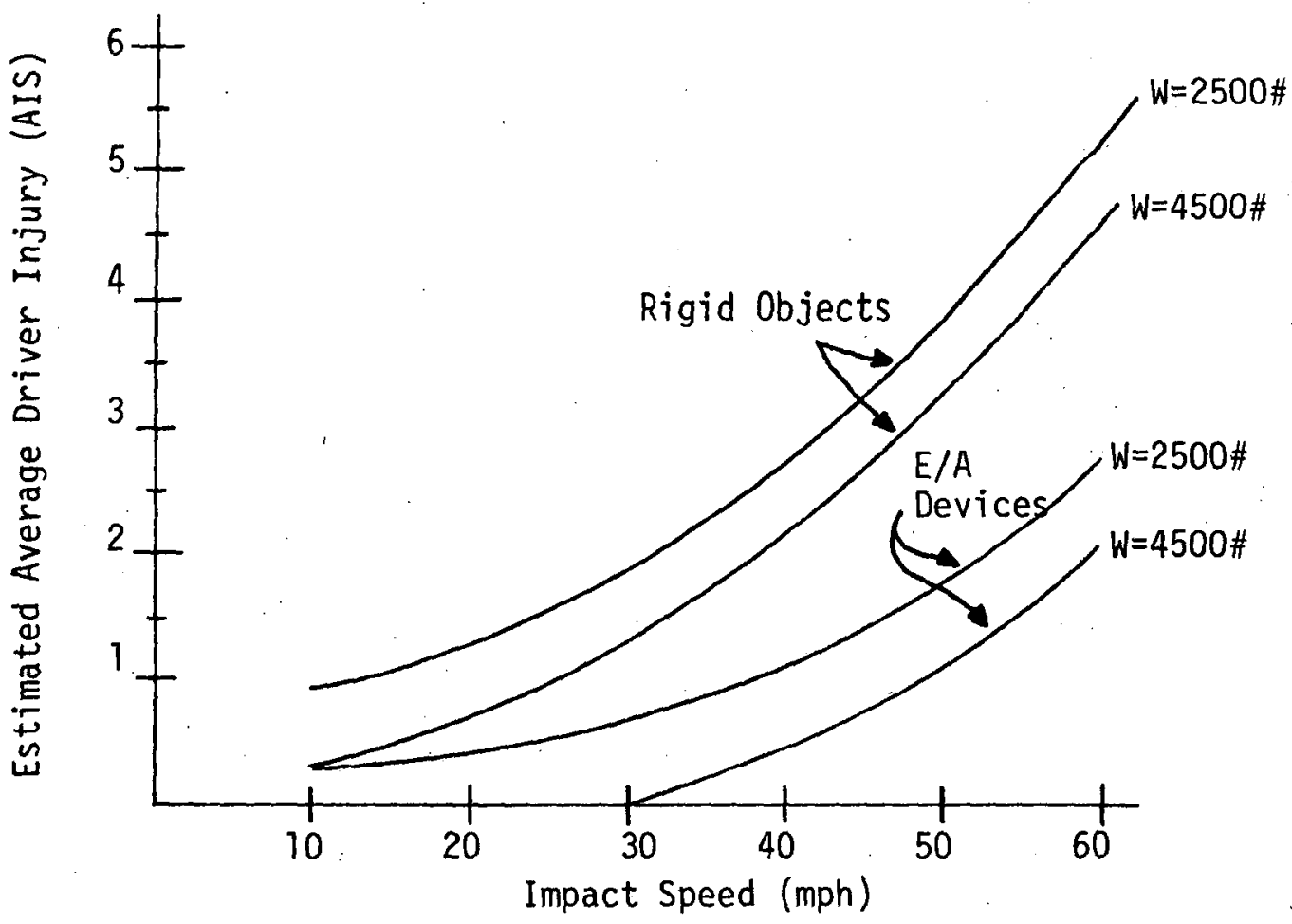


The actual distributions of AIS values for various combinations of type of object contacted and impact speed are shown in Table $\mathrm{H}-4$ of Appendix $H$. The effectiveness of the E/A devices is again clearly shown even though the number of $E / A$ device impacts is rather small (8). For example, $68.5 \%$ of the high speed ( $\geq 35 \mathrm{mph}$ ) impacts with rigid objects result in driver AIS injuries greater than 1 as compared to $33.3 \%$ for $E / A$ device impacts. Note also that none of $8 \mathrm{E} / \mathrm{A}$ device impacts result in an AIS injury greater than 2 while $21(25.6 \%)$ of the 82 rigid object impacts do result in AIS injuries greater than 2 . Twenty $(52.6 \%)$ of the 38 high speed rigid object impacts result in driver AIS injuries greater than 2.

\subsubsection{THE PERFORMANCE OF GUARDRAIL IN PROTECTING VEHICLES FROM IMPACT WITH RIGID OBJECTS}

This analysis considered only cases involving passenger cars, vans; or pick-up trucks which struck an unguarded utility pole, rigid light standard, bridge pier, tree (at least 6" in diameter), or a guardrail (excluding bridge rails, abutments, and terminations). For each such case the overall injury severity (AIS) of the driver, type of object struck (rigid object or guardrail), impact speed, preceeding impacts (yes or no), number of subsequent impacts, and restraint use (yes or no) were recorded. If the driver AIS or speed at impact were unknown, or if there were preceeding or subsequent impacts, the case was dropped from further consideration. This case selection procedure yielded 158 cases in which driver AIS and the remaining variables were known and could be used for further analysis. A similar file for 60 front seat passengers was aiso successfuily developed.

It should be noted that the following analysis compare only injuries for guardrail impacts and rigid object hits. A full analys is of the effectiveness of guardrails would include consideration of the relative frequencies with which guardrail and unguarded objects are hit. However, such data were unavailable for this study.

\section{Driver Analysis}

Several models were examined using the BMD02R Stepwise Regression program in order to determine whether guardrail impacts result in less severe driver injury than rigid object hits, after adjustment for impact severity (impact speed), restraint use, etc. The model selected is:

$$
\begin{aligned}
\text { AIS }=.72541 & +.00119 V^{2}-.03740 V G-.01453 V R \text { (Equation 6-3) } \\
\text { where AIS } & =\text { Estimated average driver AIS } \\
V & =\text { Vehicle speed at impact (mph) }
\end{aligned}
$$




$$
\begin{gathered}
G=\text { Object contacted }(0=\text { unguarded rigid object, } \\
1=\text { guardrail }) \\
R=\text { Restraint use }(0=\text { no, } 1=\text { yes })
\end{gathered}
$$

The statistical properties of this model, which are presented in Table $\mathrm{H}-5$ of Appendix $\mathrm{H}$, indicate that all terms are highly significant with the possible exception of the restraint use term. No other terms considered were even marginally significant when added to the above model.

The mode 7 is graphed in Figure 6-3 for various values of $G$ and $R$. The graphs show a substantial reduction in estimated average driver injury. The effectiveness of both guardrail and restraint use increases as impact speed increases. Although the rigid object impacts used in this analysis are the same as those utilized in the $E / A$ device analysis, the effect of restraint use is significant in the present analysis as indicated in the graphs. The additional guardrail impact cases allow restraint use effectiveness to be detected, there being some evidence that restraints are more effective in guardrail impacts.

FIGURE 6-3. RESTRAINED AND UNRESTRAINED DRIVER AIS VS. SPEED. FOR GUARDRAIL IMPACTS AND RIGID OBJECT IMPACTS

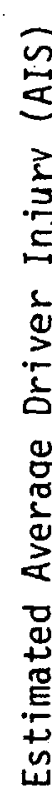
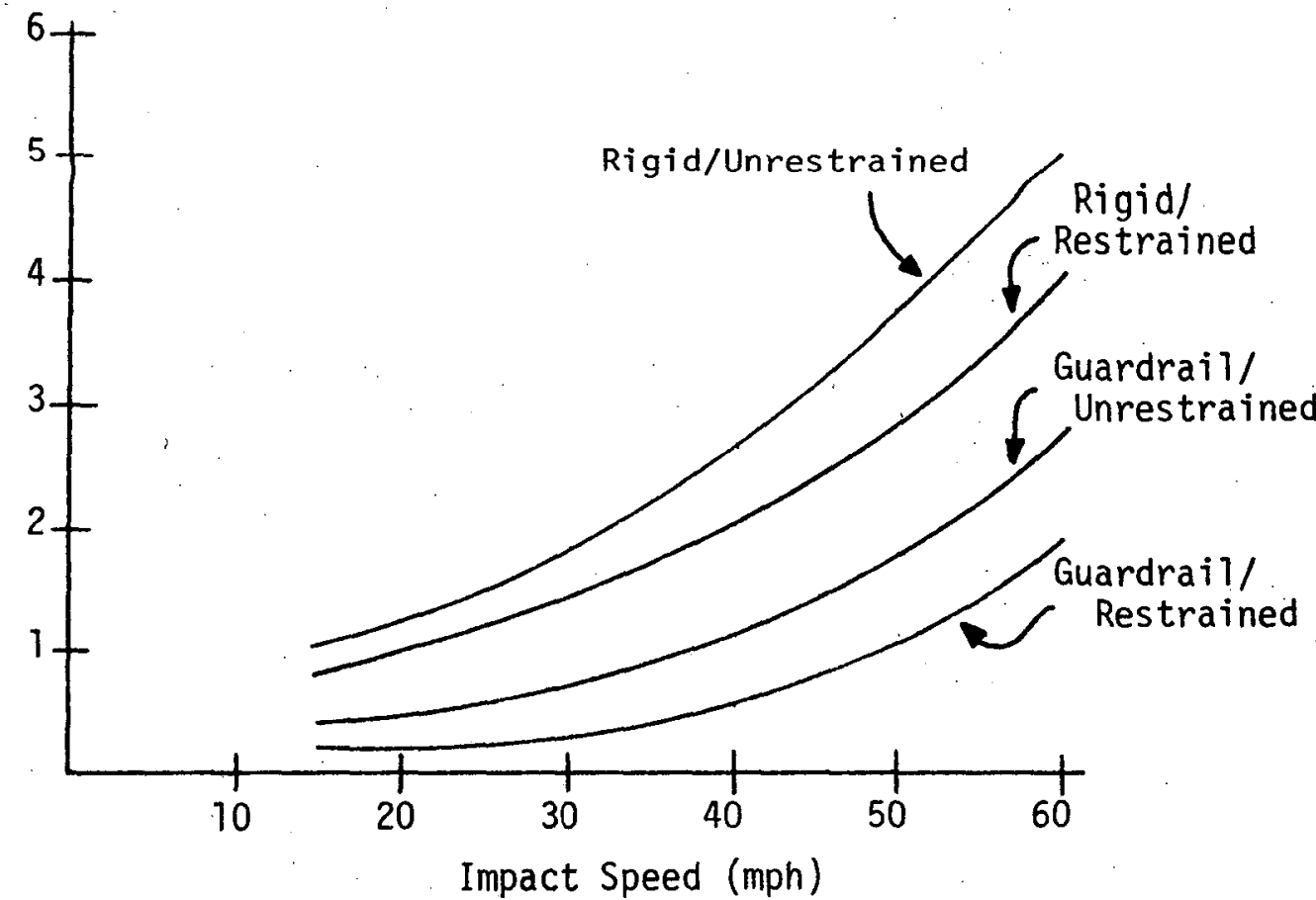
The actual distribution of AIS values for various combinations of type of object contacted and impact speed are shown in Table H-6 of Appendix $H$. The effectiveness of guardrail is again demonstrated in several ways. For example, $25.8 \%$ of the unrestrained drivers involved in a low speed ( $<35 \mathrm{mph}$ ) collision with a rigid object receive serious injuries (AIS $\geq 2$ ) as compared to $4.2 \%$ for unrestrained drivers in low speed guardrail collisions. The results are more striking for unrestrained drivers in high speed ( $235 \mathrm{mph}$ ) collisions. In this case serious injuries are sustained by $70.6 \%$ of the drivers in rigid object collisions as compared to $18.2 \%$ for guardrail impacts. Similar results appear to hold for restrained drivers although the sample sizes are too small to draw firm conclusions.

\section{Front Seat Passenger Analysis}

The model selected for evaluating the effectiveness of guardrail in reducing front seat passenger injuries is:

$$
\begin{aligned}
\text { AIS }=-.04515 & +.00169 V^{2}+1.08979 G-.07582 V G \text { (Equation 6-4) } \\
\text { where AIS } & =\text { Estimated average front seat passenger AIS } \\
V & =\text { Vehicle speed at impact (mph) } \\
G & =\text { Object contacted }(0=\text { unguarded rigid object, } \\
1 & =\text { guardrai } 1)
\end{aligned}
$$

The statistical properties of this model, which are presented in Table $H-7$ of Appendix $H$, indicate that all terms are highly significant with the possible exception of the $G$ term which is significant at $\alpha=.08$. No other terms were even marginally significant when added. to this model.

The model is graphed in Figure 6-4. Note that the effectiveness of guardrail increases as speed at impact increases, as it did for driver injuries. Also shown are the graphs for driver injury ignoring the affect of restraint use. As indicated, front seat passengers tend to receive more serious injuries for high speed impacts than do drivers for collisions with unguarded rigid objects. By comparison there is practically no difference between the injury vs. speed relationships for drivers and passengers involved in guardrail impacts.

The actual distribution of front seat passenger AIS is presented in Table $\mathrm{H}-8$ of Appendix $H$. The guardrail effectiveness is again demonstrated by the greater percentages of injuries for rigid object impacts as compared to guardrail impacts. For example, only 2 out of 27 passengers (7.4\%) involved in guardrail impacts receive serious injuries (AIS $\geq 2$ ) as compared to 7 out of 33 passengers (21.2\%) involved in rigid object impacts. 
FIGURE 6-4. FRONT SEAT PASSENGER AIS VS. SPEED FOR GUARDRAIL IMPACTS AND RIGID OBJECT IMPACTS

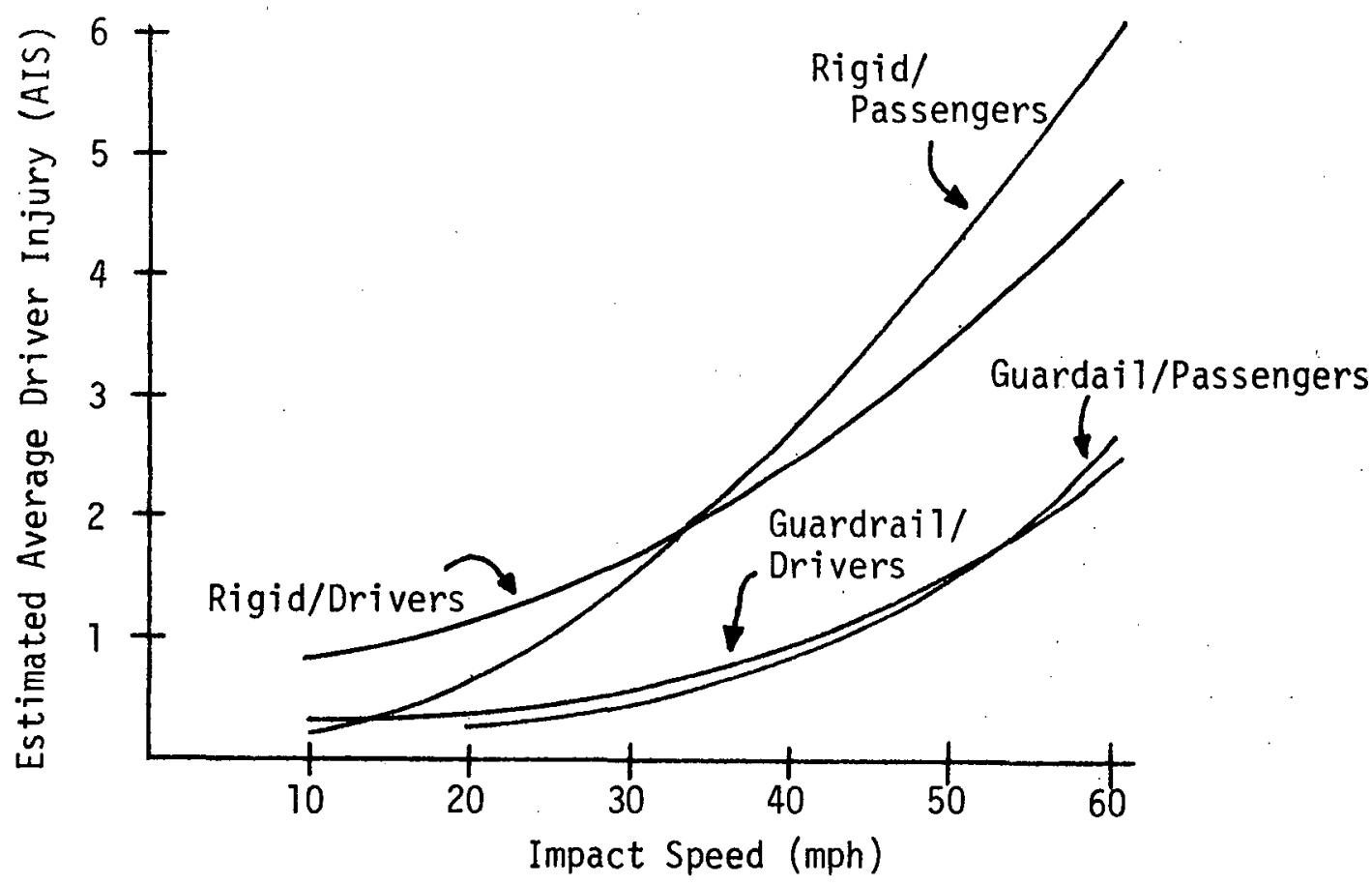

\subsection{ANALYSIS OF CURBS}

The use of curbs adjacent to roadways is a frequent and well established practice in highway design. Curbs have been used traditionally to aid in drainage, to provide a "finished" appearance to the roadway and to inhibit or prevent vehicles from entering the roadside area. The analysis of curbs is based upon a total of 199 curb impacts and the resultant effect upon vehicle redirection, vauiting of redirection devices, damage and loss of control by the driver.

\subsubsection{VEHICLE REDIRECTION}

The original sample of 199 impacts was reduced to 120 impacts by eliminating cases involving trucks and motorcycles and those curb impacts occurring simultaneously with a bridgerail or guardrail. The redirection performance categorized by curb type (small barrier, large barrier, mountable and bridge curb) is presented in Figures $\mathrm{H}-9$ and 
H-10 of Appendix $H$. None of these curbs appear to have effective redirection capabilities for vehicle approach angles greater than 100. In addition, speed has no noticeable effect on redirection. The small barrier curbs do not tend to cause redirection except at very shallow angles (less than $4^{\circ}$ ). The large barrier curbs are somewhat more effective but still exhibit a number of non-redirections at shallow angles. The bridgerail curbs tend to be the most effective, but it should be noted that two of these redirections are accompanied by simultaneous driver steering input. As expected, the mountable curbs demonstrate no redirective capability.

In addition to these descriptive results, regression and discriminant techniques were utilized to develop statistical models relating redirection to curb height, slope, etc. The discriminant analysis proved to be the best method since it allowed for the development of redirection boundaries. The sample used in this analys is was reduced to 111 impacts by eliminating those cases involving simultaneous steering input and initial redirections to $0^{\circ}$ which were followed by a curb mounting. In addition, the sample was limited to approach angles of $20^{\circ}$ or less.

The model selected is graphed in Figure 6-5. The area to the left of the non-redirection boundary represents the combinations of approach angles and curb heights for which redirection would not be expected to occur. Redirections would be expected for those combinations in the area to the right of the redirection boundary. The area between the two boundaries represents a region where redirections may occur. The statistical properties of the model are described in Table $\mathrm{H}-11$ of Appendix $\mathrm{H}$.

FIGURE 6-5. CURB REDIRECTION BOUNDARIES

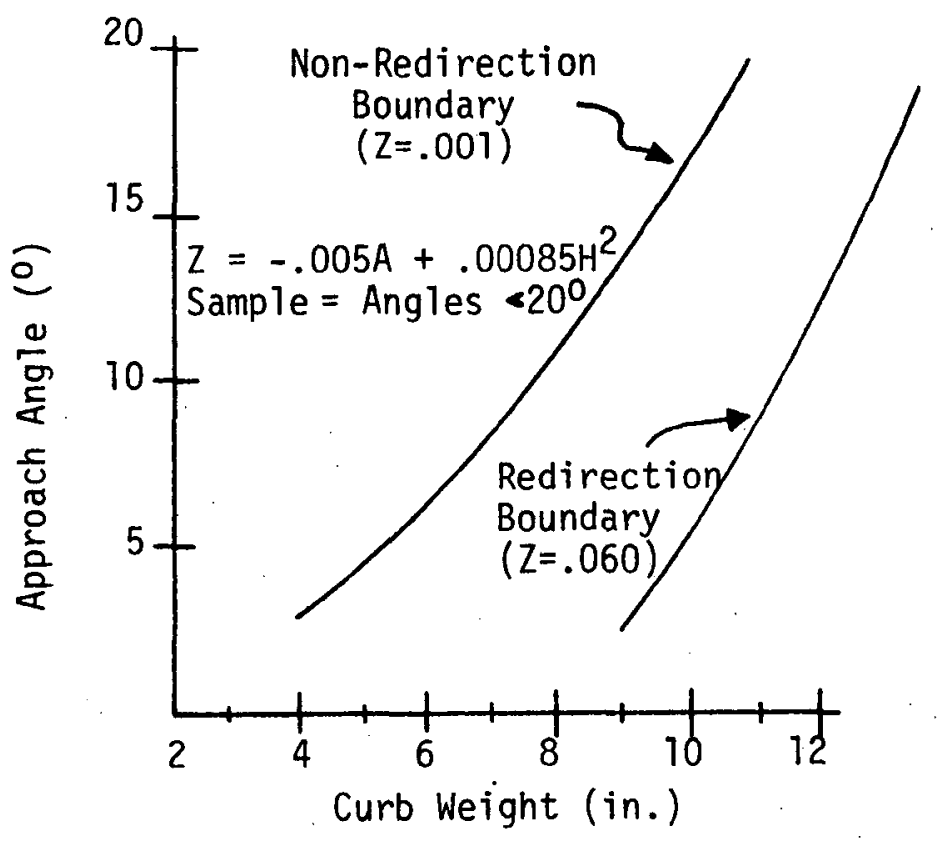


In the evaluation of these results it should be noted that the range of speeds encountered was essentially 20 to $50 \mathrm{mph}$. It is also possible that the sample may be biased by both redirection and nonredirection events not resulting in impacts and, therefore, not included in the sample. These results do, however, indicate that curbs in the 8 to 10 inch height range are not reliable as redirection devices and that smaller barrier curbs have little, if any, use for the redirection of errant vehicles.

\subsubsection{VAULTING}

A comparison of the vaulting performance of two types of bridgerail for both types of impact is presented in Table 6-1. Although the determination of the effect of curbs upon vaulting of guardrails and bridgerails is complicated in this study by variations in rail height, it appears that the width of the curb and the height of the rail are significant. Impact with the curb prior to striking the rail (non-simultaneous impact) also appears to promote vaulting. This occurrence is, of course, dependent upon the vehicle overhang, the approach angle and the width of the curb. Although these results are not conclusive it appears that increasing the curb width, as well as decreasing the rail height, tends to promote vaulting.

TABLE 6-1. VAULTING BY BRIDGERAIL TYPE AND IMPACT CONFIGURATION

\begin{tabular}{|c|c|c|c|c|c|}
\hline \multirow{2}{*}{$\begin{array}{c}\text { Rail } \\
\text { Type }\end{array}$} & Type of Impact & $\begin{array}{c}\text { No. of } \\
\text { Events }\end{array}$ & \multicolumn{3}{|c|}{ Rail Herage Dimensions (in.) } \\
\hline 1 & $\begin{array}{l}\text { Simultaneous } \\
\text { (No Vaulting) }\end{array}$ & 4 & 32.3 & Curb Height & Curb Width \\
\hline & $\begin{array}{l}\text { Non-Simultaneous } \\
\text { (No Vaulting) }\end{array}$ & 5 & 30.6 & 9.2 & 23.5 \\
1 & $\begin{array}{l}\text { Non-Simultaneous } \\
\text { (Vaulting) }\end{array}$ & 5 & 30.4 & 8.8 & 24.8 \\
$\begin{array}{l}\text { Simultaneous } \\
\text { (No Vaulting) }\end{array}$ & 22 & 36.4 & 8.9 & 10.2 \\
$\begin{array}{l}\text { Non-Simultaneous } \\
\text { (No Vaulting) }\end{array}$ & 3 & 36.7 & 8.3 & 18.3 \\
\hline
\end{tabular}




\subsubsection{VEHICLE DAMAGE AND LOSS OF CONTROL}

The effect of curb impacts on vehicle damage and loss of control are summarized in Table 6-2. The four types of vehicle damage investigated are blowouts, rim damage, sheet metal damage (including bumpers), and undercarriage damage. All damage types were compared to vehicle speed and curb type. Sheet metal and undercarriage damage were also compared to vehicle type. Cases involving trucks and motorcycles and those for which an accurate damage evaluation was not possible were excluded.

TABLE 6-2. VEHICLE DAMAGE AND LOSS OF CONTROL BY TYPE OF CURB IMPACTED?

\begin{tabular}{|c|c|c|c|c|}
\hline \multirow{2}{*}{$\begin{array}{c}\text { Effect of } \\
\text { Impact }\end{array}$} & \multicolumn{4}{|c|}{ Curb Type/Height Impacted } \\
\cline { 2 - 5 } & $\begin{array}{c}\text { Mountable } \\
4 "-5\end{array}$ & $\begin{array}{c}\text { Barrier } \\
5 "-6 "\end{array}$ & $\begin{array}{c}\text { Barrier } \\
8 "-10 "\end{array}$ & $\begin{array}{c}\text { Bridge Curb } \\
8 "\end{array}$ \\
& & & & $10 "$ \\
\hline Type of Damage: & $0.0 \%$ & $23.7 \%$ & $65.2 \%$ & $69.7 \%$ \\
Blowout & $0.0 \%$ & $21.2 \%$ & $59.1 \%$ & $65.4 \%$ \\
Rim & $0.0 \%$ & $0.0 \%$ & $13.6 \%$ & $34.6 \%$ \\
Sheet Metal & $0.0 \%$ & $14.7 \%$ & $23.8 \%$ & $30.4 \%$ \\
Undercarriage & $0.3 \%$ & $18.2 \%$ & $60.0 \%$ & $81.8 \%$ \\
\hline Loss of Control & $13.3 \%$ & & & \\
\hline
\end{tabular}

1 See Appendix $\mathrm{H}$, Tables $\mathrm{H}-12$ and $\mathrm{H}-13$.

Curb type is the only variable which appeared to be significant in the production of vehicle damage. As indicated in Table 6-2, no damage occurs during impacts with the mountable curbs. The barrier curbs, particularly those $8 \mathrm{in}$. or more in height, do produce damage in a significant number of cases. The increased damage incurred through impact with the bridge curbs may be attributed to the fact that the top radius on these curbs is generally sharper than other types.

Loss of control was defined as a vehicle rotation produced by the curb, vehicle damage causing loss of control, or a driver overreaction in response to the curb impact. Trucks and motorcycles were excluded along with the cases in which the vehicle was already out of control or a definite evaluation of the criteria for loss of control could not be made. In the remaining 42 cases vehicle type and vehicle speed had little or no effect upon loss of control. As indicated in Table 6-2, curb type did have some influence upon loss of control in that curbs 8 in. and higher tend to be more likely to produce loss of control. 


\subsection{ANALYSIS OF ROLLOVER ACCIDENTS}

Rollover accidents are significant from several aspects. In many cases $(13.1 \%$ from Table F-23) there would be no impact producing damage and/or injuries except for the occurrence of a rollover. In other cases the rollover produces more serious consequences than if the vehicle simply strikes and object (see Figure 4-5). A significant percentage of the rollovers $(45.4 \%$ ) occur after the vehicles strikes an object - often resulting in increased damage and injuries. The number of occupant ejections in rollovers is, as expected, much larger than those resulting from other impact configurations. The occupant injury severity resulting from these ejections is quite high as compared to other injury producing mechanisms (see Table I-22).

The cause of rollovers may be attributed to a variety of factors including location (on/off the roadway), surface conditions, roadside characteristics, previous impacts and vehicle characteristics. Since a significant (39.3\%) portion of the 28 truck accidents and all of the 24 motorcycle accidents resulted in rollovers, and these are specialized vehicles, the analys is of rollover accidents was restricted to the 557 cases involving pickups, vans and passenger cars.

TABLE 6-3. CHARACTERISTICS OF IN-DEPTH SAMPLE RELATED TO ROLLOVERS

\begin{tabular}{|c|l|c|}
\hline Base & \multicolumn{1}{|c|}{ Characteristic } & \% of Base \\
\hline $\begin{array}{l}\text { Total Accidents } \\
(n=557)\end{array}$ & Rollovers (106) & $19.0 \%$ \\
& Wet Surface (736) & $24.4 \%$ \\
& Pickup/Van (44) & $7.9 \%$ \\
\hline Rollovers: & First/Only Impact (60) & $56.6 \%$ \\
$(n=106)$ & Off Roadway (90) & $84.9 \%$ \\
& Wet Surface (19) & $17.9 \%$ \\
& Pickup/Van (16) & $15.1 \%$ \\
\hline
\end{tabular}

1 See Appendix $\mathrm{H}$, Tables $\mathrm{H}-14$ and $\mathrm{H}-15$.

2

Excludes trucks and motorcycles.

As indicated in Table $6-3,106(19 \%)$ of the 557 single vehicle accidents evaluated involve a rollover, thus demonstrating that this type of crash configuration is significant. Sixty $(57 \%)$ of these 106 rollovers are the first or only impact configuration occurring in the accidents. The determination of the causal or contributing. factors specifically leading to vehicle rollovers would, therefore, appear to be an important aspect of highway safety research. 
The importance of roadside design parameters is demonstrated by the fact that 90 (85\%) of the 106 rollovers occur off the roadway. of these 90 rollovers, $53(59 \%)$ cases do not involve any previous impacts, thus indicating the importance of roadside surface characteristics and geometry as well as the distribution and nature of roads ide objects.

Pavement surface ambient condition appears to be significant in rollovers occurring on the roadway. Of the 16 on-roadway rollovers none occur on wet pavements. The relationship between vehicle geometry and the tire-pavement friction capacity, therefore, may be a significant factor in determining the potential for on-roadway rollovers. In general (on or off the roadway) rollovers appear less likely to occur in wet weather than other types of single vehicle crash configurations.

The effect of vehicle type is also apparent in Table 6-3. Pickups and vans represent $7.9 \%$ (44) of the 557 single vehicle accidents evaluated, but account for $15.1 \%$ of the rollovers. This is, of course, an expected result due to the generally higher center of gravity of this type of vehicle.

The involvement ratios for vehicle makes involved in rollovers and other type crash configurations is presented in Table 6-4. Of the various makes, Chevrolet and to lesser extent Buick/01dsmobile/Pontiac and Ford/Mercury vehicles appear to be underrepresented in rollover accidents. Foreign makes appear to be significantly overrepresented in rollover occurrences in that they accounted for only $9.8 \%$ of the registered vehicle population but were involved in $37.8 \%$ of the rollover accidents (11.5\% of the non-rollover and $16.5 \%$ of the total sample accidents). It also interesting to note that over one-half (9 of 16) of the on-roadway, dry surface rollovers involved foreign make vehicles.

TABLE 6-4. INVOLVEMENT RATIO BY VEHICLE MAKE ${ }^{7}$

\begin{tabular}{|l|c|c|c|}
\hline \multirow{2}{*}{ Make } & \multicolumn{3}{|c|}{ Involvement Ratios } \\
\cline { 2 - 4 } & $\begin{array}{c}\text { Rollover } \\
\text { Accidents }\end{array}$ & $\begin{array}{c}\text { Other } \\
\text { Accidents }\end{array}$ & Total \\
\hline Buick/Olds./Pontiac & 0.623 & 1.090 & 1.018 \\
Cadillac/Lincoln/Chrysler & 0.770 & 0.811 & 0.797 \\
American Motors & 1.900 & 1.550 & 1.600 \\
Plymouth/Dodge & 0.863 & 0.878 & 0.878 \\
Ford/Mercury & 0.744 & 1.093 & 1.028 \\
Chevrolet & 0.512 & 0.981 & 0.891 \\
Volkswagen & 3.700 & 0.957 & 1.478 \\
Foreign & 4.000 & 1.365 & 1.865 \\
Others & 0.475 & 0.225 & 0.275 \\
\hline
\end{tabular}

1 See Appendix $\mathrm{H}$; Table $\mathrm{H}-16$.

2 Involvement Ratio $=\%$ involvement $/ \%$ of registered vehicles. 


\subsection{MOTOR VEHICLE AND HIGHWAY SAFETY STANDARDS}

The purpose of this section is to estimate the extent to which various safety standards are involved in single vehicle accidents and, where possible, to evaluate their effectiveness in reducing injuries. Selected statistics from the in-depth sample of 609 cases are used in the analyses.

\subsection{MOTOR VEHICLE SAFETY STANDARDS (MVSS) INVOLVEMENT AND EVALUATION}

The in-depth sample was analyzed to determine the involvement of the various standards and to evaluate their effectiveness in reducing injuries. The basic methodology consisted of identifying situations in which a standard(s) was involved, determining whether the standard was in effect for the model year of the vehicle involved, and conducting Chi-Square tests of independence between model year (i.e., the standard in effect indicator) and injury severity (AIS). The standards were analyzed on both an overall basis and an individual basis. The particular standards considered in the individual analyses are listed in Table 7-3.

\subsubsection{OVERALL STANDARDS EVALUATION}

This analysis basically involves a comparison of the overall injury severity (AIS) distributions for occupants of passenger cars built before to those built after the MVSS went into effect. Since the standards were not introduced simultaneous $7 y$, model year is broken into four categories $(\leq 67,68-69,70-71, \mathbf{z} 72)$ for the analysis. Both driver AIS and passenger A (front right seat) AIS distributions are compared for the various model year categories. Other variables describing the nature of collision, the driver, and the vehicle are also compared by model year to detect possible variation in injury severity due to factors other than the MVSS. The actual comparisons were made by conducting Chi-Square tests for independence using the BMD02S Contingency Table Analys is program. The statistical properties of the comparisons are presented in Table 7-1.

As shown, the AIS distributions do not differ by model year at a level of significance $(\alpha)$ below . 14. The driver AIS distributions are very similar while the passenger AIS distributions, although showing some reduction in severity as model year increases, can be considered only marginally different. Even including restrained 
passengers in the analysis does not develop a significant difference within the sample. The AIS distributions for restrained and unrestrained occupants are presented in Table I-22 of Appendix I and are summarized in Figure 7-1.

TABLE 7-1. RESULTS OF CHI-SQUARE TESTS FOR THE OVERALL EFFECTIVENESS OF MVSS

\begin{tabular}{|l|c|c|c|}
\hline \multicolumn{1}{|c|}{ Characteristic } & $\begin{array}{c}\text { Degrees of } \\
\text { Freedom }\end{array}$ & $\begin{array}{c}\text { Calculated } \\
\text { Chi-Square }\end{array}$ & $\begin{array}{c}\text { Approximate } \\
\text { Probability2 }\end{array}$ \\
\hline Driver AIS (A11) & 9 & 5.89 & .750 \\
Driver AIS (Unrestrained) & 9 & 5.97 & .750 \\
Passenger A AIS (A11) & 3 & 5.52 & .160 \\
Passenger A AIS (Unrestrained) & 3 & 5.91 & .140 \\
\hline Driver Restraint Use & 3 & 47.53 & $.000^{3}$ \\
Passenger A Restraint Use & 2 & 14.21 & $.000^{3}$ \\
Age of Driver & 15 & 20.63 & .170 \\
Sex of Driver & 3 & .69 & .800 \\
\hline Point of Collision (POC) & 6 & 4.03 & .650 \\
Speed at First Point of Col1ision & 15 & 9.38 & .850 \\
\hline Vehicle Weight & 18 & 35.91 & $.010^{3}$ \\
Body Style & 15 & 55.08 & $.000^{3}$ \\
\hline
\end{tabular}

1 Null hypothesis = Characteristic is independent of model year.

2 Probability = Chance of getting the calculated Chi-Square value when the null hypothesis is really true.

3 Significant at $\propto=.01$

Occupant restraint use and vehicle weight/style characteristic differences by model year, however, are highly significant. The patterns are summarized in Table 7-2. As might be expected, restraint use increased with model year. The vehicle weight and body style trend towards light, 2 door cars is quite evident, with both the percentage of cars weighing less than 2500 pounds and the percentage of 2-door steadily increasing with model year. The possibility that the trend towards smaller cars in later model years is negating the overall. effectiveness of the standards was also examined. This was accomplished by dividing the passenger cars into three weight categories and by repeating the analyses of Table 7-1 on each separate category. The vehicle weight categories used were less than 2500 pounds, between 2500 and 3999 pounds, and over 3999 pounds. The AIS distributions were found to be independent of model year in each of the weight 
categories. It is possible that a further breakdown in vehicle weight and/or body style is necessary since both of these variables remain marginally significant within each of the above weight categories. The number of available cases, however, limits the number of weight/ style categories for which analysis is feasible.

TABLE 7-2. SUMMARY OF OVERALL CHARACTERISTICS WHICH MAY VARY WITH MODEL YEAR

\begin{tabular}{|c|c|c|c|}
\hline \multirow[b]{2}{*}{ Characteristic } & \multicolumn{3}{|c|}{ Model Year } \\
\hline & Before 168 & $168-171$ & After 171 \\
\hline $\begin{array}{c}\text { Driver Restraint Use: } \\
\text { Yes }\end{array}$ & $5.4 \%$ & $14.7 \%$ & $37.9 \%$ \\
\hline $\begin{array}{c}\text { Passenger } A \text { Use: } \\
\text { Yes }\end{array}$ & $0.0 \%$ & $13.3 \%$ & $34.0 \%$ \\
\hline $\begin{array}{l}\text { Vehicle Weight: } \\
\text { Under } 2500 \text { lbs. }\end{array}$ & $11.7 \%$ & $21.7 \%$ & $28.4 \%$ \\
\hline $\begin{array}{l}\text { Body Style: } \\
2 \text { door }\end{array}$ & $47.7 \%$ & $65.8 \%$ & $77.0 \%$ \\
\hline
\end{tabular}

1 See Appendix I, Tables I-1 and I-2.

\subsubsection{INDIVIDUAL STANDARD ANALYSIS}

This analysis consists of determining the involvement of individual standards and evaluating their individual effectiveness in terms of a suitable measure for which data were collected. Involvement is measured by counts of the number of occupants (vehicles) having characteristics (e.g., contact points, collision types, etc.) related to each particular standard. Evaluation consists of comparing injury severity or some other suitable measure for vehicle model years before and after a standard went into effect, considering only occupants (vehicles) involved in a particular standard. Comparisons were made using the BMD02S Contingency Table Analys is program. Injury severity is measured by the AIS value of the most serious injury received in an attempt to improve the sensitivity of the evaluations.

A summary of the results of the individual analyses is presented in Table 7-3. Involvement is given in both absolute and relative frequency terms. For example, 26 out of 702 occupants $(3.7 \%)$ received their most serious injury from an instrument panel contact and 33 out of 515 vehicles $(6.4 \%)$ had at least one door open during the collision. 
As can be seen, only one standard (301) has statistically significant support for its effectiveness. There are, however, six instances where the data support the effectiveness of the standards although not with statistical significance and only three cases where the data do not support standard effectiveness. No analys is of standards omitted from Table 7-3 were attempted due to lack of suitable data.

The individual analyses are presented in Tables I-3 through I-12. Each table contains the involvement and evaluation results, along with a remarks section which describes the data selected for each standard and other appropriate considerations. Because of the extent of the results available, restraint analyses are presented separately in Section 7.2.

TABLE 7-3. SUMMARY OF INDIVIDUAL STANDARDS ANALYSES ${ }^{\top}$

\begin{tabular}{|c|c|c|c|}
\hline Standard No. & $n$ & $\begin{array}{l}\text { Overall Involvement } \\
\% \text { of Occupants/Vehicles }\end{array}$ & $\begin{array}{c}\text { Evaluation } \\
\text { Result }^{2}\end{array}$ \\
\hline $\begin{array}{l}\text { 201: Instrument Panel } \\
\text { Sun Visors } \\
\text { Seat Backs } \\
\text { Arm Rests }\end{array}$ & $\begin{array}{r}26 \\
4 \\
22 \\
1\end{array}$ & $\begin{array}{r}3.7 \\
.6 \\
26.2 \\
.1\end{array}$ & $\begin{array}{l}b \\
b \\
b \\
d\end{array}$ \\
\hline 202: Head Restraints & 1 & .1 & d \\
\hline 203/204: Steering Assembly & 116 & 22.5 & c \\
\hline 205: G1azing & 62 & 6.4 & $b$ \\
\hline $\begin{array}{l}\text { 206: Door Latches \& Hinges } \\
\text { Doors Opened } \\
\text { Doors Jammed }\end{array}$ & $\begin{array}{r}33 \\
181\end{array}$ & $\begin{array}{r}6.4 \\
35.1\end{array}$ & $\begin{array}{l}b \\
b\end{array}$ \\
\hline 208/210: Restraint Systems & & See Section 7.2 & \\
\hline 212: Windshields & 55 & 8.1 & c \\
\hline 214: Intrusion & 19 & 3.7 & c \\
\hline 301: Fuel Spil1s & 42 & 10.3 & a \\
\hline
\end{tabular}

1

See Appendix I, Tables I-3 through I-12

2 a - Supports effectiveness of standard, significant at $\alpha=.05$

$b$ - Supports effectiveness, not significant at $\propto=.05$

c - Does not support effectiveness, not significant at $\alpha=.05$

d - Insufficient observations 


\subsection{RESTRAINT SYSTEMS EVALUATION (MVSS 208/210)}

Restraint systems were examined with respect to installation, usage, and injury reduction. Variables describing these characteristics were tabulated for various model year categories and Chi-Square tests of independence run on each variable using the SPSS CROSS TAB program. All variable differences presented in this section are significant at the $\alpha=.05$ level.

\subsubsection{RESTRAINT SYSTEM INSTALLATION AND USAGE}

Installation and usage differences by model year for vehicles other than trucks, buses, and motorcycles are summarized in Table 7-4. As shown, restraint system installations increase from $11.1 \%$ for model years prior to 1972 , to $99.5 \%$ for model years 1972 and later. Restraint use by drivers and passengers of passenger cars having restraint installations increases for 1972 and later model vehicles, although passenger usage is lower than that for drivers. Note that an occupant is considered to be restrained if the lap belt and/or shoulder harness are used.

TABLE 7-4. SUMMARY OF RESTRAINT SYSTEM CHARACTERISTIC CHANGES WITH MODEL YEAR

\begin{tabular}{|l|c|c|}
\hline \multirow{2}{*}{$\begin{array}{c}\text { Restraint System } \\
\text { Characteristic }\end{array}$} & Before 172 & Yodel \\
\cline { 2 - 3 } Installation & $11.1 \%$ & $99.5 \%$ \\
\hline Use by: & & \\
Driver & $8.8 \%$ & $35.3 \%$ \\
Passenger & $6.3 \%$ & $13.7 \%$ \\
\hline Equipped with: & & \\
Warning Device & $0.0 \%$ & $61.1 \%$ \\
Locking Retractors & $9.2 \%$ & $49.2 \%$ \\
Inertia Reels & $10.6 \%$ & $29.5 \%$ \\
\hline Warning Device: & - & $17.8 \%$ \\
Disconnected & - & $37.6 \%$ \\
By passed & & \\
\hline
\end{tabular}

1 See Appendix I, Tables I-13 through I-21.

2 Except for Installation, all entries are expressed as a percent of vehicles having restraint systems installed. 
One of the major reasons for the increased use of restraints is the installation of warning devices on 1972 and later models. Although at least $96 \%$ of the post 1968 passenger cars had restraint systems installed, the jump in usage did not occur until the 1972 and after model years. This increase in usage coincided with the introduction of warning devices on 1972 and later model year passenger cars. The effectiveness of warning devices in encouraging restraint use is shown by the fact that $42.2 \%$ of the occupants of vehicles in which a warning device was installed used restraints as compared to $11.0 \%$ for those in vehicles without warning devices (see Table I-21).

Another reason for the increase in restraint use is the improvements which made the restraints easier to use. For example, the installation rate of both locking retractors and inertia reels increased substantially in 1972 and later model year passenger cars. It appears that the combination of warning devices and more convenient restraint systems substantially. increases restraint use. Some individuals circumvent the warning systems, however, as shown in Table 7.4.

\subsubsection{RESTRAINT SYSTEM EFFECTIVENESS}

The effectiveness of restraint use is demonstrated in various ways in this study. For example, the distributions of overall AIS for restrained and unrestrained occupants of passenger cars are summarized in Figure 7-1. As can be seen, restrained drivers received substantially fewer serious injuries than unrestrained drivers. Although slightly more restrained passengers received serious injuries than unrestrained, more unrestrained passengers were injured in the first place $(60.5 \%$ for unrestrained vs. $53.6 \%$ for restrained). The effectiveness of restraint use is also demonstrated in the analyses of breakaway supports and guardrails presented in Section 6.1. Here the effects of speed are considered and it becomes apparent that restraint use becomes more effective as speed increases.

FIGURE 7-1. SERIOUS INJURY VS. RESTRAINT USE AND EJECTION STATUS ${ }^{1}$

\begin{tabular}{|c|c|}
\hline Occupant Status & $\%$ Serious Injury (AIS $\geq 2$ ) \\
\hline $\begin{array}{l}\text { Restrained Drivers } \\
\text { Unrestrained Drivers } \\
\text { Restrained Passengers }{ }^{2} \\
\text { Unrestrained Passengers. }\end{array}$ & $\begin{array}{c}7.7 \% \\
14.3 \% \\
11.9 \%\end{array}$ \\
\hline
\end{tabular}

See Appendix I, Table I- 22.

2 Biased upward by a serious accident with two passenger fatalities 
It should be noted that none of the 43 occupants ejected from in-depth sample vehicles (excluding trucks, buses, and motorcycles) were wearing restraints. The importance of preventing ejections can be seen by examining the injury severity distribution for ejected occupants summarized in Figure $7-1$. Nearly $56 \%$ of ejected occupants receive severe injuries (AIS $\geq 2$ ).

\subsection{HIGHWAY SAFETY PROGRAM STANDARDS}

The evaluation of the Highway Safety Program Standards was conducted primarily by the field investigators on a case by case basis. The involvement of a given standard, to a large extent, merely indicates the situation in the study area only. Involvement included violations of the purpose or intent of a standard, as well as, violations of specific requirements set forth in that standard. A summary of the number of cases involving each standard evaluated in this study is given as follows:

$\begin{array}{lrrrrrrrrrrr}\text { HSPS } & 1 & 3 & 4 & 5 & 8 & 9 & 10 & 12 & 13 & 15 & 18 \\ \text { No. } & 420 & 24 & 343 & 188 & 237 & 163 & 417 & 537 & 83 & 402 & 110\end{array}$

In addition to involvement as indicated by violations within the local jurisdiction, certain recommendations for changes in or expansion of the standards were developed from the results of this research effort. A description of the nature of the involvement and the recommended changes for each of the cited standards is presented as follows:

HSPS 1 - Periodic Motor Vehicle Inspection

It was noted in a few cases that the scope and/or quality of inspection procedures are not adequate (see Section 4.3.4). In only a small number of cases was the inspection stricker missing or overdue. The primary problem encountered is that often the vehicle damage incurred in the accident is sufficient to have destroyed or seriously altered certain safety components which would go uninspected, following repair, until the annual reinspection is performed.

In order to realize the stated purpose of this standard it appears reasonable that all repairable vehicles which suffer damage to safety components or which have been damaged sufficiently to warrant towing should be required to be presented for reinspection. It is recommended that this standard be modified to incorporate this post-repair reinspection requirement. 
HSPS 3 - Motorcycle Safety

The standard (Section I.A.) was violated in all motorcycle cases in that no specific examination or licensing procedures are required for motorcycle operators in this jurisdiction.

HSPS 4 - Driver Education

Probable violations of the standard (Sections II \& III) in this jurisdiction include generally nonexistent or inadequate programs and driving facilities for adult driver training and retraining. Provisions for practice driving by students for handling emergency situations are similarly inadequate. As indicated in Section 5.0 CAUSAL FACTORS, overreaction to emergency situations appears to be a significant accident causation factor. It is, therefore, recommended that the standards establish requirements for actual driving practice involving emergency response and avoidance maneuvers to be incorporated in driver education programs.

HSPS 5 - Driver Licensing

A significant violation of at least the intent of this standard (Section VI) consists of the lack of a realistic and effective program for identification and improvement of problem drivers. The overrepresentation in single vehicle accidents of drivers with poor prior driving records is demonstrated in Section 4.2.4. The high percentage of accidents caused by these relatively few drivers indicates the need for significant changes in the methods for identification of problem drivers and the criteria for license removal or other appropriate action.

HSPS 8 - Alcohol in Relation to Highway Safety

Standard (Section III.B) was violated in certain cases in that surviving drivers of fatal accidents were not administered alcohol tests. The overall intent of this standard was, also, not fully realized due to the fact thay many suspected drivers in non-fatal accidents were not required to submit to alcohol testing. This is primarily due to inadequate legislation regarding police enforcement procedures and cooperation by medical treatment facilities. It is recommended that the standard be expanded to include requirements enabling and requiring testing for all drivers suspected of being alcohol impaired.

HSPS 9 - Identification and Surveillance of Accident Locations

No apparent effective program relating to this standard (Sections I.A.2.C., I.A.3 and I.B) has been implemented in this jurisdiction, possibly resulting in a less effective utilization of highway safety funds. The experience gained during this study indicates that this 
standard should be expanded to specifically include highway construction projects.

\section{HSPS 10 - Traffic Records}

The intent of this standard (Section III.E) is generally violated since the police report which provides the basis for these records is not adequate for describing environmental conditions, particularly those which may be causal in nature. The police officer's training in this area (see HSPS 15 and 18) is also inadequate to allow for a qualified assessment of environmental conditions.

\section{HSPS 12 - Highway Design, Construction and Maintenance}

In most of the cases investigated during this study one or more violations of this standard were noted. At the time these accidents occurred there were no consistent or meaningful regulations for the design, construction and maintenance of roadways in this jurisdiction. Due in large part to this research effort and the direct involvement of study personne1, the Florida Department of Transportation has developed and adopted a "Manual of Uniform Minimum Standards for Design, Construction, and Maintenance for Streets and Highways". This Manual, which becomes effective June 1, 1976, establishes minimum standards for all public streets and highways in the State of Florida which are generally equal to or more stringent than current A.A.S.H.T.O. standards. It is felt that the State is now in substantial compliance with both the intent and the specific requirements of this standard.

\section{HSPS 13 - Traffic Engineering Services}

Violations of the intent of this standard (particularly Section III.D) were generally due to a lack of sufficient routine surveillance of the roadway network and inadequate coordination with design, construction and maintenance activities.

\section{HSPS 15 - Police Traffic Services}

Procedures in this jurisdiction lead to general violation of this standard (Sections I.D. and I.E.) regarding accurate and complete reporting of those factors (particularly environmental) which may be classified as causal in nature. This deficiency, which also leads to violation of HSPS 14 - Traffic Records and HSPS 9 - Identification and Surveillance of Accident Locations, is primarily due to insufficient training for police officers and inadequate liaison with appropriate highway agencies. 
HSPS 18 - Accident Investigation and Reporting

Violation of this standard (Section IV.D) is essentially due to the same factors listed for HSPS 9 and HSPS 14. In addition, there has been no apparent establishment of State accident investigation teams as prescribed by Section IV.D.2. 


\subsection{CONCLUSIONS AND COUNTERMEASURES}

Certain conclusions regarding the nature of the single vehicle accident problem are presented in this section along with recommended general and specific countermeasures. These conclusions and recommendations are based upon the field investigations, the review and analysis process, the causal factors identified, certain descriptive results and various specific analyses. Areas considered for countermeasures included: education; legislation; licensing, inspection and enforcement procedures; standards promulgation; vehicle design; and highway design, construction, maintenance and operation requirements. Specific countermeasures are generally limited to those problems which may be uniquely important in single vehicle accidents and which have a high frequency or serious consequence. The feasibility of a given countermeasure along with the frequency and importance of a problem is also considered in these recommendations.

The conclusions and countermeasures presented are initially classified as to whether they are directed to the reduction of accident frequency as opposed to accident severity. Within each of these two categories, they are further subset as being either human, vehicular or environmental in nature.

\subsection{COUNTERMEASURES FOR ACCIDENT CAUSATION}

Various conclusions regarding accident causation, as well as, specific human, vehicular and environmentai countermeasures recommended to reduce accident frequency are presented in the following sections.

\subsubsection{HUMAN COUNTERMEASURES FOR ACCIDENT CAUSATION}

Human actions and failures, as presented in Section 5.0 CAUSAL FACTORS, constitute a major factor in the causation of the single yehicle accidents investigated in this study. The human causal factors most frequently identified during the review and analysis process as contributing to accident causation include alcohol, speeding, inattention, fatigue, poor judgement, inexperience and driver overreaction. the majority of these causal mechanisms contribute to event sequence failures which result in the vehicle leaving the roadway and then overturning or striking a fixed object. Since the consequent damage and injury production is often quite serious, the elimination or alleviation of these human failures is, obviously, an essential component of an overall countermeasure program. 
The driver population involved in these single vehicle accidents is, as described in Table 4-8 overrepresented by high risk "problem drivers". These drivers have approximately two to four times the conviction and at-fault accident rate of the Dade County driver population. This ratio is higher for both younger and male drivers. As also indicated in Figure 4-2 alcohol-involved accidents are more frequent at night and on weekends. There is a similar overrepresentation of youthful drivers.

The distribution of accidents by time of day does not indicate any significant bias except possibly that involving the convenience of the reporting police officer. This rather even distribution throughout the day may indicate that these single vehicle accidents are randomly occurring events. This is not particularly surprising in view of the variety of causal mechanisms identified as precipitating the accidents. The driver involved in these single vehicle accidents, as indicated in Table 4-9, is generally familiar with the route and area being transversed and is typically driving to his residence from work or a social engagement. It appears that, due to the reasonable representiveness of this single vehicle accident sample, the driver characteristics and human causal mechanisms encountered in this study should reflect the overall single vehicle accident problem.

Countermeasures considered as potentially effective in alleviating these human problems included recommendations involving education, driver training, licensing requirements and revocation criteria, enforcement priorities and enabling legislation. The basic problem in the development and implementation of effective human countermeasures is that they essentially constitute an attempt to modify human behavioral patterns and attitudes. This is not only extremely difficult but also may be somewhat outside the purview of the highway safety field jurisdiction. Recommendations in this area are not merely technical in nature since they involve serious social, political or philosophical conflicts. It is felt, however, that the scientific investigator who is aware of the problems and possible solutions should, as a minimum, suggest potential countermeasures for consideration by the public. It is also important that the public be made aware of the consequences of a failure to implement meaningful countermeasures to reduce the frequency of accidents.

The following specific countermeasures are recommended to reduce the frequency of single vehicle accidents. The specific countermeasures along with the supporting justification, are presented within the context of the countermeasure objectives.

1. Problem Driver Control

Countermeasure: Legislate requirements for revocation of licenses of problem drivers and provide for penalties sufficient to effectively discourage driving while their licenses are under suspension. The problem driver would be identified 
by a "point system" based upon prior violation convictions and at-fautt accidents. This system would be similar to, but more stringent than, that presently in use by many states.

Justification: As indicated in Table 4-8, the previous driving record of the drivers involved in this study is roughily 2 to 4 times worse than the general driving population. The mean conviction rate for the general population of drivers in various age groups is approximately 0.2 to 0.5 violations per year. From the records of the drivers involved in this study it can be shown (see Section 4.2.4) that, if for example a "cut off" potnt of 1.5 violation convictions per year is used as a criteria for jicense revocation, a reduction in the rate of single vehicle accidents of approximately $23 \%$ would be expected. This indicates that a signiffcant reduction in the number of accidents could be achieved by the elimination of a relatively smal1 and easily identifiable group of drivers who have demonstrated unacceptable driving behavior.

\section{Reduction of Inattention and Fatigue Failures}

Countermeasure: Assign a significant number of "points" toward the criteria for driver's license revocation for violations involving these failures. The typical violations in this category, "careless driving" and "failure to have vehicle under control", would then be considered as serious violations along with speeding and driving under the influence of alcohol.

Justification: Although these errors are not necessarily willful violations and do not actually indicate basic driver irresponsibility, they are frequent causal mechanisms for precipitating single vehicle accidents. It is recognized that control of this type of problem is difficult, but implementation of incentives or penalties which demonstrate the seriousness of these driving errors may produce a significant reduction in their occurrence. Inattention alone, which was identified as contributing to accident causation in 233 of the 609 cases is the most frequently cited causal factor.

\section{Reduction of Speeding Accidents}

Countermeasure: Assign a high priority in the enforcement process for speeding violations to streets and highways with low speed limits.

Justification: Speeding was identified in 192 of 609 cases as contributing to accident causation. The majority of the significant speeding violations, as indicated in Figure 4-7, occur on low speed iimit facilities. For example, the average precrash speed on streets with a $30 \mathrm{mph}$ speed limit in excess of 
$40 \mathrm{mph}$ (refer also to Figure 4-14).

4. Reduction of Oriver Overreaction Errors

Countermeasure: Provide appropriate actual or simulated driving practice to develop the capability to respond properly in emergency situations. Incorporate an examination of these capabilities as a requirement for issuing or renewing a driver's Ticense.

Justification: A significant number (184 or 1370) of the roadway departures and crash occurrences were caused, at least in part, by driver overreaction when confronted with an unexpected situation or hazard such as another vehicle or an unintentional departure. It appears that the natural reaction is to brake and/or swerve excessively, which often results in a total loss of control. The only realistic countermeasure for this type of driver action error is, in our opinion, actual practice under simulated emergency situations to develop a reasonable, non-panic driver response capability. This type of training, testing and licensing requirements should also be beneficial in reducing evaluation, decision and driver action errors resulting from poor judgement and/or inexperience.

The variety of other problems involved in accident causation due to human factors (see Section 5.0 CAUSAL FACTORS) are also important, and indicate that a series of actions are necessary to reduce the role of human factors in the causation of single vehicle accidents. Adequate education and training are required so that drivers understand and properly respond to emergency as well as normal roadway and traffic conditions. Realistic driver examination and licensing requirements are also necessary to ensure that each driver has these minimum capabilities.

The control and regulation of driving behavior is probably even more important than the requirements for driving capability. Poor attitudes, hostility and irresponsibility may quite likely play a more significant role in the causation of accidents. Enforcement priorities, penalty assessments and license revocation criteria should, therefore, be directed toward the reduction of those previously described violattions which contribute significantly to accident causation. Penalties for violations, particularly driving while a license is under suspension, must be of sufficient severity to encourage compliance and improved driving behavior. Appropriate legislation (federal, state, and loca1) enabling the implementation of these recommended countermeasures is, of course, the required initial step in the process of reducing driver failures which result in single vehicle accidents. 


\subsubsection{VEHICULAR COUNTERMEASURES FOR ACCIDENT CAUSATION}

The contribution of vehicular factors to accident causation does not appear to be as significant as human or environmental factors. As indicated in Table 5-2, vehicle problems (blowouts, fires, etc.) were identified as precipitating the accident in 33 cases. The most frequently cited vehicle factors contributing to accident causation are instability against rollover (63 cases) and inadequate tire tread depth (48 cases). Other tire, brake and steering problems are involved to a lesser degree. The following countermeasures should be useful in reducing accident frequency.

1. Reduce Frequency of Rollover Accidents

Countermeasure: Establish design or performance criteria for passenger cars which would limit the likelihood of a rollover.

Justification: This type of crash occurrence is both frequent and serious. A rollover occurred in $106(19 \%)$ of the 557 accidents involving vehicles other than motorcycles or trucks. As indicated in Figure 4-5 the driver is injured in $88.5 \%$ of the rollover accidents, as opposed to an injury rate of $62.7 \%$ in accidents not involving a rollover. The fact that none of the rollovers occurred on wet pavement surfaces (see Section 6.3) indicates that there is a strong relationship between pavement friction capabilities and vehicle configuration in determining the probability of a rollover. The data given in Table 6-4 demonstrates that there are substantial differences between vehicle makes. For example, foreign make cars comprised on 7 y $9.8 \%$ of the registered vehicle population but were involved in $37.8 \%$ of the in-depth rollover accidents $(16.5 \%$ of the total sample, $11.5 \%$ of non-rollovers) thus indicating basic vehicle performance differences.

In the attempt to reduce the frequency of rollovers the required performance criteria might be directly related to a required maximum friction factor which would precipitate a rollover. Design criteria could be related to the ratio of track width to height of the vehicle center of gravity, roll angle and other suspension system characteristics.

\section{Reduce Loss-of-Control Caused Accidents}

Countermeasure: Increase the emphasis on maintaining adequate tire tread depth through vehicle inspection requirements, police enforcement priorities and violation penalties.

Justification: Inadequate tire tread depth was the most frequently cited (48 of 609 cases) vehicle defect contributing to accident causation. 
In addition to these major countermeasures, improvements in vehicle design and inspection procedures should be encouraged to reduce the likelihood of failures in tires, brakes and other vehicle components.

\subsubsection{ENVIRONMENTAL COUNTERMEASURES FOR ACCIDENT CAUSATION}

The contribution of environmental factors to accident causation is discussed in detail in Section 5.0 CAUSAL FACTORS. The environmental factors are identified as Tasks presented to the driver as well as specific causal factors contributing to accident causation. Causal mechanisms for on-roadway crash occurrences, leaving the roadway and offroadway impacts (including rollovers) are considered in this analysis. The nature of the objects struck (see Table 4-5) is not included in the causal analysis but is considered in the development of countermeasures.

The wide distribution of environmental causal factors and corresponding potential countermeasures demonstrates that there are problems and deficiencies in virtually every phase of highway design, construction, maintenance, and operation. Traffic control regulations and procedures, work site safety regulations, design standards and procedures, and priorities for construction and maintenance are considered in the development of the recommended countermeasures. The following specific countermeasures which are recommended as being useful in reducing the frequency of single venicle accidents, are listed under the pertinent roadway element.

1. Roadsides

Countermeasure: Require wide, clear roadside recovery areas (including continuous and stable shoulders) on all new facilities and direct reconstruction efforts to clearing, where feasible, existing narrow roadsides. Encourage the design of roadsides with shallow cross slopes and stable surfaces. Place more emphasis on roadside safety in the location of utility poles, sign supports, lighting standards, ditches, trees and bridge structures. Place a high priority upon the removal or relocation of objects adjacent to the roadway. Place more stringent requirements upon keeping construction equipment and material away from the roadside.

Justification: Over $90 \%$ of the single vehicle accidents involved a rollover or impact with an object off the roadway. Many of the rollovers are caused by an unstable surface or by excessive cross slope. Lack of a sufficient width of clear. roadside recovery area is the most frequently cited cause ( 205 cases) of the off-roadway crash occurrences investigated in this study. As indicated in Table 4-6, over $70 \%$ of the objects impacted are within 12 feet of the roadway. These 
objects impacted (see Table 4-5) including trees, poles, bridge structures and ditches are often located much closer to the roadway than was justified by other criteria. This practice in effect reduced the available clear roadside and increased the probability of an impact.

Due to the lack of information regarding roadway departures which did not result in crashes, a definitive statement cannot be made regarding the relationship between the roadside width and the expected accident frequency. However, since the average departure angles are only 10 to 15 degrees (see Figure 4-9) and the majority of objects impacted are close ( $<12$ feet) to the roadway, it would be reasonable to expect that a significant number of these crash occurrences could have been avoided. The large number of intentional departures (137) indicates that a significant percentage of the drivers are alert, in control of their vehicle and could make a recovery given sufficient time and space. From the results of this study it does appear that the required width should increase with speed and volume and should be increased on curves and at other locations subject to higher rates of roadway departures.

Countermeasure: Provide a narrow paved strip of high, rough textured surface adjacent to the through travel lane, at least on high-speed, high-volume roadways.

Justification: This rumble strip effect would provide a tactile warning to the many drivers who unintentionally depart the pavement surface. In $240(39.4 \%)$ of the cases investigated the driver was still generally in control of the vehicle but simply allowed the vehicle to drift off the roadway.

Countermeasure: Design criteria and maintenance priorities should emphasize the maintenance of stable shoulders without pavement/shoulder drop-offs.

Justification: These problems were frequently involved ( 29 cases) as causal factors in rollovers and other loss-of-control accidents due to an adverse influence upon vehicle response and a tendency to promote overreaction by the driver.

\section{Curbs}

Countermeasure: The use of curbs should be discouraged on all except low-speed roadways. When used on high-speed roadways, they should be set back from the roadway as far as possible and should, if feasible, be placed behind guardrails or be mountable in nature. 
Justification: As indicated in Section 6.2 ANALYSIS OF CURBS, curbs tend to cause damage, produce loss of control, and promote vaulting. In addition, these curbs are generally ineffective as redirection devices. As indicated in Figure 6-5 the only curbs demonstrating any effective redirection capability are the 8"-10" barrier and bridge curbs, and then only for shallow angle impacts. These impacts with the higher curbs do, however, generally produce damage and/or loss of control (see Table 6-2). The standard 6 in. "barrier" curbs that are commonly used on city streets produce damage and loss of control in approximate7y $20 \%$ of the cases and are for all practical purposes totally ineffective as redirection devices.

\section{Alignment}

Countermeasure: Improve the requirements for maximum degree of curvature in horizontal alignment. This would include the use of a higher assumed running speed and/or reduction in the allowable side friction factor.

Justification: Curves accounted for nearly $30 \%$ of the roadway departures. In 79 of approximately 170 cases the degree of curvature was considered excessive for either the posted speed limit or the vehicle speed reasonably expected, and was judged to be a contributing factor in the cause of the accident.

Countermeasure: Place more restrictions upon the location and sequencing of horizontal alignment changes such as compound and reverse curves, jogs, abruptiy changing sequences and the location of sharp curves at the end of long tangent sections.

Justification: A number of leaving the roadway occurrences (approximately 60 of 568) resulted from these unusual and often unsuspected alignment changes. Several truck rollovers were precipitated by reverse curves with inadequate tangent separation.

4. Traffic Control Devices

Countermeasure: Increase the usage of signs for regulating and informing drivers for: speed limit regulation on exit ramps, entrance ramps and turning roadways; exit locations; curve locations and speed limits; alignment and cross section changes; and advance warning and information at construction sites or other hazardous locations. Place signs for freeway exit locations far enough from the exit to allow adequate time for the decision process and any potential maneuvers (e.g. a lane change) that may be required. Increase the use of temporary pavement markings on construction detours and other temporary roadways. 
Justification: In 51 of 609 cases driver "evaluation" and "identification" errors resulted, at least in part, from an absence of signing informing drivers of an upcoming roadway hazard or situation. Confusion due to inadequate roadway delineation also resulted in a number of driver "evaluation" errors on temporary roadways.

\section{Pavement Surface}

Countermeasure: Provide increased pavement macrotexture $(0.15-.20$ in.) at approaches to toll booths.

Justification: This relatively frequent accident type in a very limited location is generally due to driver inattention and/or loss-of-control on a worn (and often oily) pavement surface. The provision of high pavement surface texture at these locations could provide a tactile warning for the driver, as well as, improved friction capabilities.

The preceding countermeasures address the most significant problems that appear to be uniquely important in single vehicle accidents. It is, however, recommended that general improvements be made in the standards for sight distance, alignment, cross section, lighting and intersection layout and design.

\subsection{COUNTERMEASURES FOR DAMAGE AND INUURY PRODUCTION}

The specific human, vehicular and environmental countermeasures presented in the following sections are recommended for reducing the severity of crash occurrences.

\subsubsection{HUMAN COUNTERMEASURES FOR DAMAGE AND INJURY PRODUCTION}

The severity of the consequences of accidents may be significantly influenced by human actions and failures. Damage as well as injury severity resulting from a crash occurrence may be increased by driver errors such as misjudgement, overreaction and speeding. Drivers frequently do not, when a crash occurrence is inevitable, take the proper action (é.g. attempting to steer through a situation instead of braking) to minimize the consequences. Loss of control through driver overreaction often results in a rollover or side impact which may be more severe than an impending head-on impact configuration. Speed, as indicated in several of the analyses presented in Section 6.0 SELECTED ACCIDENT AND INJURY PRODUCING MECHANISMS, is a primary variable influencing the severity of 
damage and injuries resulting from single vehicle accidents. Countermeasures for these human errors and the difficulties associated with their implementation have been discussed in Section 8.1.1. HUMAN COUNTERMEASURES FOR ACCIDENT CAUSATION.

Countermeasures for the reduction of occupant injury severity have the greatest potential benefit for reducing accident costs to society. The single most important occupant action influencing the severity of injuries is restraint system usage. The analyses summarized in Table 7-2 and Figures 6-1 and 6-3 clearly demonstrate the effectiveness of restraint usage in reducing injury severity, particularly at higher. impact speeds. Various factors influencing restraint usage are associated with vehicle design and are discussed in the following section of this report. Until the automobile industry develops and implements an effective passive restraint system, every effort should be made to encourage and/or require vehicle occupants to use the presently available restraint systems.

It is recognized that a significant segment of the population does not utilize available restraints and that a large number of people are actively opposed to restraint usage. It is however, recommended that legislation be enacted which requires usage (and penalizes non-use) of available restraint systems by all vehicle occupants. The initial rationale for this requirement is the generally cited justification for the motorcycle "helmet laws", in that the costs of accident injuries and fatalities are born by the general public as well as by the accident victim. Although this is correct, there is still the conflict with the philosophical argument that requiring a person to protect him from himself is a basic violation of his personal liberties.

This conflict can, however, be resolved if the potential consequences to others as a result of not utilizing available restraint systems is clearly understood. A properly restrained driver is more likely to be able to retain control of the vehicle during violent maneuvers or impacts. Even minor impacts can cause the driver to be displaced from his proper position or be injured sufficiently to cause loss of control which can then lead to a subsequent, and possibly unnecessary, impact with another vehicle, a pedestrian or other object. It should be noted that in four of the single vehicle accidents investigated, restraint non-use was identified as a causal factor precipitating a crash occurrence. Requiring that a driver be restrained sufficiently to maintain control of his vehicle so as to not endanger others does not appear to be unreasonable.

An unrestrained occupant may, by impacting the driver, interfere with proper control of the vehicle, thus unnecessarily endangering other vehicle occupants and other motorists and pedestrians. An occupant not restrained also constitutes a potentially lethal flying object which produces an additional and unnecessary hazard to other occupants during a crash event. Requirements for mandatory restraint usage on this basis 
should be defensible from a social and philosophical, as well as, a technical viewpoint.

\subsubsection{VEHICULAR COUNTERMEASURES FOR DAMAGE AND INJURY PRODUCTION}

Vehicle design is, in our opinion, the area with the greatest potential for countermeasures to reduce the severity of occupant injuries resulting from single vehicle and other type accidents. This opinion is substantiated by the previously discussed difficulties encountered in the modification of human behavior and the existence of a vast network of hazardous roadways. The various restraint use analyses demonstrate the obvious effectiveness of this rather simple and inexpensive vehicle modification. The evaluation of other recent changes in vehicle design presented in Section 7.1 MOTOR VEHICLE SAFETY STANDARDS (MVSS) INVOLVEMENT AND EVALUATION indicates that marginal, although not statistically significant, improvements have been achieved through their implementation. Although lack of statistical significance may be due to sample size (609 cases), these minor alterations do not appear to have provided the extent of improvement in overall vehicle crashworthiness that might be expected.

In order to achieve a significant increase in vehicle crashworthiness, it is recommended that the following design objectives be encouraged and implemented:

1. Develop and implement an occupant restraint system (passive or active) that is effective and which must be used by the vehicle occupants.

2. Provide a passenger compartment of sufficient size to allow for effective operation of the restraint system without producing serious occupant impacts to the vehicle interior.

3. Develop a passenger compartment which will retain its continuity without door failures or other ruptures occurring during impacts or rollovers.

4. Develop a structurally adequate passenger compartment "cage" which will not collapse or significantly reduce in size during rollovers, side impacts or other crash configurations.

The specific design criteria for these changes should include the consideration of the objects (trees, poles, etc.) likely to be struck, the variety of vehicle orientations at impact, and the vehicle speeds normally expected. These design changes might be most effectively implemented as overall performance criteria for vehicle crashworthiness. The goal of this program should be to achieve a vehicle in which an 
occupant would be expected to surviye, with only minor injuries, a crash at the speed (e.g. $55 \mathrm{mph}$ ) normally expected in higher speed impacts.

\subsubsection{ENVIRONMENTAL COUNTERMEASURES FOR DAMAGE/INJURY PRODUCTION}

Environmental conditions not only are a major factor in the causation of single vehicle accidents but also have a significant influence upon the severity of the resulting damage and injuries. Damage and injury producing mechanisms, which were evaluated in the review and analysis process are reported in part in Section 5.0 CAUSAL FACTORS. Additional analyses which are presented in Section 6.0 SELECTED ACCIDENT AND INUURY PRODUCING MECHANISMS, were conducted to compare the injury severity resulting from impact with various type objects. These analyses provide the primary basis for the development of environmental countermeasures for the reduction of crash severity.

Since the majority of impacts $(91.6 \%)$ occurred off the roadway, the general recommendation to reduce crash severity is to provide and maintain a "forgiving" roadside. The three major factors involved in the evaluation of the safety characteristics of a roadside are the roadside geometry, the nature of the roadside objects present and the use and characteristics of protective devices such as redirection devices, energyabsorbing devices and breakaway supports. The following specific countermeasures are presented in accordance with this general classification scheme.

1. Roadside Geometry and Objects

Countermeasure: Provide wide roadside recovery areas with gentle contours.

Justification: In addition to reducing the likelihood of a crash occurrence, the speed at impact and therefore the probable severity of the crash would be reduced. This speed reduction is demonstrated in. Figure 4-10. The "average" off-road speed is, for example, approximately $20 \mathrm{mph}$ at 30 feet from the roadway as opposed to approximately $40 \mathrm{mph}$ just off the roadway.

Countermeasure: Discourage the location of canals or other water bodies adjacent to roadways. If this is not feasible protect them with a guardrail or other redirection device.

Justification: Vehicles entering canals as the primary impact or after impact with another object generally result in severe consequences. Several fatalities were the direct result of this occurrence. 


\section{Protective Devices}

Countermeasure: Utilize guardrails or other redirection devices to prevent impact with trees, utility poles, sign and signal supports, lighting standards and bridge structures and to guard steep embankments and canals.

Justification: The effectiveness of redirection devices is clearly demonstrated by the comparisons presented in Figure 6-3. For example at $50 \mathrm{mph}$ the average AIS for an unrestrained driver was approximately 4 for rigid object impacts and approximately 2 for guardrail impacts. This reduction in injury severity is particularly significant since vaulting and rollovers due to inadequacies in the redirection devices tend to increase the injury severity. Better design of the redirection devices (e.g. increasing the height) would probably further reduce the severity of the driver injuries.

Countermeasure: Increase significantly the use of energyabsorbing devices (sand barrels, hydrocells; etc.) for shielding rigid roadside objects such as signal poles, bridge piers and abutments, train signais, elevated gore areas and other unavoidable hazards.

Justification: As indicated in Figure 6-2, the expected average driver injury severity (AIS) for a $50 \mathrm{mph}$ impact into a rigid object would be approximately equal to four. A similar impact with an energy-absorbing device should produce an average injury level of approximately 1.5. This demonstrated effectiveness of $E / A$ devices in reducing injury severity and their relativeiy low cost would indicate that an increased usage is justified.

Countermeasure: Require that all lighting standards and sign supports adjacent to the roadway, except in areas with high pedestrian traffic volume, be breakaway in nature.

Justification: The expected injury severity (AIS) for an unrestrained driver in an impact of $50 \mathrm{mph}$ with a rigid pole (see Figure 6-1) would be in excess of two. Replacement by a breakaway pole would reduce the expected severity to approximately 0.5 . Since the replacment. cost is not large as compared to the cost of a severe accident, the use of breakaway supports would appear to be justified. 